Portland State University

PDXScholar

TREC Final Reports

Transportation Research and Education Center

(TREC)

$10-2013$

\title{
Influence of Road Cross Section on Access Spacing
}

\author{
Karen K. Dixon \\ Oregon State University \\ Yanfen Zhou \\ Oregon State University \\ J. L. Gattis \\ University of Arkansas
}

Follow this and additional works at: https://pdxscholar.library.pdx.edu/trec_reports

Part of the Transportation Commons, and the Urban Studies and Planning Commons Let us know how access to this document benefits you.

\section{Recommended Citation}

Dixon, K., Zhou, Y., \& Gattis,, J.L., Influence of Road Cross Section on Access Spacing. OTREC-RR-433. Portland, OR: Transportation Research and Education Center (TREC), 2013. https://doi.org/10.15760/ trec. 63

This Report is brought to you for free and open access. It has been accepted for inclusion in TREC Final Reports by an authorized administrator of PDXScholar. Please contact us if we can make this document more accessible: pdxscholar@pdx.edu. 


\section{5)OTREC}

FINAL REPORT

\section{Influence of Road Cross Section on Access Spacing}

OTREC-RR-433

October 2013 



\title{
INFLUENCE OF ROAD CROSS SECTION ON ACCESS SPACING
}

Final Report

OTREC-RR-433

by

\author{
Karen K. Dixon, Ph.D., P.E. \\ Oregon State University \\ Yanfen Zhou \\ Oregon State University \\ J.L. Gattis, Ph.D., P.E. \\ University of Arkansas
}

for

\author{
Oregon Transportation Research \\ and Education Consortium (OTREC) \\ P.O. Box 751 \\ Portland, OR 97207
}

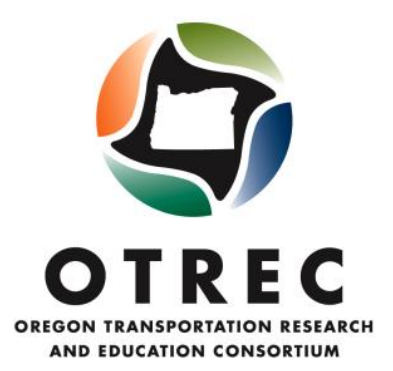

October 2013 



\section{Technical Report Documentation Page}

\begin{tabular}{l|l|l}
\hline $\begin{array}{l}\text { 1. Report No. } \\
\text { OTREC-RR-433 }\end{array}$ & 2. Government Accession No. & 3. Recipient's Catalog No. \\
\hline 4. Title and Subtitle & & $\begin{array}{l}\text { 5. Report Date } \\
\text { October 2013 }\end{array}$ \\
\cline { 2 - 3 } Influence of Road Cross Section on Access Spacing & 6. Performing Organization Code \\
\hline 7. Author(s) & 8. Performing Organization Report No.
\end{tabular}

Karen K. Dixon, Yanfen Zhou, J.L. Gattis

9. Performing Organization Name and Address

Oregon State University

School of Civil and Construction Engineering

Corvallis, OR 97331-3212

12. Sponsoring Agency Name and Address

Oregon Transportation Research and Education Consortium (OTREC)

P.O. Box 751

Portland, Oregon 97207

15. Supplementary Notes
University of Arkansas

Department of Civil Engineering

Fayetteville, AR 72701-1201
10. Work Unit No. (TRAIS)

11. Contract or Grant No.

13. Type of Report and Period Covered

Final Report

14. Sponsoring Agency Code

\section{Abstract}

This report presents a study on the influences of select cross-sectional-related design elements (specifically median configurations and bicycle lanes) and their impact on crash severity and type, as well as the associated driver gap acceptance for turning maneuvers at midblock driveway locations on urban arterials. The primary goal of this proposed research is to better understand how the median and bicycle lane configurations can influence safety and operations at driveway locations.

The research team utilized crash data, traffic data, and roadway information from driveway locations in the U.S. states of Oregon, Arkansas and Oklahoma. The project team supplemented the data with digital videos acquired during field studies of the sites. The traffic videos helped the research team better understand how road features and traffic influenced driver behavior at selected urban arterial driveway locations. As part of this effort, the research team conducted gap-acceptance studies to determine the critical gaps for driveway locations at arterial roads with and without bicycle lanes. The research team evaluated four different critical gap analysis methods to estimate the driveway operations and noted potential procedural biases associated with two of the techniques. The report describes these field studies and summarizes how the gap acceptance varied at the different arterial driveway locations. The research team also performed simulation analysis in CORSIM in order to examine the influence that median type, traffic volume, and access density have on traffic operational performance.

\begin{tabular}{|l|l|l|l|}
\hline $\begin{array}{l}\text { 17. Key Words } \\
\begin{array}{l}\text { ACCESS SPACING, DRIVEWAY, MEDIAN TYPE, BICYCLE LANE, } \\
\text { GAP-ACCEPTANCE STUDY, SIMULATION }\end{array}\end{array}$ & $\begin{array}{l}\text { 18. Distribution Statement } \\
\text { No restrictions. Copies available from OTREC: } \\
\text { www.otrec.us }\end{array}$ & $\begin{array}{l}\text { 22. Price } \\
102\end{array}$ \\
\hline $\begin{array}{l}\text { 19. Security Classification (of this report) } \\
\text { Unclassified }\end{array}$ & $\begin{array}{l}\text { 20. Security Classification (of this page) } \\
\text { Unclassified }\end{array}$ & $\begin{array}{l}\text { 21. No. Pages } \\
102\end{array}$
\end{tabular}

Technical Report Form DOT F 1700.7 (8-72)

Reproduction of completed page authorized 


\section{ACKNOWLEDGEMENTS}

The PIs would like to thank the Oregon Transportation Research and Education Consortium (OTREC) for support on this research effort. The PIs would also like to thank the various transportation agencies in Oregon, Arkansas, and Oklahoma that supported the data collection efforts in their respective states.

\section{DISCLAIMER}

The contents of this report reflect the views of the authors, who are solely responsible for the facts and the accuracy of the material and information presented herein. This document is disseminated under the sponsorship of the U.S. Department of Transportation University Transportation Centers Program in the interest of information exchange. The U.S. Government assumes no liability for the contents or use thereof. The contents do not necessarily reflect the official views of the U.S. Government. This report does not constitute a standard, specification, or regulation. 


\section{TABLE OF CONTENTS}

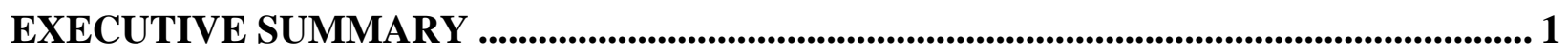

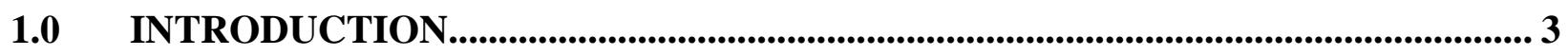

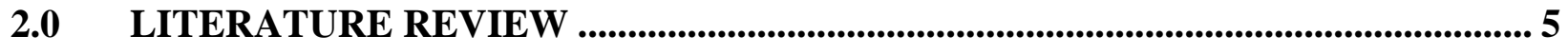

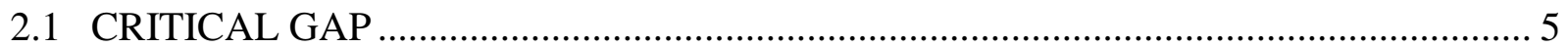

2.2 BICYCLE LANES AND ON-STREET PARKING …………................................... 11

3.0 DATA COLLECTION AND REDUCTION PROCEDURES ..................................... 13

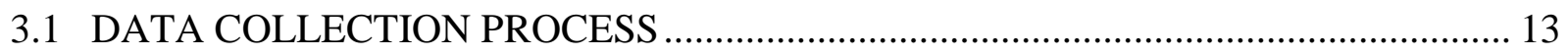

3.1.1 Data Collection Site Selection ............................................................................ 13

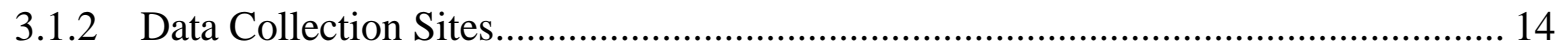

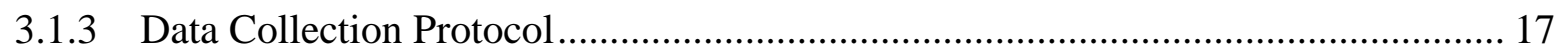

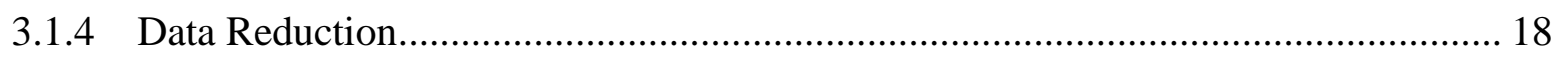

4.0 FIELD DATA ANALYSIS AND FINDINGS........................................................... 21

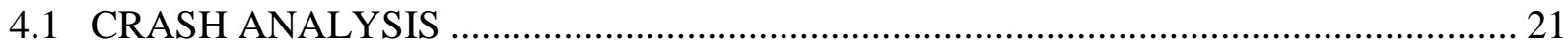

4.2 OPERATIONAL (GAP) ANALYSIS ……………............................................... 23

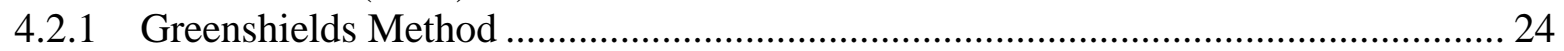

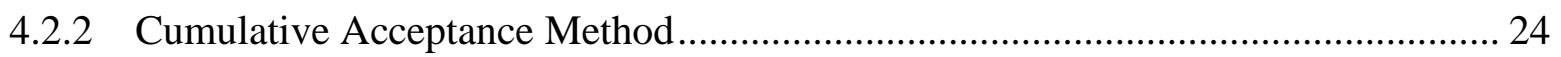

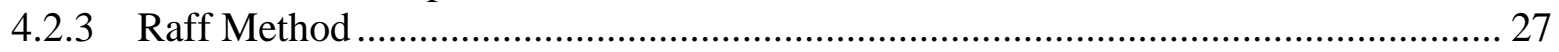

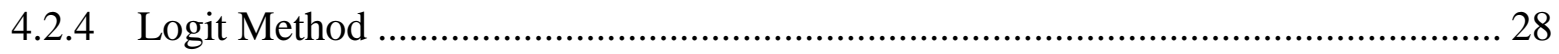

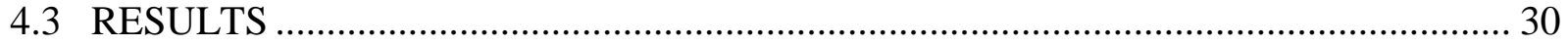

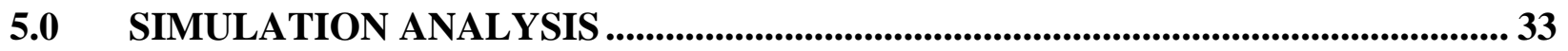

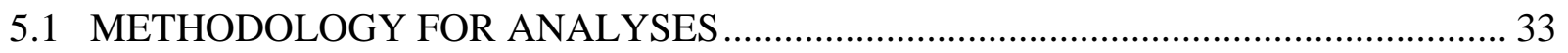

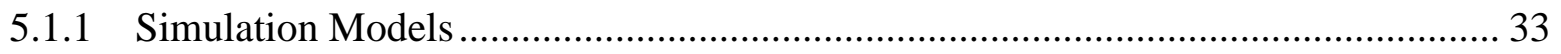

5.1.2 Number of Simulation Runs and Time ……………............................................ 35

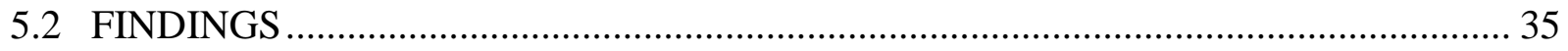

6.0 CONCLUSIONS AND RECOMMENDATIONS.............................................................. 43

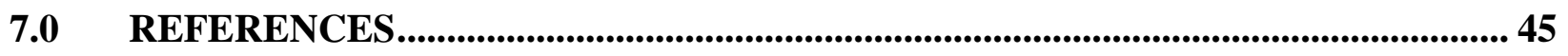

APPENDIX A. ABBREVIATION SUMMARY ……............................................................... A-1

APPENDIX B. DETAILED DRIVEWAY INFORMATION .............................................. B-1 


\section{LIST OF TABLES}

Table 2.1: Gap-acceptance Field Study Results (Right and Left Turns) ................................... 5

Table 2.2: Gap-acceptance Field Study Results (Right and Left Turns - Low Volume)............... 6

Table 2.3: Unsignalized Intersection Critical Gap Values..................................................... 7

Table 2.4: Major Road Critical Gaps (Right and Left Turns on a Major Road).......................... 7

Table 2.5: Recommended Travel Times for Determining Sight Distance for Left and Right Turns onto the Major Road at Stop-controlled Intersections .............................................. 8

Table 2.6: Comparison of Gap Acceptance Field Study Results from Various Studies................ 8

Table 2.7: Base Critical Gap for Two-way, Stop-controlled Intersection .................................. 9

Table 2.8: Base Critical Gap for Two-way, Stop-controlled Intersection .................................. 9

Table 2.9: Time Gap for Case B2-Right Turn from Stop and Case B3-Crossing Maneuver ....... 10

Table 2.10: Design Intersection Sight Distance - Case B2, ............................................... 10

Table 2.11: Time Gap for Case F, Left Turns from the Major Road....................................... 11

Table 2.12: Parking Setback Requirements for Typical Urban Street ..................................... 12

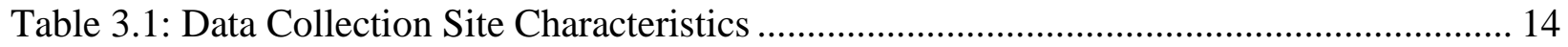

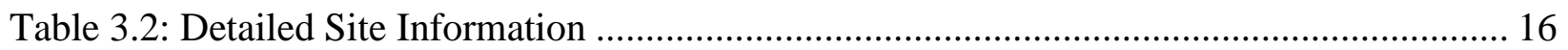

Table 4.1: Critical Gap Values for Study Driveways ............................................................ 31

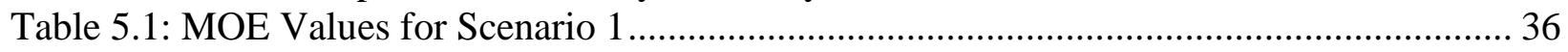

Table 5.2: MOE Values for Scenario 2 ............................................................................. 38

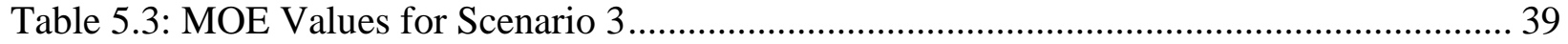

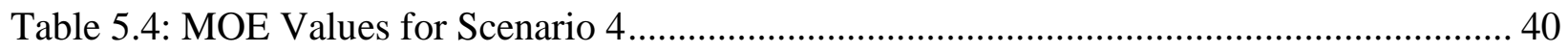

Table A.1: Abbreviation Summaries ............................................................................. A-3

Table B.1: Driveway Site 1 - Gap-acceptance Study Results ................................................ B-4

Table B.2: Driveway Site 2 - Gap-acceptance Study Results ................................................ B-8

Table B.3: Driveway Site 3 - Gap-acceptance Study Results ........................................... B-12

Table B.4: Driveway Site 4 - Gap-acceptance Study Results ............................................ B-16

Table B.5: Driveway Site 5 - Gap-acceptance Study Results .............................................. B-20

Table B.6: Driveway Site 6a - Gap-acceptance Study Results ........................................... B-23

Table B.7: Driveway Site 6b - Gap-acceptance Study Results .......................................... B-27

Table B.8: Driveway Site 7a - Gap-acceptance Study Results ......................................... B-31

Table B.9: Driveway Site 7b - Gap-acceptance Study Results ............................................. B-35

Table B.10: Driveway Site 8 - Gap-acceptance Study Results .............................................. B-39 


\section{LIST OF FIGURES}

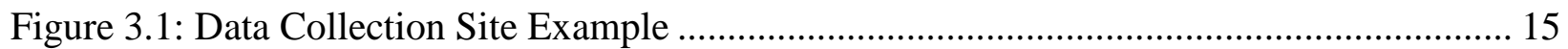

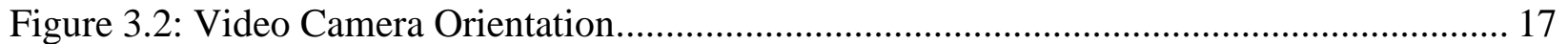

Figure 3.3: Site Videos with Time Stamp........................................................................ 18

Figure 3.4: Example of Excel Spreadsheet and Associated Data Reduction............................... 19

Figure 4.1: Distribution of Collision Types along Oregon and Arkansas Study Corridors.......... 22

Figure 4.2: Maximum Accepted Gap Values per Site ............................................................. 23

Figure 4.3: Example Greenshields Method Left-Turn Gap Acceptance at Large Commercial Site

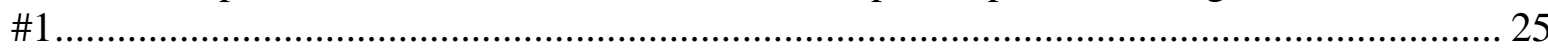

Figure 4.4: Example Cumulative Acceptance Method Approach at Large Commercial Site \#1. 26

Figure 4.5: Raff Method Approach at Large Commercial Site \#1 ........................................... 28

Figure 4.6: Logit Model Approach ..................................................................................... 29

Figure 4.7: Critical Gap Comparison of Right Turns at Study Driveways.................................. 30

Figure 4.8: Critical Gap Comparison of Left Turns into Study Driveways.................................... 32

Figure 5.1: Screen Shot of Driveway Layout ........................................................................... 34

Figure 5.2: Scenario 1- Aligned Driveways with a Raised Median on Major Street .................... 37

Figure 5.3: Scenario 2 - Aligned Driveways with a TWLTL on Major Street ............................. 38

Figure 5.4: Scenario 3 - Staggered Driveways with a Raised Median on Major Street ................ 40

Figure 5.5: Scenario 4 - Staggered Driveways with a TWLTL on Major Street............................ 41

Figure B.1: Driveway Site 1 - Road and Traffic Data ……................................................ B-3

Figure B.2: Driveway Site 1 - Aerial Photos ……………………………………........ B-4

Figure B.3: Driveway Site 1 - Gap-acceptance Analysis for Left Turns ................................. B-5

Figure B.4: Driveway Site 1 - Gap-acceptance Analysis for Right Turns ................................. B-6

Figure B.5: Driveway Site 2 - Road and Traffic Data ........................................................ B-7

Figure B.6: Driveway Site 2 - Aerial Photos .................................................................... B-8

Figure B.7: Driveway Site 2 - Gap-acceptance Analysis for Left Turns .................................. B-9

Figure B.8: Driveway Site 2 - Gap-acceptance Analysis for Right Turns ............................... B-10

Figure B.9: Driveway Site 3 - Road and Traffic Data …………………………………........ B-11

Figure B.10: Driveway Site 3 - Aerial Photos ………………………………………... B-12

Figure B.11: Driveway Site 3 - Gap-acceptance Analysis for Left Turns ............................... B-13

Figure B.12: Driveway Site 3 - Gap-acceptance Analysis for Right Turns ............................. B-14

Figure B.13: Driveway Site 4 - Road and Traffic Data ....................................................... B-15

Figure B.14: Driveway Site 4 - Aerial Photos .............................................................. B-16

Figure B.15: Driveway Site 4 - Gap-acceptance Analysis for Left Turns .............................. B-17

Figure B.16: Driveway Site 4 - Gap-acceptance Analysis for Right Turns ............................. B-18

Figure B.17: Driveway Site 5 - Road and Traffic Data .................................................... B-19

Figure B.18: Driveway Site 5 - Aerial Photos ................................................................ B-20

Figure B.19: Driveway Site 5 - Gap-acceptance Analysis for Right Turns ............................. B-21

Figure B.20: Driveway Site 6a - Road and Traffic Data ………………………................ B-22

Figure B.21: Driveway Site 6a - Aerial Photos ................................................................. B-23

Figure B.22: Driveway Site 6a - Gap-acceptance Analysis for Left Turns ………………...... B-24

Figure B.23: Driveway Site 6a - Gap-acceptance Analysis for Right Turns .......................... B-25 
Figure B.24: Driveway Site 6b - Road and Traffic Data ................................................. B-26

Figure B.25: Driveway Site 6b - Aerial Photos ................................................................. B-27

Figure B.26: Driveway Site 6b - Gap-acceptance Analysis for Left Turns........................... B-28

Figure B.27: Driveway Site 6b - Gap-acceptance Analysis for Right Turns ........................ B-29

Figure B.28: Driveway Site 7a - Road and Traffic Data ................................................ B-30

Figure B.29: Driveway Site 7a - Aerial Photos .......................................................... B-31

Figure B.30: Driveway Site 7a - Gap-acceptance Analysis for Left Turns ......................... B-32

Figure B.31: Driveway Site 7a - Gap-acceptance Analysis for Right Turns ......................... B-33

Figure B.32: Driveway Site 7b - Road and Traffic Data ................................................. B-34

Figure B.33: Driveway Site 7b - Aerial Photos ................................................................. B-35

Figure B.34: Driveway Site 7b - Gap-acceptance Analysis for Left Turns .......................... B-36

Figure B.35: Driveway Site 7b - Gap-acceptance Analysis for Right Turns ........................ B-37

Figure B.36: Driveway Site 8 - Road and Traffic Data ...................................................... B-38

Figure B.37: Driveway Site 8 - Aerial Photos .................................................................... B-39

Figure B.38: Driveway Site 8 - Gap-acceptance Analysis for Left Turns ............................ B-40 


\section{EXECUTIVE SUMMARY}

Studies have revealed that among more than 50 roadway-related features, cross-sectional roadway elements are one of the most important in affecting road safety performance. Unfortunately, quantifying the safety for urban road cross-sectional features historically has not received as much attention as it has for rural roads. This report presents a study on the influences of select cross-sectional-related design elements, specifically median configurations and bicycle lanes. This research further focuses on the influence of crash severity/type as well as the associated driver headway or gap acceptance for turning maneuvers at midblock driveway locations on urban arterials. The primary goal of this proposed research is to better understand how the median and bicycle lane configurations can influence safety and operations at driveway locations.

The research team utilized crash data, traffic data, and roadway information from driveway locations in Oregon, Arkansas, and Oklahoma. The project team supplemented the data with digital videos acquired during field studies of the sites. The traffic videos helped the research team better understand how road features and traffic influenced driver behavior at selected urban arterial driveway locations. As part of this effort, the researchers conducted gap-acceptance studies to determine the critical gaps for driveway locations at arterial roads with and without bicycle lanes. This study evaluates four different critical gap analysis methods to estimate the driveway operations and noted potential procedural biases associated with two of the techniques. The report describes these field studies and summarizes how the gap acceptance varied at the different arterial driveway locations. The research team also performed additional operational analysis, using the micro-simulation tool CORSIM, to examine the influence that median type, traffic volume, and access density have on traffic operational performance. 


\subsection{INTRODUCTION}

In 2003, the Transportation Research Board (TRB) published the Access Management Manual, the first large-scale effort since the publication of Access Management for Streets and Highways (Flora and Keitt, 1982). Both documents provided guidance about how access management can be successfully accommodated in a way that can enhance safety as well as traffic operations. Many of the techniques included in these manuals were developed based on mature research, and the resulting recommendations and guidelines provided quantifiable information about how best to successfully provide access management. For example, these documents provided clear direction regarding the use and type of medians, and identified the expected effectiveness resulting from converting a road without a median to one that includes a median. The Access Management Manual (TRB, 2003) also includes substantial information that can help an agency establish an access management program and incorporate a wide variety of strategies into this program. In the manual, access points include the intersections of public roads as well as driveway locations; however, most of the supporting research for the spacing of driveways is based on simple human factors and geometric principles that are applied to standard highway design procedures. Driveway placement techniques have not been thoroughly evaluated for access spacing conditions based on a variety of road cross-section and functional-purpose configurations.

This lack of robust research associated with quantifying the various conflicts at driveway locations has been due to a number of data collection limitations. There are numerous combinations of road features that may influence assess spacing, and identifying and studying these configurations is an onerous task.

The primary goal of the research effort summarized in this report is to better understand how driveway spacing and the associated roadway cross-sectional features influence safety and operations. Since the separation of conflict points will generally improve safety, it is critical that the transportation industry understand how to balance access spacing decisions that accommodate the needs of the adjacent land use while also enhancing safety. This research effort, therefore, evaluated how drivers react to increased workload demands when navigating a corridor with a variety of driveways and varying geometric characteristics. This research effort used field analysis complemented by micro-simulation evaluations as a way to try to identify critical cross-sectional elements that must be included in consideration of access spacing decisions.

The research team utilized crash data, traffic data, and roadway information from driveway locations in Oregon, Arkansas and Oklahoma. The researchers supplemented the data with digital videos acquired during field studies of the sites. The traffic videos helped the research team better understand how road features and traffic influenced driver behavior at selected urban arterial driveway locations. As part of this effort, the research team conducted gap-acceptance studies to determine the critical gaps for driveway locations at arterial roads with and without bicycle lanes. This analysis included an evaluation of four different critical gap analysis methods 
and their potential procedural biases for estimating the driveway operational performance. The report describes these field studies and summarizes how the gap acceptance varied at the different arterial driveway locations.

The research team also performed micro-simulation analysis, using CORSIM, to examine the influence that median type, traffic volume, and access density have on traffic operational performance.

Chapter 1.0 of this report introduces the purpose of the project and the objectives of this research effort. Chapter 2.0 reviews literature that summarized previous research efforts and identifies common methodologies used to conduct gap acceptance analysis. These methodologies are more fully described in Chapter 4.0. Chapter 3.0 illustrates data collection procedures and data reduction procedures, with data analysis results presented in detail in Chapter 4.0. Chapter 5.0 reviews the simulation procedure and results. Finally, Chapter 6.0 summarizes the conclusions and recommendations for the research effort. This report also includes a list of cited references (Chapter 7.0); a list of abbreviations (Appendix A); and geometric design features, traffic data and a detailed summary of data analysis results for each collection site (Appendix B). 


\subsection{LITERATURE REVIEW}

This research effort addresses driveway characteristics, based on gap analysis and microsimulation, and how select cross-sectional features such as median configuration and the presence of bicycle lanes can influence traffic operations. The reviewed literature explains a variety of critical gap procedures. Studies that utilized these various techniques are summarized in Section 2.1. Additional details as to how to conduct these procedures are included in Chapter 4.0. Bicycle-lane sight distance in the vicinity of driveways is reviewed in Section 2.2.

\subsection{CRITICAL GAP}

The safe operation of intersections or driveways requires adequate sight distance to enable drivers to determine whether potential conflicting vehicles are present before entering the roadway safely. The primary definition for intersection sight distance has been provided by the American Association of State Highway and Transportation Officials (AASHTO) publication titled A Policy on Geometric Design for Streets and Highways (AASHTO, 2011), commonly known as the Green Book and referred to in this manner for the remainder of this document.

Until 1994, the Green Book used a model that considered the acceleration behavior of the minorroad vehicle and the deceleration behavior of a potentially conflicting major-road vehicle to determine intersection sight distance for stop-controlled intersections (AASHTO, 1994).

Harwood et al. (1996), as presented in the National Cooperative Highway Research Program (NCHRP) Report 383, identified inconsistencies in the AASHTO model and recommended a revised model based on the gap-acceptance behavior of the minor-road driver. In more recent editions of the Green Book, the criteria for intersection sight distance for stop-controlled intersections have been fundamentally changed (AASHTO 2001, 2004, 2011). The updated method is based on the gap-acceptance behavior of the minor-road driver.

Several researchers have performed field studies to measure gap acceptance as a means of assessing the intersection sight distance. Fitzpatrick et al. (1991) used field studies to obtain the gap-acceptance results for both right and left turns as shown in Table 2.1. The same research team also acquired gap-acceptance data at low volume and/or intersections as shown in Table 2.2 .

Table 2.1: Gap-acceptance Field Study Results (Right and Left Turns)

\begin{tabular}{c|c|c}
\hline $\begin{array}{c}\text { Probability of Accepting a Gap } \\
(\boldsymbol{\%})\end{array}$ & $\begin{array}{c}\text { Passenger Car } \\
\text { (seconds) }\end{array}$ & $\begin{array}{c}\text { 5-Axle Truck } \\
\text { (seconds) }\end{array}$ \\
\hline 50 & 6.5 & 8.5 \\
\hline 85 & 8.25 & 10.0 \\
\hline
\end{tabular}

Source: Fitzpatrick et al. (1991) 
Table 2.2: Gap-acceptance Field Study Results (Right and Left Turns - Low Volume)

\begin{tabular}{c|c|c}
\hline $\begin{array}{c}\text { Probability of Accepting a Gap } \\
(\%)\end{array}$ & $\begin{array}{c}\text { Passenger Car } \\
\text { (seconds) }\end{array}$ & $\begin{array}{c}\text { 5-Axle Truck } \\
\text { (seconds) }\end{array}$ \\
\hline 85 & 10.5 & 15.0 \\
\hline
\end{tabular}

Source: Fitzpatrick et al. (1991)

Prior to 2001, the California Department of Transportation (CALTRANS) required that a vehicle must be visible for 7.5 seconds to determine the corner sight distance at unsignalized intersections. This threshold was assumed to be adequate for crossing and turning maneuvers. For left-turning vehicles on two-lane roadways, this approach resulted in some slowing of the vehicle on the major facility. For left-turning vehicles on four-lane facilities, a 7.5 second time for sight distance to the outside lane (i.e., the near lane) provides increased sight distance for leftturning vehicles to clear oncoming vehicles in the inside lane. CALTRANS did not apply the corner sight distance requirements to urban driveways.

A 7.0-second gap is supported by the 1984 and 1990 Green Book, the field studies from the Fitzpatrick et al. effort, and as the standard used by Michigan. The 1990 Green Book states that "a minimum of seven seconds should be available to the driver of a passenger vehicle crossing the through lanes" of a local road or street. Also, the "sight distance should be sufficient to permit a vehicle in the minor leg of the intersection to cross the travel way without requiring the approaching through traffic to slow down" (AASHTO, 1990).

Some field studies have identified the minimum gap as 6.5 seconds. Two states, Michigan and California, used gap acceptance measures for intersection sight distance at stop-controlled intersections. The 85 th percentile gap of 8.25 seconds applied to both right- and left-turning vehicles for moderate- to high-volume intersections. An 85th percentile gap of 10.5 seconds occurred at intersections with low volumes.

Lerner et al. (1995) performed a field study of gap-acceptance evaluations that assessed older and younger drivers for through, right-turning, and left-turning maneuvers. Without actually executing turns or crossing maneuvers, test subjects seated in a stationary vehicle were asked to identify gaps that they would and would not accept. The critical gap for which 50 percent of drivers across all age groups indicated they would accept was approximately 7.0 seconds. This feedback did not include any significant differences based on time of day or site configuration or location. Gaps that would be accepted by male drivers were found to be approximately one second less than those female drivers would accept during the day time.

Kyte et al. (1996) conducted an extensive field study of gap-acceptance behavior as part of a larger effort to develop capacity and level-of-service procedures for inclusion in the unsignalized intersections chapter in the Highway Capacity Manual (HCM) (TRB, 1994). Kyte et al. (1996) used the maximum likelihood method through a procedure developed by Troutbeck (1992) to analyze the gap-acceptance data collected at 44 unsignalized intersections in the United States. The research results are as shown in Table 2.3. 
Table 2.3: Unsignalized Intersection Critical Gap Values

\begin{tabular}{|c|c|c|c|c|}
\hline \multirow[b]{2}{*}{ Geometry } & \multicolumn{4}{|c|}{ Maneuver } \\
\hline & $\begin{array}{l}\text { Right turn } \\
\text { from minor } \\
\text { road }\end{array}$ & $\begin{array}{l}\text { Left turn } \\
\text { from minor } \\
\text { road }\end{array}$ & $\begin{array}{c}\text { Crossing } \\
\text { maneuver from } \\
\text { minor road }\end{array}$ & $\begin{array}{l}\text { Left turn } \\
\text { from major } \\
\text { road }\end{array}$ \\
\hline $\begin{array}{l}\text { Base critical gap value for } \\
\text { passenger cars at single-lane sites } \\
\text { (seconds) }\end{array}$ & 6.2 & 7.1 & 6.5 & 4.1 \\
\hline Multilane adjustment (seconds) & 0.7 & 0.4 & 0.5 & - \\
\hline $\begin{array}{l}\text { Heavy-vehicle adjustment }{ }^{\mathrm{a}} \\
\text { (seconds) }\end{array}$ & & & $1-2$ & $\rightarrow$ \\
\hline $\begin{array}{l}\text { Adjustment for minor-road grade } \\
\text { (seconds/percent) }\end{array}$ & 0.1 & 0.2 & 0.1 & - \\
\hline $\begin{array}{l}\text { Adjustment for three-leg site } \\
\text { (seconds) }\end{array}$ & - & - & - & -0.7 \\
\hline
\end{tabular}

${ }^{a}$ Heavy-vehicle adjustment is +1 second for single-lane sites and +2 seconds for multilane sites

Source: Kyte et al. (1996)

Harwood et al. (2000) developed and quantified an alternative intersection sight-distance model based on gap acceptance. This study used the Raff method (Raff and Hart, 1950) and logistic regression analysis to determine the critical gaps appropriate for use in intersection sight-distance design. The data analysis results are shown in Table 2.4. This research recommended that the sight distance along the major road for a passenger car at a stop-controlled intersection be based on a distance equal to 7.5 seconds of time for vehicles traveling at the design speed of the major road. Longer sight distances were recommended for minor-road approaches with sufficient truck volumes to warrant consideration of a truck as the design vehicle (see Table 2.5). Based on the analyses, Harwood et al. (2000) indicated that gap acceptance appears to be an appropriate basis for intersection sight-distance criteria for both passenger cars and trucks. The values shown in Table 2.5 also represent the current Green Book time-gap recommendations for left turns from a stop at locations where the minor road is stop-controlled and the major road is not (AASHTO, 2011).

Table 2.4: Major Road Critical Gaps (Right and Left Turns on a Major Road)

\begin{tabular}{l|c|c}
\hline \multirow{2}{*}{ Vehicle Type } & \multicolumn{2}{|c}{ Travel time at design speed of major speed (seconds) } \\
\cline { 2 - 3 } & Raff method & Logistic method \\
\hline Right-turn maneuvers & & \\
\hline Passenger car & 6.3 & 6.5 \\
Single-unit truck & 8.4 & 9.5 \\
Combination truck & 10.7 & 11.3 \\
\hline Left-turn maneuvers & & 8.2 \\
\hline Passenger car & 8.0 & 10.8 \\
Single-unit truck & 9.8 & 12.2 \\
Combination truck & 10.0 & \\
\hline
\end{tabular}

Source: Harwood et al. (2000) 
Table 2.5: Recommended Travel Times for Determining Sight Distance for Left and Right Turns onto the Major Road at Stop-controlled Intersections

\begin{tabular}{l|c}
\hline Vehicle Type & Travel time at design speed of major speed (seconds) \\
\hline Passenger car & 7.5 \\
Single-unit truck & 9.5 \\
Combination truck & 11.5 \\
\hline Note: For left turns onto two-way highways with more than two lanes, add 0.5 s for passenger cars or \\
0.7 s for trucks for each additional lane to be crossed. \\
\hline
\end{tabular}

Source: Harwood et al. (2000)

Note that the recommended gap-acceptance values by Harwood et al. have been based on the critical gap with a probability of acceptance by the minor-road driver of 50 percent. Harwood et al. (2000) compared gap-acceptance results from various studies, as summarized in Table 2.6.

Table 2.6: Comparison of Gap-acceptance Field Study Results from Various Studies

\begin{tabular}{l|cccc}
\hline \multirow{2}{*}{ Maneuver } & \multicolumn{4}{c}{ Critical gap (seconds) } \\
\cline { 2 - 4 } & \multicolumn{4}{c}{ Current study } \\
\cline { 2 - 4 } & Raff Method & $\begin{array}{c}\text { Logistic } \\
\text { Regression }\end{array}$ & Lerner et al. (1995) & Kyte et al. (1996) \\
\hline Right turn from minor road & 6.3 & 6.5 & 7.0 & 6.2 \\
\hline Left turn from minor road & 8.0 & 8.2 & 7.0 & 7.0 \\
\hline \multicolumn{2}{l}{ Note: Based on data for turns from stop-controlled intersections onto a two-lane major road }
\end{tabular}

Note: Based on data for turns from stop-controlled intersections onto a two-lane major road

Source: Harwood et al. (2000)

As defined in the Highway Capacity Manual (TRB, 2000), the critical gap, $\mathrm{t}_{\mathrm{c}}$, is the minimum time interval for the major-street traffic stream that allows intersection entry for one minor-street vehicle. For a two-way, stop-controlled intersection, base values for the critical gaps are shown in Table 2.7. The critical gaps for left turns from a major roadway are shown to be 4.1 seconds for both two-lane major streets and four-lane major streets. The critical gaps for right turns from a minor street are 6.2 seconds for two-lane major streets and an additional 0.7 seconds for fourlane major streets. Base values for the critical gap for a six-lane major street are assumed to be the same as those for a four-lane major street. Adjustments are needed for these values to account for the presence of heavy vehicles, approach grade, T-intersections, and two-stage gap acceptance.

As shown in Table 2.7, the critical gaps range from 4.1 to 7.5 seconds. Research has shown that critical gaps durations decrease as volume on the major facility increases. This decreased acceptable gap observation also corresponds to an increased waiting time for an entering vehicle or at locations where a two-way left-turn lane (TWLTL) is present. 
Table 2.7: Base Critical Gap for Two-way, Stop-controlled Intersection

\begin{tabular}{|c|c|c|}
\hline \multirow{2}{*}{ Vehicle Movement } & \multicolumn{2}{|c|}{ Base Critical Gap, $t_{\mathrm{c}}$ (seconds) } \\
\hline & Two-lane Major Street & Four-lane Major Street \\
\hline Left turn from major & 4.1 & 4.1 \\
\hline Right turn from minor & 6.2 & 6.9 \\
\hline Through traffic on minor & 6.5 & 6.5 \\
\hline Left turn from minor & 7.1 & 7.5 \\
\hline
\end{tabular}

Source: Highway Capacity Manual (TRB, 2000)

The most recent publication of the Highway Capacity Manual (TRB, 2010) has updated a few items associated with the critical gap at two-way, stop-controlled intersections, but has retained the basic approach. "Critical gap" has been replaced by the term "critical headway," where a gap represents the distance from the rear of the first vehicle to the front of a second vehicle and headway represents the distance from the front of the first vehicle to the front of a second vehicle. Critical headways for six-lane major streets have been added as shown in Table 2.8.

Table 2.8: Base Critical Gap for Two-way, Stop-controlled Intersection

\begin{tabular}{l|ccc}
\hline \multirow{2}{*}{ Vehicle Movement } & \multicolumn{3}{|c}{ Base Critical Gap, $\mathbf{t}_{\mathbf{c}}$ (seconds) } \\
\cline { 2 - 4 } & $\begin{array}{c}\text { Two-lane } \\
\text { Major Street }\end{array}$ & $\begin{array}{c}\text { Four-lane } \\
\text { Major Street }\end{array}$ & $\begin{array}{c}\text { Six-lane } \\
\text { Major Street }\end{array}$ \\
\hline Left turn from major & 4.1 & 4.1 & 5.3 \\
\hline Right turn from minor & 6.2 & 6.9 & 7.1 \\
\hline Through traffic on minor & 6.5 & 6.5 & 6.5 \\
\hline Left turn from minor & 7.1 & 7.5 & 6.4 \\
\hline
\end{tabular}

Source: Highway Capacity Manual (TRB, 2010)

In the Green Book (AASHTO, 2011), the intersection sight distance is based on a gap-acceptance concept. It assumes that drivers on the major road do not need to reduce their initial speed by more than 30 percent (so less than 70 percent of the initial speed is expected to be maintained). The intersection sight distance is determined from the size of acceptable gap required for a driver to enter the roadway. This distance is depicted by Equation 2-1.

$$
\mathrm{d}=1.47 V_{m} t_{c}
$$

Where,

$\mathrm{d}=$ required intersection sight distance along a major road, $\mathrm{ft}$;

$\mathrm{V}_{\mathrm{m}}=$ design speed for the major road, mph;

$t_{c}=$ gap that drivers will accept for entering roadway, sec.

For vehicles turning right from a minor road to a major road, the required acceptable gaps are provided in Table 2.9. Adjustments for approach grade and for number of lanes are shown in the footnotes of the table. The required intersection sight distance for crossing a roadway from a stop is shown in Table 2.10 . 
Table 2.9: Time Gap for Case B2-Right Turn from Stop and Case B3-Crossing Maneuver

\begin{tabular}{l|c}
\hline Design Vehicle & Travel time at design speed of major speed * (seconds) \\
\hline Passenger car & 6.5 \\
\hline Single-unit truck & 8.5 \\
\hline Combination truck & 10.5 \\
\hline *Base conditions: \\
Two-lane highways with no median and grades $\leq 3$ percent; \\
*Adjustment for multilane highways: \\
$\begin{array}{l}\text { For crossing a major road with more than two lanes, add } 0.5 \text { seconds for } \\
\text { passenger cars and 0.7 seconds for trucks for each additional lane to be crossed } \\
\text { and for narrow medians that cannot store the design vehicle; }\end{array}$ \\
*Adjustment for multilane highways: \\
$\begin{array}{l}\text { If the approach grade on the minor road is an upgrade that exceeds } 3 \text { percent, } \\
\text { add } 0.1 \text { seconds per percent grade; }\end{array}$
\end{tabular}

Source: Green Book (AASHTO, 2011)

Table 2.10: Design Intersection Sight Distance - Case B2, Right Turn from Stop and Case B3, Crossing Maneuver (U.S. Customary)

\begin{tabular}{c|cc}
\hline \multirow{2}{*}{$\begin{array}{c}\text { Design Speed } \\
\text { (mph) }\end{array}$} & $\begin{array}{c}\text { Stopping Sight Distance } \\
\text { (feet) }\end{array}$ & $\begin{array}{c}\text { Right-turn Lanes and } \\
\text { Crossing-intersection Sight } \\
\text { Distance for Passenger } \\
\text { Cars (feet) }\end{array}$ \\
\hline 20 & 115 & 195 \\
\hline 25 & 155 & 240 \\
\hline 30 & 200 & 290 \\
\hline 35 & 250 & 335 \\
\hline 40 & 305 & 385 \\
\hline 45 & 360 & 430 \\
\hline 50 & 425 & 480 \\
\hline 55 & 495 & 530 \\
\hline 60 & 570 & 575 \\
\hline 65 & 645 & 625 \\
\hline 70 & 730 & 670 \\
\hline
\end{tabular}

Source: Adapted from the Green Book (AASHTO, 2011)

The required intersection sight distance for left turns from the major road is the distance traveled by an approaching vehicle at the design speed of the major roadway for the distances shown in Table 2.11. Generally, there is not a need to perform a separate check for this condition where sight distance for stop-controlled intersections and for yield-controlled intersections is provided. It is helpful, however, to confirm this information at three-legged intersections, at midblock approaches or driveways, and at locations on horizontal curves or with sight obstructions present in the median. 
Table 2.11: Time Gap for Case F, Left Turns from the Major Road

\begin{tabular}{c|c}
\hline Design Vehicle & Travel Time (sec) at Design Speed of Major Road* (seconds) \\
\hline Passenger Car & 5.5 \\
\hline Single-Unit Truck & 6.5 \\
\hline Combination Truck & 7.5 \\
\hline *Adjustment for multilane highways: \\
$\begin{array}{c}\text { For left turns that must cross more than one apposing lane, add } 0.5 \text { seconds for } \\
\text { passenger cars and } 0.7 \text { seconds for trucks for each additional lane to be crossed. }\end{array}$ \\
Source: Green Book (AASHTO, 2011)
\end{tabular}

In Transportation and Land Development (Stover and Koepke, 2002), the intersection sight distances for left turns from a major roadway are longer than distances that are based on the gapacceptance criteria in the 2001 edition of the Green Book. The intersection sight distances shown were based on evaluations of the perception-reaction time and the maneuver time of passenger vehicle drivers making left turns from two-lane roadways (Micsky and Mason, 1996). They found an average perception-reaction time of 6.3 to 7.0 seconds, a value that is longer than the 5.5 gap size indicated in the 2001 AASHTO criteria. They also noted that the 85 th percentile time ranged from 6.8 to 8.5 seconds, with a turning maneuver of approximately 4.2 seconds (Micsky and Mason, 1996).

\subsection{BICYCLE LANES AND ON-STREET PARKING}

In urban areas, interactions between vehicles at driveways and on-street parked cars, motorized vehicles, bicycles and pedestrians create complicated roadway operations and increase the likelihood of collisions. Dixon et.al (2009) evaluated the required sight distance needed for motor vehicles at locations with and without bicycle lanes and on-street parking. The researchers also analyzed the appropriate design geometry needed to provide adequate sight distance for safety at driveways with and without bicycle lanes. Table 2.12 presents the different longitudinal parking setbacks for the left approach (S1) and the right approach (S2) on urban streets with vehicle lane widths of 12 feet and parking, buffer, and sidewalk widths of eight and six feet, respectively. The parking setbacks were developed based on two different perception-reaction time assumptions, 1.5 seconds and 2.0 seconds, respectively. 
Table 2.12: Parking Setback Requirements for Typical Urban Street

\begin{tabular}{|c|c|c|c|c|c|c|}
\hline \multirow[b]{2}{*}{$\begin{array}{l}\text { Speed } \\
(\mathrm{mph})\end{array}$} & \multicolumn{3}{|c|}{ Perception-Reaction Time of 1.5 seconds } & \multicolumn{3}{|c|}{ Perception-Reaction Time of 2.5 seconds } \\
\hline & S1 (feet) & $\begin{array}{l}\text { S2 -- Two } \\
\text { Lanes (feet) }\end{array}$ & $\begin{array}{c}\text { S2- Four } \\
\text { Lanes (feet) }\end{array}$ & S1 (feet) & $\begin{array}{c}\text { S2 -- Two } \\
\text { Lanes (feet) }\end{array}$ & $\begin{array}{l}\text { S2 - Four } \\
\text { Lanes (feet) }\end{array}$ \\
\hline \multicolumn{7}{|c|}{ Bike Lane Present } \\
\hline 20 & 34 & 29 & 20 & 55 & 45 & 33 \\
\hline 25 & 55 & 45 & 33 & 83 & 66 & 50 \\
\hline 30 & 83 & 66 & 50 & 114 & 89 & 68 \\
\hline 35 & 110 & 87 & 66 & 149 & 115 & 89 \\
\hline 40 & 145 & 113 & 87 & 187 & 144 & 112 \\
\hline 45 & 180 & 139 & 108 & 225 & 173 & 135 \\
\hline 50 & 218 & 167 & 131 & 270 & 206 & 162 \\
\hline \multicolumn{7}{|c|}{ No Bike Lane } \\
\hline 20 & 44 & 34 & 24 & 68 & 52 & 37 \\
\hline 25 & 68 & 52 & 37 & 100 & 75 & 55 \\
\hline 30 & 100 & 75 & 55 & 136 & 101 & 76 \\
\hline 35 & 132 & 98 & 74 & 177 & 130 & 99 \\
\hline 40 & 173 & 127 & 96 & 221 & 162 & 124 \\
\hline 45 & 213 & 157 & 119 & 265 & 194 & 149 \\
\hline 50 & 257 & 188 & 144 & 318 & 232 & 178 \\
\hline
\end{tabular}

Note: Values shown are based on 12-ft lane widths, 5-ft bicycle lane widths (where applicable), 8 -ft wide on-street parking, a 6-ft landscape buffer, and a 6-ft sidewalk. Shaded regions represent required longitudinal parking setbacks from the curb return that are greater than $120 \mathrm{ft}$.

Source: Dixon et al. (2009)

Dixon et al. concluded that adding a bicycle lane between the motor vehicle lanes and on-street parking provides additional sight distance and, as a result, enables better visibility of driveway operations. The use of a landscape buffer between the curb and the sidewalk helps to separate pedestrians from road operations, and provides additional space to enable vehicles that are exiting a driveway that does not have adequate sight distance to drive forward without encroaching on the operations of the bicycle lane or the sidewalk. 


\subsection{DATA COLLECTION AND REDUCTION PROCEDURES}

The goal of the data collection effort was to evaluate safety and operational performance at a variety of commercial driveways characterized by different traffic volume and cross-section configurations. To achieve this objective, members of the research team recorded the arrival and departure times of vehicles approaching the driveway (as they exit the site or approach on the adjacent street) in preparation for evaluating driveway operations and the associated gap acceptance. This chapter provides an overview of the driveway site selection, data collection, and data reduction procedures for driveway analysis.

\subsection{DATA COLLECTION PROCESS}

To assess driveway safety and operations (through the use of gap-acceptance studies), the research team collected data at five Oregon sites, two Arkansas sites, and one Oklahoma location, as summarized in Table 3.1. The eight study sites were located along urban and suburban commercial corridors. The data collection effort incorporated video-based technology as a method to collect vehicle arrival and departure time data at different locations and for varying time periods for the study sites. This type of traffic data enabled the research team to obtain high-quality, accurate traffic-operational information, including specific arrival and departure times.

\subsubsection{Data Collection Site Selection}

Driveway locations vary by configuration, traffic volume, vehicle speeds, collision history, and a variety of other characteristics. In an effort to eliminate the effect of the various roadway features, the researchers established the following criteria for selection of candidate data collection sites:

a) Data collected at unsignalized retail driveways in urban/suburban areas;

b) Through roadway with four standard travel lanes with either a TWLTL, turn lane in median, or median without an opening;

c) Through roadway has a daily traffic volume greater than $20,000 \mathrm{veh} / \mathrm{day}$;

d) Through roadway is characterized by relatively straight and flat geometry (good sight distance);

e) Driveway intersects through roadway at what appears to be close to a 90 degree angle;

f) Driveway is straight and not steep (vertical slope less than 9 percent) for minimum of 40 feet from right edge of through lane; and

g) Driveway edge is at least 500 feet from edge of nearest signalized intersection. 
Table 3.1: Data Collection Site Characteristics

\begin{tabular}{|c|c|c|c|c|c|c|c|}
\hline State & Date & Site & $\begin{array}{l}\text { Land Use } \\
\text { Accessed }\end{array}$ & $\begin{array}{l}\text { Video } \\
\text { Length } \\
\text { (hours) }\end{array}$ & $\begin{array}{l}\text { ADT } \\
\text { (vpd) }\end{array}$ & $\begin{array}{l}\text { Roadway } \\
\text { Design }\end{array}$ & $\begin{array}{l}\text { Posted } \\
\text { Speed } \\
(\text { mph })\end{array}$ \\
\hline \multirow{4}{*}{$\begin{array}{c}\text { Oregon } \\
\text { (Bicycle Lanes, } \\
\text { TWLTL) }\end{array}$} & $9 / 15 / 2011$ & 1 & Office Supply & 3 & 22,000 & $\begin{array}{l}4 \text { lanes }+ \\
\text { TWLTL }\end{array}$ & 35 \\
\hline & $9 / 21 / 2011$ & 2 & $\begin{array}{c}\text { Large Size } \\
\text { Commercial \#1 }\end{array}$ & 3 & 28,430 & $\begin{array}{l}4 \text { lanes }+ \\
\text { TWLTL }\end{array}$ & 35 \\
\hline & $11 / 01 / 2011$ & 3 & $\begin{array}{c}\text { Large Size } \\
\text { Commercial \#2 }\end{array}$ & 3 & 31,850 & $\begin{array}{l}4 \text { lanes }+ \\
\text { TWLTL }\end{array}$ & 35 \\
\hline & $11 / 08 / 2011$ & 4 & $\begin{array}{c}\text { Large Size } \\
\text { Commercial \#3 }\end{array}$ & 3 & 30,470 & $\begin{array}{l}4 \text { lanes }+ \\
\text { TWLTL }\end{array}$ & 35 \\
\hline $\begin{array}{c}\text { Oregon } \\
\text { (Bicycle Lanes, } \\
\text { Nontraversable } \\
\text { Median) } \\
\end{array}$ & $11 / 10 / 2011$ & 5 & $\begin{array}{l}\text { Medium Size } \\
\text { Commercial }\end{array}$ & 3 & 37,700 & $\begin{array}{c}4 \text { lanes }+ \\
\text { nontraversable } \\
\text { median }\end{array}$ & 45 \\
\hline \multirow{4}{*}{$\begin{array}{l}\text { Arkansas (No } \\
\text { Bicycle Lanes, } \\
\text { TWLTL) }\end{array}$} & $6 / 24 / 2011$ & $6 a$ & $\begin{array}{c}\text { Restaurant \#1 - } \\
\text { Day } 1 \\
\end{array}$ & 0.5 & 34,000 & $\begin{array}{l}4 \text { lanes }+ \\
\text { TWLTL }\end{array}$ & 50 \\
\hline & $6 / 29 / 2011$ & $6 b$ & $\begin{array}{c}\text { Restaurant \#1 - } \\
\text { Day } 2\end{array}$ & 1.5 & 34,000 & $\begin{array}{l}4 \text { lanes + } \\
\text { TWLTL }\end{array}$ & 50 \\
\hline & $6 / 2 / 2011$ & $7 a$ & $\begin{array}{c}\text { Large Size } \\
\text { Commercial \#4 - } \\
\text { Day } 1\end{array}$ & 1 & 38,000 & $\begin{array}{l}4 \text { lanes + } \\
\text { TWLTL }\end{array}$ & 45 \\
\hline & $7 / 25 / 2011$ & $7 b$ & $\begin{array}{c}\text { Large Size } \\
\text { Commercial \#4 - } \\
\text { Day } 2\end{array}$ & 1 & 38,000 & $\begin{array}{l}4 \text { lanes }+ \\
\text { TWLTL }\end{array}$ & 45 \\
\hline $\begin{array}{c}\text { Oklahoma (No } \\
\text { Bicycle Lanes, } \\
\text { Nontraversable } \\
\text { Median) } \\
\end{array}$ & $8 / 4 / 2011$ & 8 & Restaurant \#2 & 1.8 & 28,000 & $\begin{array}{c}4 \text { lanes + } \\
\text { nontraversable } \\
\text { median }\end{array}$ & 45 \\
\hline
\end{tabular}

\subsubsection{Data Collection Sites}

By applying the site selection criteria identified in Section 3.1.1, the research team identified eight candidate sites located adjacent to urban and suburban commercial corridors. The five Oregon sites included bicycle lanes while the two Arkansas sites and one Oklahoma site did not have bicycle lanes. As shown in Table 3.1, video data collection for each of the five Oregon sites extended for a three-hour period. In Arkansas and Oklahoma, the members of the research team collected traffic video during five separate time periods spanning three sites, with each video lasting between 0.5 and 1.8 hours. In an effort to study a variety of available traffic gaps, all data collection occurred at non-peak time periods.

A gap can be defined as the space between the back of a leading car and the front of a trailing car, while space headway is the distance between common locations (say the front bumper) on subsequent vehicles and includes the length of the vehicle in the overall measurement. Though the purpose of this assessment is to evaluate acceptable gaps, the analysis typically is based on headway data as this information is more straightforward to acquire.

In total, the final study sites included four Oregon locations and two Arkansas locations characterized by four lanes plus a TWLTL. In addition, the data collection included information 
for one Oregon location and one Oklahoma location with four lanes plus a nontraversable median. Figure 3.2 shows an example of one of the Oregon data collection sites.

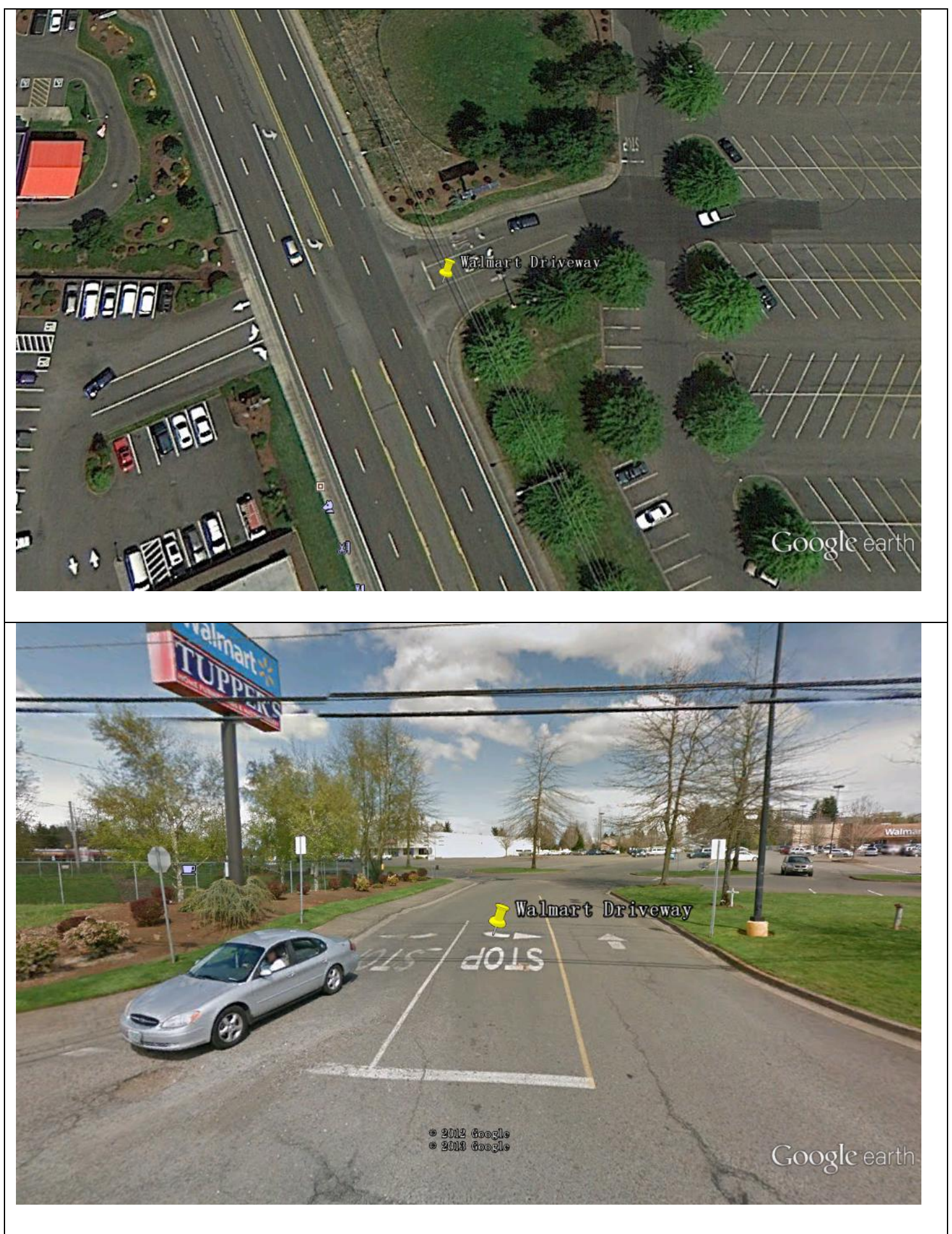

Source: Google Earth

Figure 3.1: Data Collection Site Example 
Table 3.2 provides a sample data collection summary form for one of the study sites. Site information includes basic location, traffic, speed, and geometric design characteristics.

Table 3.2: Detailed Site Information

\begin{tabular}{l|l}
\hline Location Information & 5250 Commercial Street Southeast \\
\hline Address & Salem \\
\hline City & OR \\
\hline State & \\
\hline \hline Traffic Information & 30,470 \\
\hline ADT (vehicles/day) & 35 \\
\hline Posted Speed (mph) & 36.1 \\
\hline \multicolumn{2}{l}{ Field Speed Mean (mph) } \\
\hline Cumulative Speed Distribution Curve
\end{tabular}

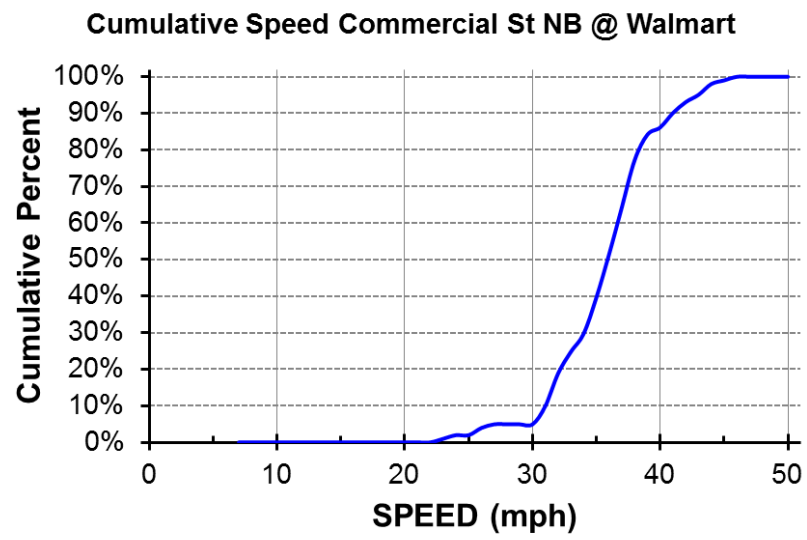

\begin{tabular}{l|l}
\hline \hline Geometric Design Information - Roadway in Vicinity of Driveway \\
\hline Width of Roadway (ft) & \multicolumn{2}{l}{} \\
\hline Number of Lanes & 4 lanes + TWLTL \\
\hline Lane Width (ft) & 12 \\
\hline Present of Bicycle Lane & Yes \\
\hline Present of Sidewalk & Yes \\
\hline $\begin{array}{l}\text { Driveway Spacing from Upstream Access } \\
\text { Connection (ft) }\end{array}$ & NA \\
\hline $\begin{array}{l}\text { Driveway Spacing from Downstream Access } \\
\text { Connection (ft) }\end{array}$ & NA \\
\hline \hline Geometric Design Information - Driveway & \multicolumn{2}{|l}{} \\
\hline Width of Driveway (ft) & 30 \\
\hline Number of Lanes & $12,12,16$ \\
\hline Lane Width (ft) & None \\
\hline Median in Driveway & 672 \\
\hline Distance to Nearest Upstream Signal & Nov $8^{\text {th }} \& 11^{\text {th }}, 2011$ \\
\hline \hline Data Collection Information & 3 hours \\
\hline Date & Cloudy \\
\hline Duration of Traffic Videos & Dry \\
\hline Weather &
\end{tabular}




\subsubsection{Data Collection Protocol}

Consistent data collection protocols help to ensure that the acquired data can be compared across sites without concerns regarding differences in measurement and analysis techniques. The following seven steps demonstrate the data collection protocol established for this effort.

1. Record the posted speed limit.

2. Measure the distance from the left edge of the left (inner) through lane to the right edge of the right (outer) through lane.

3. Collect a 100-vehicle sample of the speeds of through vehicles opposing the left-turn entry into the driveway.

4. Place stakes at intervals of 50 feet from near edge of driveway. In addition, place pavement tape in roadway at this location (see Figure 3.2).

5. Position one video recorder at a distance 250 feet in advance of the near edge of the driveway; orient the video recorder perpendicular to the street so as to monitor upstream gaps in traffic. Position the second video recorder 50 feet further upstream of the other camera, and orient this second camera so as to capture the vehicles entering and exiting the driveway. Synchronize the cameras so that a common item is visible in both fields of view and the clocks start at the same time.

6. Record gaps for passenger cars only (exclude vehicles that are pulling a trailer). Be sure to indicate if a vehicle is turning left into the driveway or right out of driveway (where applicable).

7. At each driveway, record a minimum of 60 gap acceptances and 60 rejections.

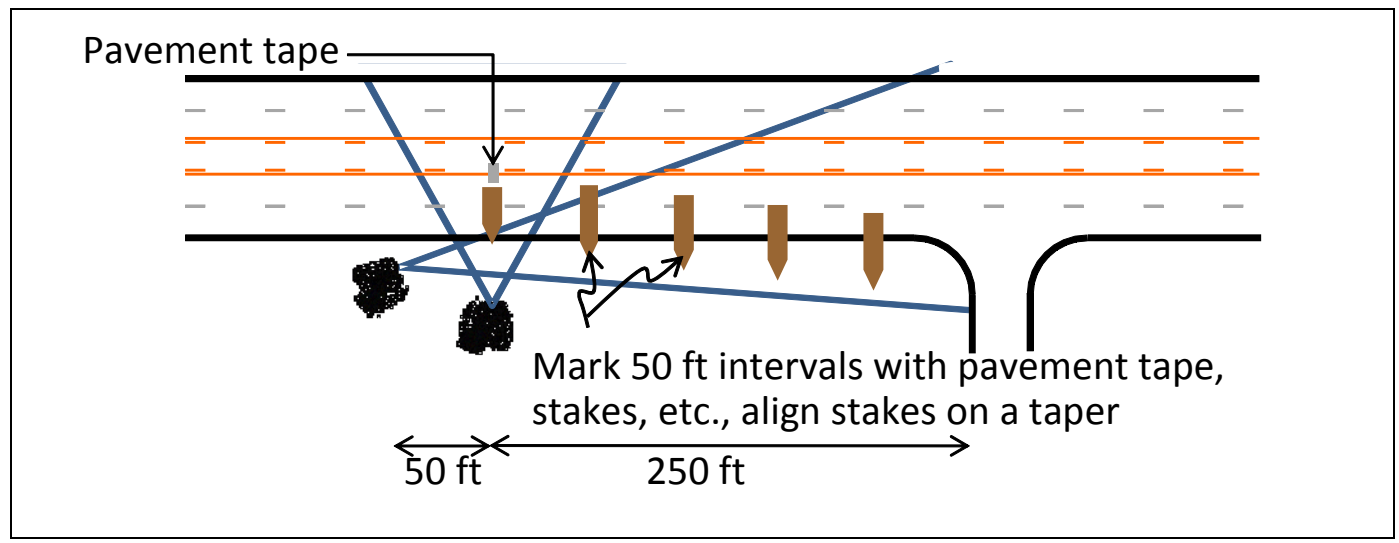

Figure 3.2: Video Camera Orientation 


\subsubsection{Data Reduction}

Following data collection, team members merged the video acquired in the field so that both camera views would be visible in a blended video file prior to data reduction (see Figure 3.3). The video image shown at the top left corner demonstrates observed gaps in traffic. The merged video also included a time code with an accuracy of one frame. Members of the research team then reduced the large sample size of the through traffic gap data to assess the arrival and departure times for individual vehicles. Figure 3.4 shows an example of data reduction using an excel data sheet. This resulting spreadsheet was then the source of information for subsequent data analysis tasks (see Chapter 4.0).

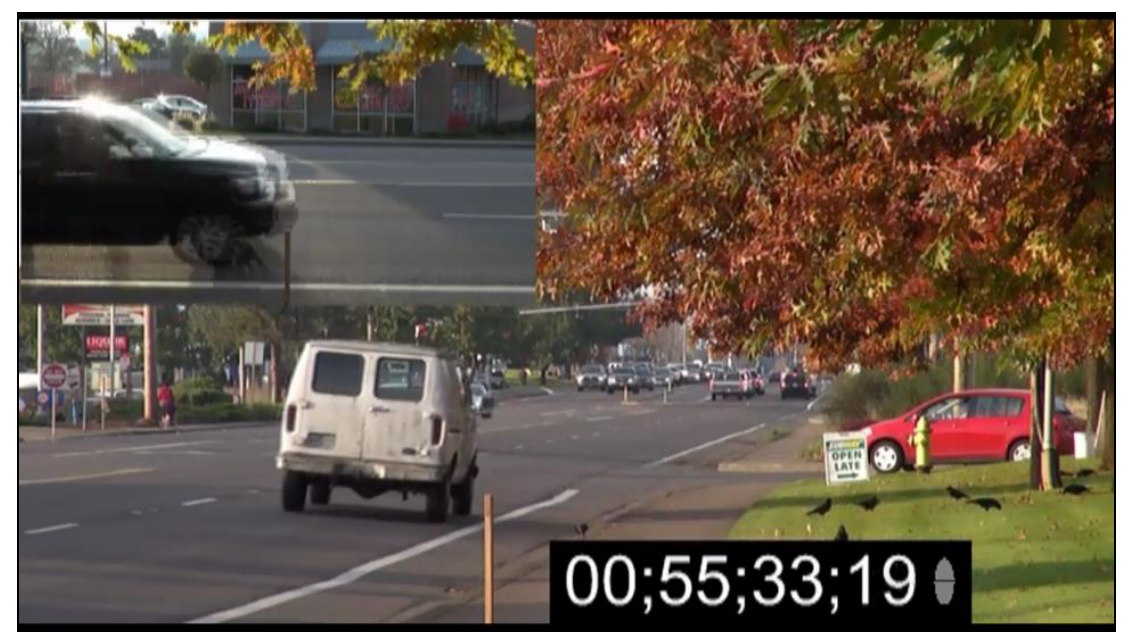

Figure 3.3: Site Videos with Time Stamp 


\begin{tabular}{|c|c|c|c|c|c|c|c|c|c|c|c|c|c|c|}
\hline \multirow{2}{*}{\multicolumn{3}{|c|}{$\begin{array}{l}\text { location: } \\
\text { date collected: }\end{array}$}} & \multirow{2}{*}{$\begin{array}{l}\text { Walmart, Commercial St, Salem, OR } \\
\text { Tuesday } 11 / 10 / 2011 \\
\end{array}$} & & & & \multicolumn{2}{|c|}{ width of 2 thru lanes $=$} & \multirow[t]{2}{*}{24} & \multirow[t]{2}{*}{$\mathrm{ft}$} & \multicolumn{2}{|c|}{ posted speed: } & \multirow[t]{2}{*}{35} & \multirow[t]{2}{*}{$\mathrm{mph}$} \\
\hline & & & & & & & & & & & & & & \\
\hline & \multicolumn{2}{|c|}{ Lane } & & \multicolumn{5}{|c|}{$\underline{\text { Time of Passage }}$} & \multicolumn{2}{|c|}{$\underline{\text { Gap }}$} & \multicolumn{2}{|c|}{$\underline{\text { Left Turn In }}$} & \multicolumn{2}{|c|}{ Right Turn Out } \\
\hline Veh\# & Left & Right & Thru-vehicle Description & Hours & Minutes & Seconds & Frames & & LT Gap & RT Gap & Accept & Reject & Accept & Reject \\
\hline 1 & $x$ & & white car & & 0 & 7 & 4 & 7.13 & & & & & & \\
\hline 2 & $\mathrm{x}$ & & white van & & 0 & 11 & 16 & 11.53 & 4.40 & & & & & \\
\hline 3 & & $\mathrm{x}$ & silver car & & 0 & 17 & 19 & 17.63 & 6.10 & & & $x$ & & \\
\hline 4 & $\mathrm{x}$ & & silver gray car & & 0 & 25 & 17 & 25.57 & 7.93 & & 1 & & & \\
\hline 5 & & $\mathrm{x}$ & white suv & & 0 & 27 & 4 & 27.13 & 1.57 & 9.50 & & & & \\
\hline 6 & $\mathrm{x}$ & & silver van & & 0 & 27 & 22 & 27.73 & 0.60 & & & & & \\
\hline 7 & & $\mathrm{x}$ & black pick-up & & 0 & 32 & 19 & 32.63 & 4.90 & 5.50 & & & & \\
\hline 8 & $\mathrm{x}$ & & silver car & & 0 & 33 & 20 & 33.67 & 1.03 & & & $\mathrm{x}$ & & \\
\hline 9 & $\mathrm{x}$ & & red van & & 0 & 43 & 17 & 43.57 & 9.90 & & 1 & & & \\
\hline 10 & $x$ & & white car & & 0 & 53 & 1 & 53.03 & 9.47 & & & & & \\
\hline 11 & & $\mathrm{x}$ & silver car & & 0 & 53 & 21 & 53.70 & 0.67 & 21.07 & & & 1 & \\
\hline 12 & $\mathrm{x}$ & & blue pick-up & & 0 & 58 & 25 & 58.83 & 5.13 & & & & & \\
\hline 13 & $x$ & & blue car & & 1 & 2 & 21 & 62.70 & 3.87 & & & $x$ & & \\
\hline 14 & & $\mathrm{x}$ & lincoln limo & & 1 & 2 & 25 & 62.83 & 0.13 & 9.13 & & $x$ & & \\
\hline 15 & & $\mathrm{x}$ & navy car & & 1 & 5 & 1 & 65.03 & 2.20 & 2.20 & & $x$ & & $\mathrm{x}$ \\
\hline 16 & & $\mathrm{x}$ & silver gray car & & 1 & 11 & 18 & 71.60 & 6.57 & 6.57 & 1 & & 1 & \\
\hline 17 & & $\mathrm{x}$ & white wagon & & 1 & 19 & 6 & 79.20 & 7.60 & 7.60 & 1 & & 1 & \\
\hline 18 & $x$ & & blue suv & & 1 & 54 & 0 & 114.00 & 34.80 & & & & & \\
\hline 19 & $\mathrm{x}$ & & silver suv & & 2 & 20 & 3 & 140.10 & 26.10 & & & & & \\
\hline 20 & & $x$ & silver car & & 2 & 21 & 14 & 141.47 & 1.37 & 62.27 & & & 3 & \\
\hline 21 & $x$ & & black car & & 2 & 23 & 0 & 143.00 & 1.53 & & & & & \\
\hline 22 & & $\mathrm{x}$ & black suv & & 2 & 23 & 11 & 143.37 & 0.37 & & & & & \\
\hline 23 & & $\mathrm{x}$ & black car & & 2 & 24 & 26 & 144.87 & 1.50 & & & & & \\
\hline 24 & & $x$ & white suv & & 2 & 26 & 8 & 146.27 & 1.40 & & & & & \\
\hline 25 & $\mathrm{x}$ & & yellow trailor & & 2 & 26 & 20 & 146.67 & 0.40 & & & & & \\
\hline 26 & & $\mathrm{x}$ & green car & & 2 & 28 & 9 & 148.30 & 1.63 & & & & & \\
\hline
\end{tabular}

Figure 3.4: Example of Excel Spreadsheet and Associated Data Reduction 


\subsection{FIELD DATA ANALYSIS AND FINDINGS}

The field data analysis for this effort included a summary statistics evaluation of available crash data for the study sites, as well as an operational analysis of the observed gap-acceptance thresholds based on road cross-section configurations. The gap-acceptance analysis focused on gap acceptance for left turns from the major street onto the driveway and for right turns from the driveway onto the major street. Chapter 4 summarizes this field data analysis and is further complemented by the simulation analysis presented in Chapter 5.

\subsection{CRASH ANALYSIS}

The research team was able to acquire historic crash data for a period of five years for the five Oregon sites and a four-year crash history at the two Arkansas locations. Unfortunately, crash data was not available for the Oklahoma nontraversable median location. The crash data acquired included corridor crash information, exclusive of the upstream and downstream signalized intersection crashes. In many instances, the exact crash location is not clear due to common crash data reporting and measurement inefficiencies.

Upon initial inspection, the most common midblock crash types that occurred at the sites included turning / angle crashes and rear-end collisions. As shown in Figure 4.1, the Oregon and the Arkansas TWLTL sites also experienced a variety of other crash types including sideswipe, head-on, single vehicle, and (in Oregon) bicycle and pedestrian crashes. By contrast, the Oregon site with a nontraversable median experienced only rear-end collisions (at 86 percent) and turn / angle crashes (at 14 percent). Though this observation represents a very small sample of corridors, it does indicate that traffic operations in the vicinity of driveways appear to have fewer conflicts at locations with restrictive medians. Of course, the construction of a median prohibits left-turn maneuvers into a driveway, and so the change in collision distributions may be simply due to the elimination of this movement.

Upon closer examination of Figure 4.1(a) and Figure 4.1(b), the Oregon sites appear to have a larger percentage of the turn / angle crashes than the Arkansas sites. In addition, the 5 percent bicycle crashes at the Oregon sites were also associated with turning maneuvers for motor vehicles and straight maneuvers for bicycles.

The Arkansas crash data did not include any bicycle crashes, nor did the Arkansas sites have bicycle lanes. From the knowledge members of the research team have of the area, it is likely that bicycle use in this environment is less than that in Oregon, and those choosing the bicycle mode would avoid the study corridors and find a more suitable route. 


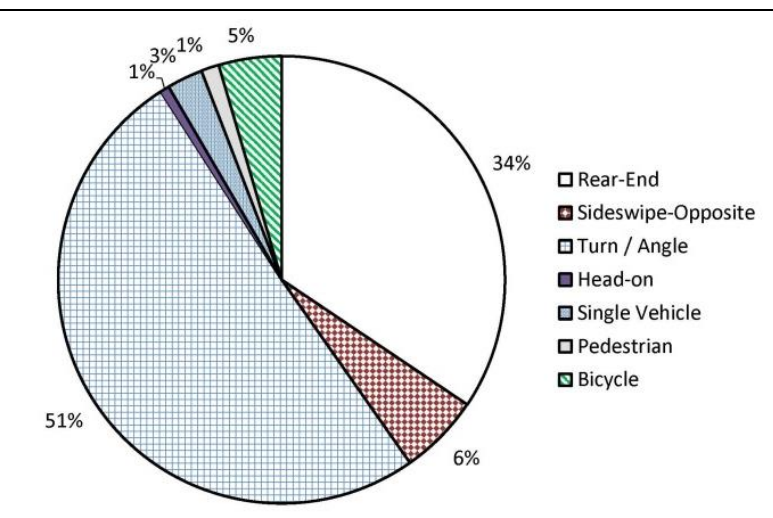

(a) Oregon Corridor Collision Types -- TWLTL \& Bike Lanes (2007-2011)

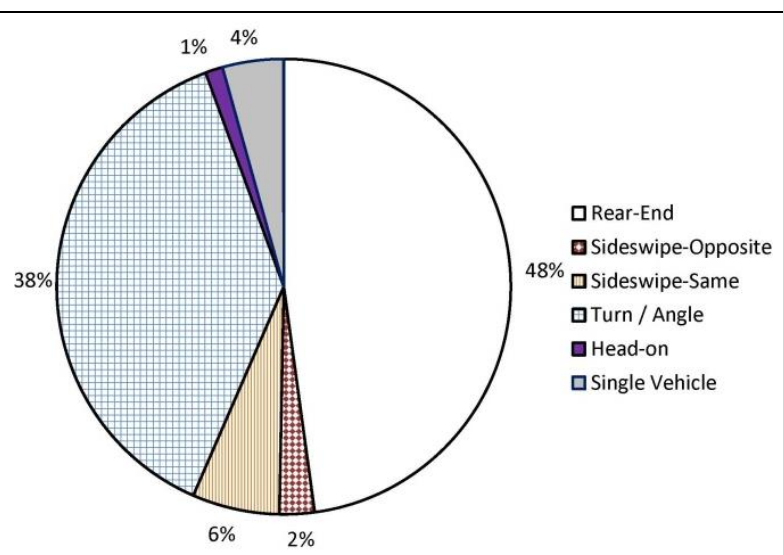

(b) Arkansas Corridor Collision Types -TWLTL \& No Bike Lanes (2008-2011)

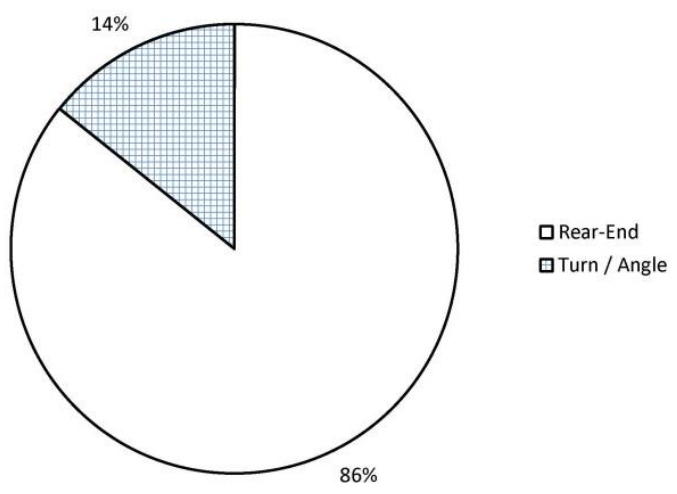

(c) Oregon Corridor Collision Types -- Non-Traversable Median \& Bike Lanes (2007-2011)

Figure 4.1: Distribution of Collision Types along Oregon and Arkansas Study Corridors

Typically, the number of crashes is also an important consideration as it reflects the magnitude of the crash problem. Since the study corridors have varying lengths and multiple driveways, linkage of a specific crash to a candidate driveway was not possible. Consequently, the research summary does not include the total number of crashes for each site since this corridor-specific information may not be directly applicable to a solitary driveway along the corridor.

Due to the limited amount of information available through the use of the crash data, the research team also evaluated the gap-acceptance behavior of drivers to determine if the added space provided by the bicycle lane would influence accepted gaps. The driver acceptance of very small gaps can provide useful operational information, and also help identify locations where the drivers may be subjected to potentially riskier maneuvers due to these shorter gaps. This gap analysis is reviewed in the following section. 


\subsection{OPERATIONAL (GAP) ANALYSIS}

As previously indicated, to assess the operations and safety of the driveway locations included in this study and their associated roadway cross-section configuration, the research team evaluated the critical gaps at each site to determine if any differences were readily apparent. Critical gap values demonstrate the smallest gap in traffic for which a driver is willing to execute a turn maneuver. This value can be influenced by the road cross section (how many lanes they must traverse), available sight distance, and traffic volume levels. Most drivers can be expected to accept a larger-size gap (e.g., 15 seconds) because their perceived risk diminishes as the gap time increases. As a result, larger size gaps do not provide meaningful information regarding drivers' gap-acceptance behavior during more congested conditions.

Previous gap-acceptance studies have used various gap-exclusion thresholds with 12 seconds identified as a common value used to exclude data from the gap-analysis data set. For this study, the research team specifically defined the maximum accepted gap value for each driveway site depending on each site's unique data set rather than using 12 seconds as a general threshold for all the sites. As shown in Figure 4.2, the observed maximum accepted gaps are depicted in contrast to the generally accepted 12 -second value. For left-turn maneuvers into the driveway, the maximum accepted gap values were all less than 12 seconds. This observation would suggest that including data with gaps greater than 12 seconds for left-turn maneuvers into the driveway has the possibility to suggest a greater critical gap value than is actually experienced by most drivers. In fact, the maximum rejected gap is likely to provide more powerful information than the maximum accepted gap, as this value may simply be an artifact of the available gaps in the traffic stream. The right-turn maneuver out of the driveway can usually be expected to have a larger gap since the vehicle is entering the traffic stream and needs to accelerate without substantially affecting traffic. As shown by the square symbols in Figure 4.2, the maximum accepted gap by drivers turning right out of a driveway fluctuated between 6 and 14.5 seconds, with the values of 6 and 7.5 seconds specifically associated with raised median locations.

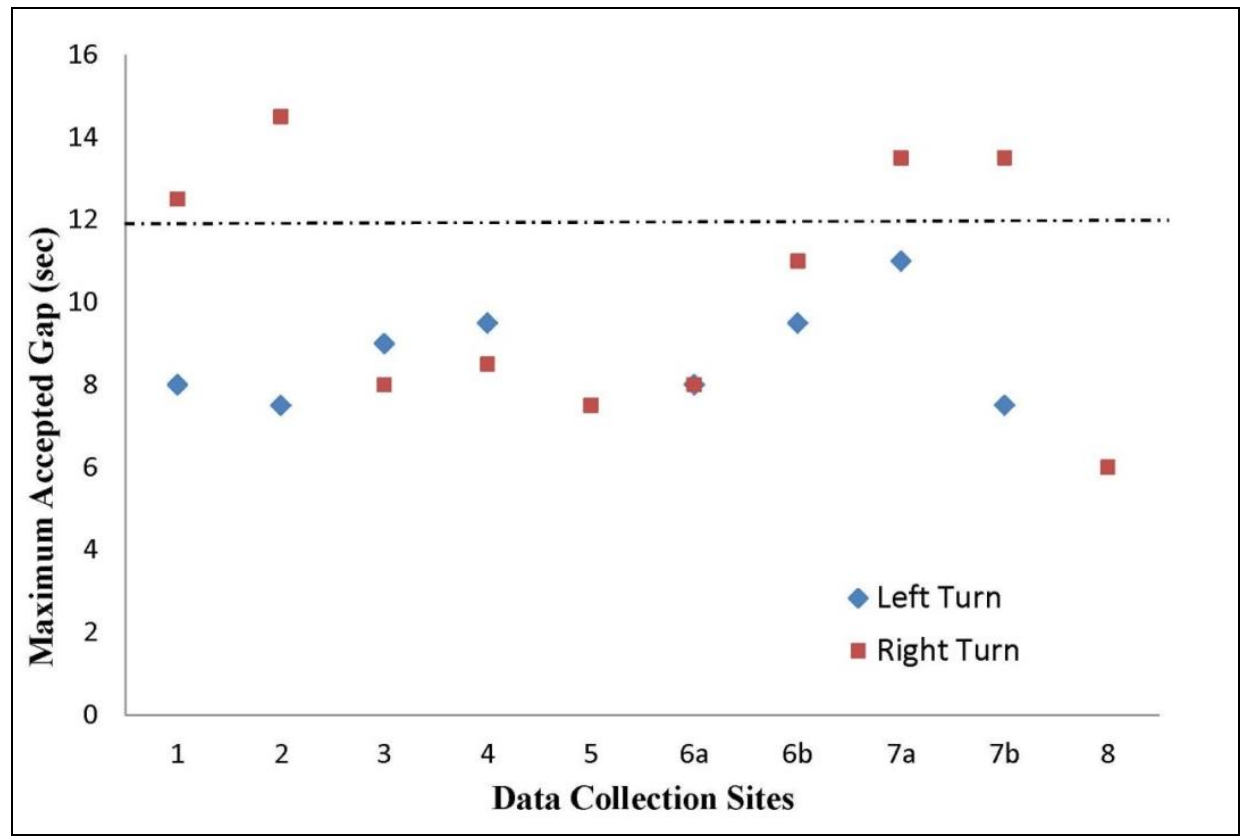

Figure 4.2: Maximum Accepted Gap Values per Site 
The published literature suggests a number of alternative modeling techniques for evaluating the critical gap. For this analysis, the research team evaluated the Greenshields, cumulative acceptance, Raff, and logit methods. Unfortunately, these various approaches can provide substantially different results. Consequently, the following sections briefly review each of the four methods and a sample application to this study. The previously identified maximum accepted gap values were used as an upper boundary for truncating the gap data for these analyses, thereby excluding excessively long gap data.

\subsubsection{Greenshields Method}

The Greenshields Method defines a critical gap as the gap time with the same number of acceptances and rejections at a location. If there is not a gap-time category with the exact same number of acceptances and rejections, then the time category with the closest number of acceptances and rejections should be used as the critical gap-time category. The mid-point of this critical gap-time category is then referred to as the critical gap. Small sample sizes may affect and distort this analysis (Mason et al., 1990).

For this study, the research team developed a histogram depicting the total number of acceptances and rejections for each 0.5 -second increment time category. Figure 4.3 represents an example histogram for the gap-acceptance data for the left-turning maneuvers into the driveway at the large commercial site \#1 in Oregon. For this example site, the resulting critical gap, per the Greenshields method, had a value of 5.5 seconds. This method is particularly sensitive to the value used for the maximum accepted gap and, if the data is not truncated appropriately, could introduce a bias resulting in a higher critical gap than appropriate. As shown in Figure 4.3a and contrasted to Figure $4.3 \mathrm{~b}$, it is also possible that, for large sample sizes, the truncated values will provide similar results. Due to the potential procedural biases, the research team chose to remove the Greenshields Method during the final analysis stage of this research effort.

\subsubsection{Cumulative Acceptance Method}

The goal of the Cumulative Acceptance Method is to identify the gap that would be acceptable to 85 percent of the drivers. To apply this method, the cumulative acceptance percentage is calculated for each particular gap-time category. The critical gap is then identified as the gap length where the cumulative percentage is greater than or equal to 15 percent (suggesting the remaining 85 percent of drivers would accept the value).

For the left-turning gap data at the large commercial site \#1 in Oregon, Figure 4.4 demonstrates that the 15-percent cumulative value occurs for a gap length of 7.25 seconds, the assumed critical gap. If the gap data is truncated and the upper boundary is limited to a maximum accepted gap of 9.5 seconds, the resulting critical gap would then change to a value of 5.75 seconds. Consequently, the Cumulative Acceptance Method suffers in a manner similar to that of the Greenshields Method in that it is very sensitive to sample size and acceptable gap truncation values. As a result, the Cumulative Acceptance Method results were also excluded during the final project analysis stages. 


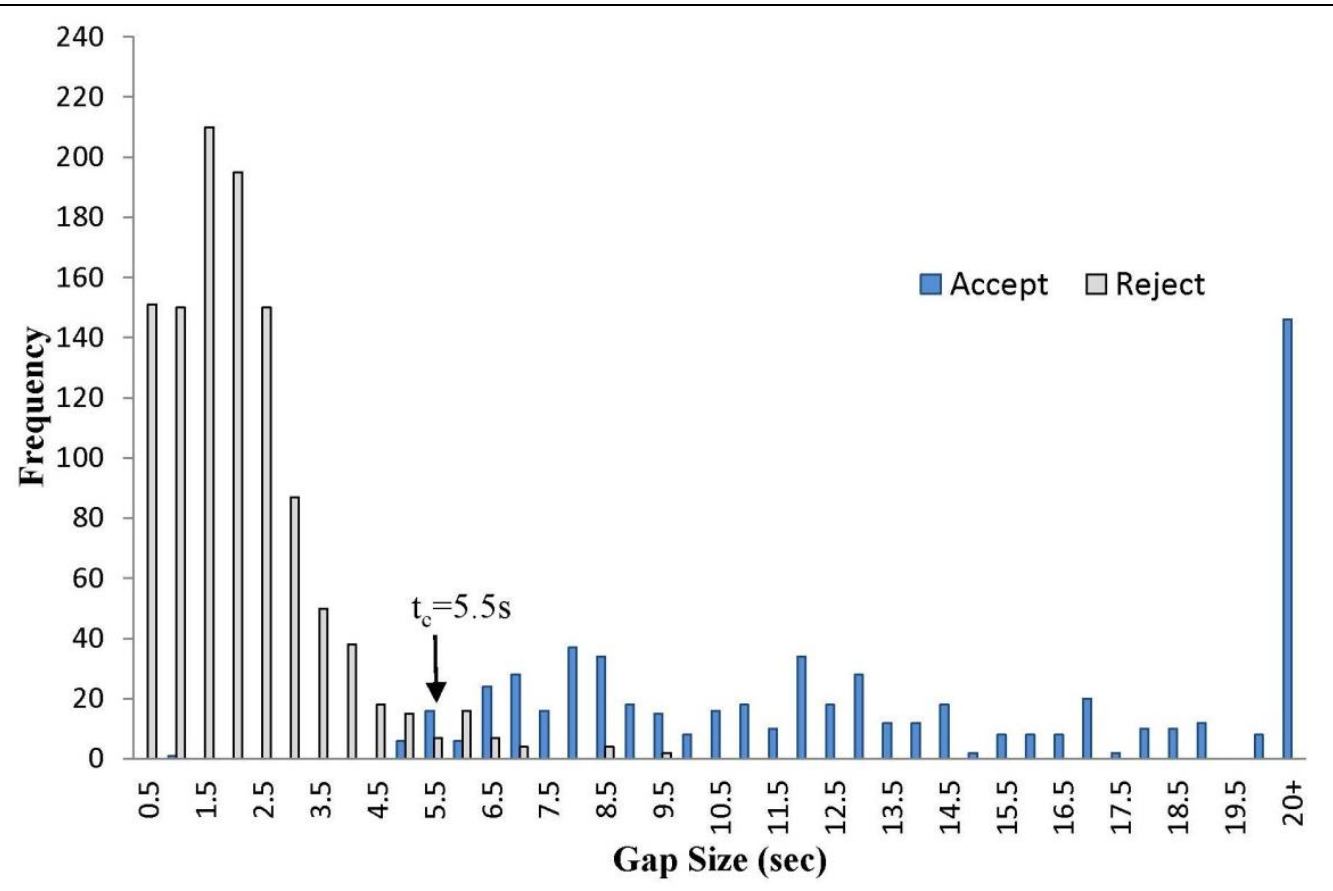

(a) Greenshields Method - Left Turns (All Gaps)

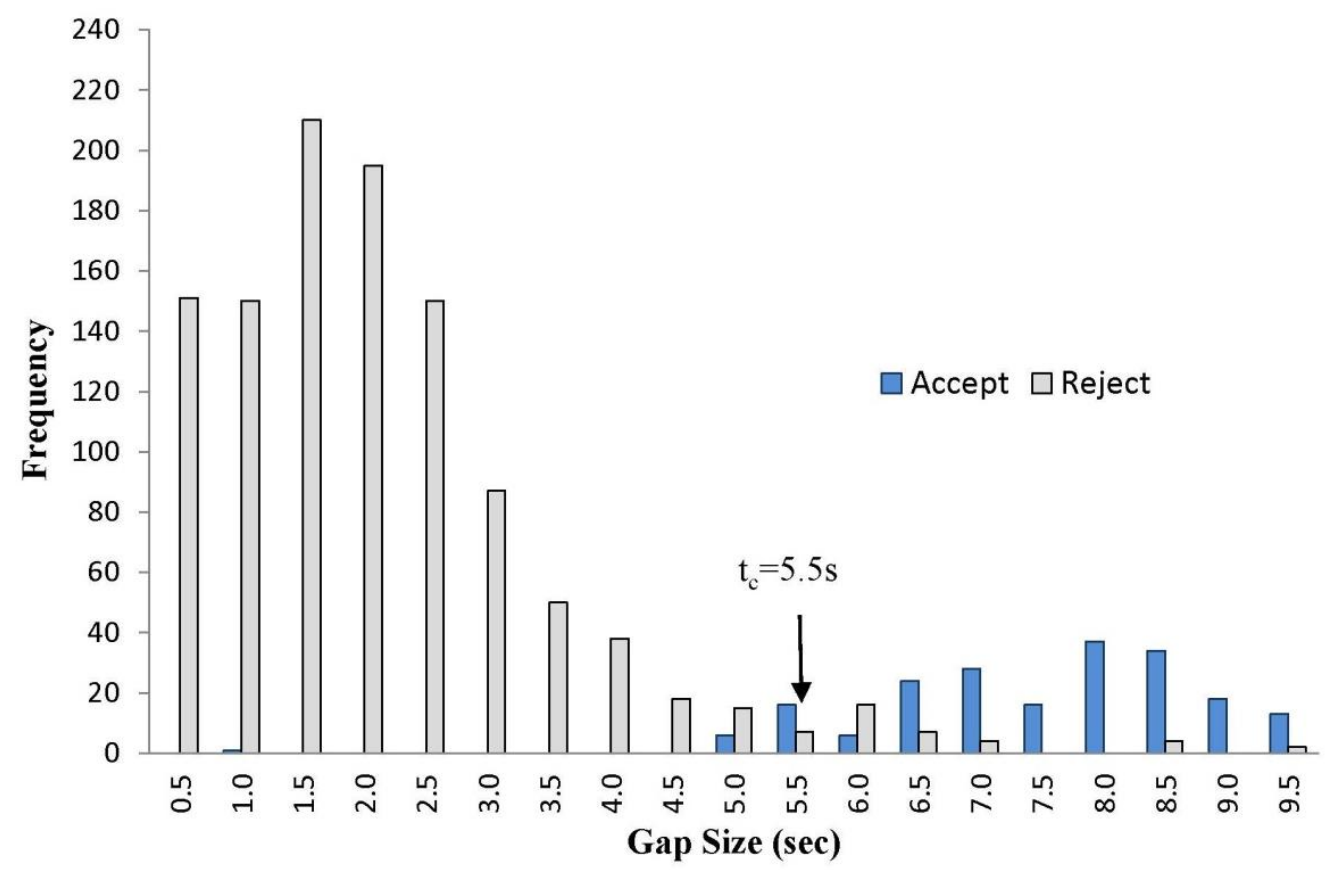

(b) Greenshields Method - Left Turns (Only Gaps $\leq 9.5$ seconds)

Figure 4.3: Example Greenshields Method Left-Turn Gap Acceptance at Large Commercial Site \#1 


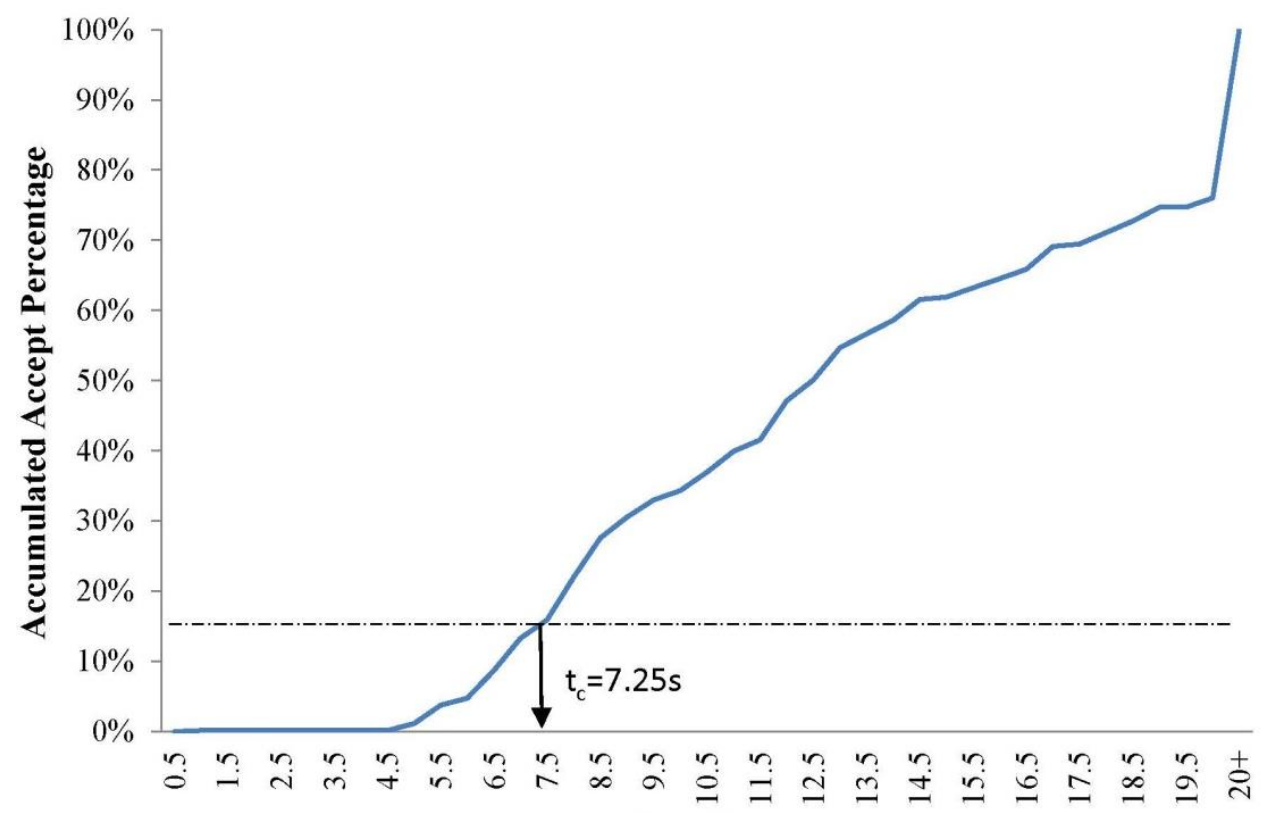

Gap Size (sec)

(a) Cumulative Acceptance Method - Left Turns (All Gaps)

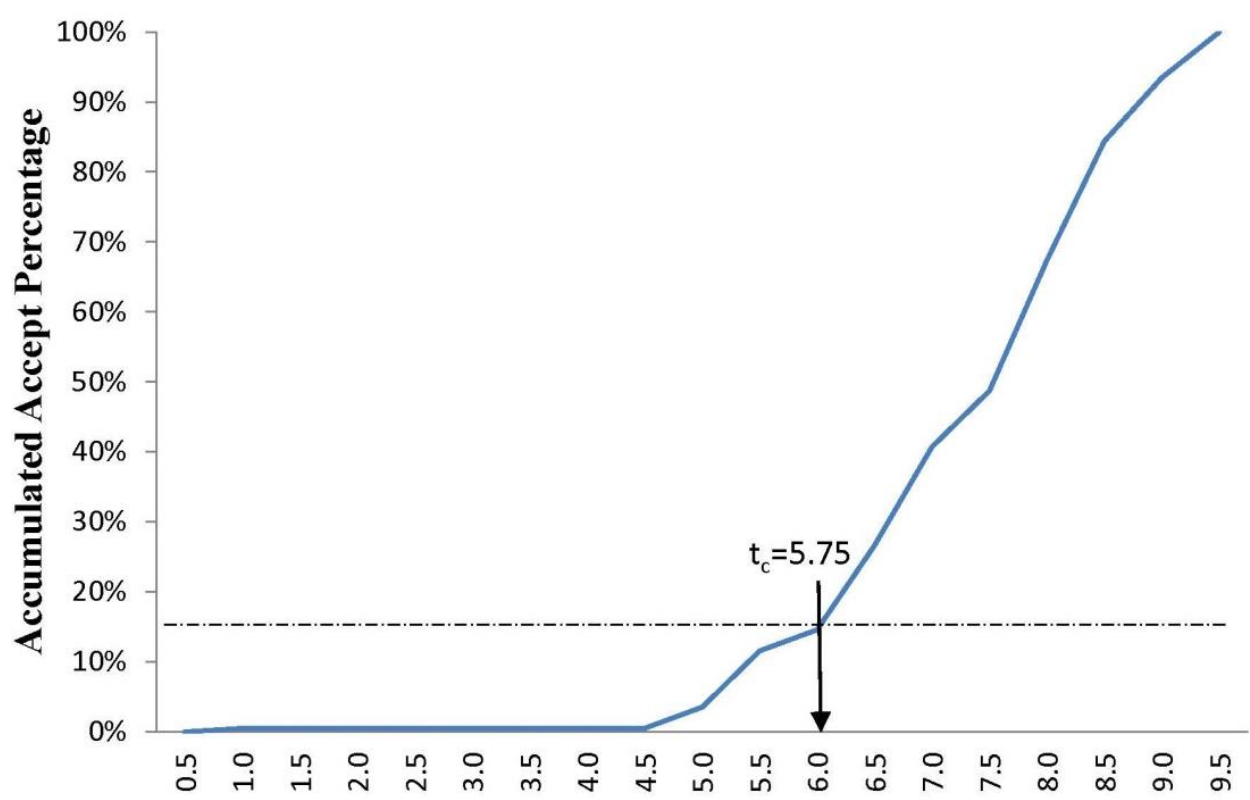

Gap Size (sec)

(b) Cumulative Acceptance Method - Left Turns (Only Gaps $\leq 9.5$ seconds)

Figure 4.4: Example Cumulative Acceptance Method Approach at Large Commercial Site \#1 


\subsubsection{Raff Method}

The Raff Method, first proposed in the late 1940s, is one of the most commonly used analysis methods to determine critical gap. It is both conceptually logical and computationally simple to apply. Using the Raff approach, the critical gap occurs where the accumulated acceptance percentage equals the accumulated rejection percentage. The accumulated acceptance percentage is obtained by determining the total number of acceptances for a particular overall gap range and other smaller gap ranges, and then dividing this value by the total number of acceptances. The rejection percentage is obtained by accumulating the total number of rejections for a particular gap-range interval or larger. Graphically, this method can be represented as a Y-axis plot of the accumulated acceptance percentage and rejection percentage against an $\mathrm{X}$-axis plot of the gaptime interval category. The intersection of the acceptance and rejection curves corresponds to the critical gap value.

Figure 4.5 shows the acceptance and rejection curves with left-turning gap data collected at the large commercial site \#1 in Oregon. The resulting critical gap value is 5.0 seconds (based on an upper gap of 9.5 seconds), as determined by the Raff Method. 


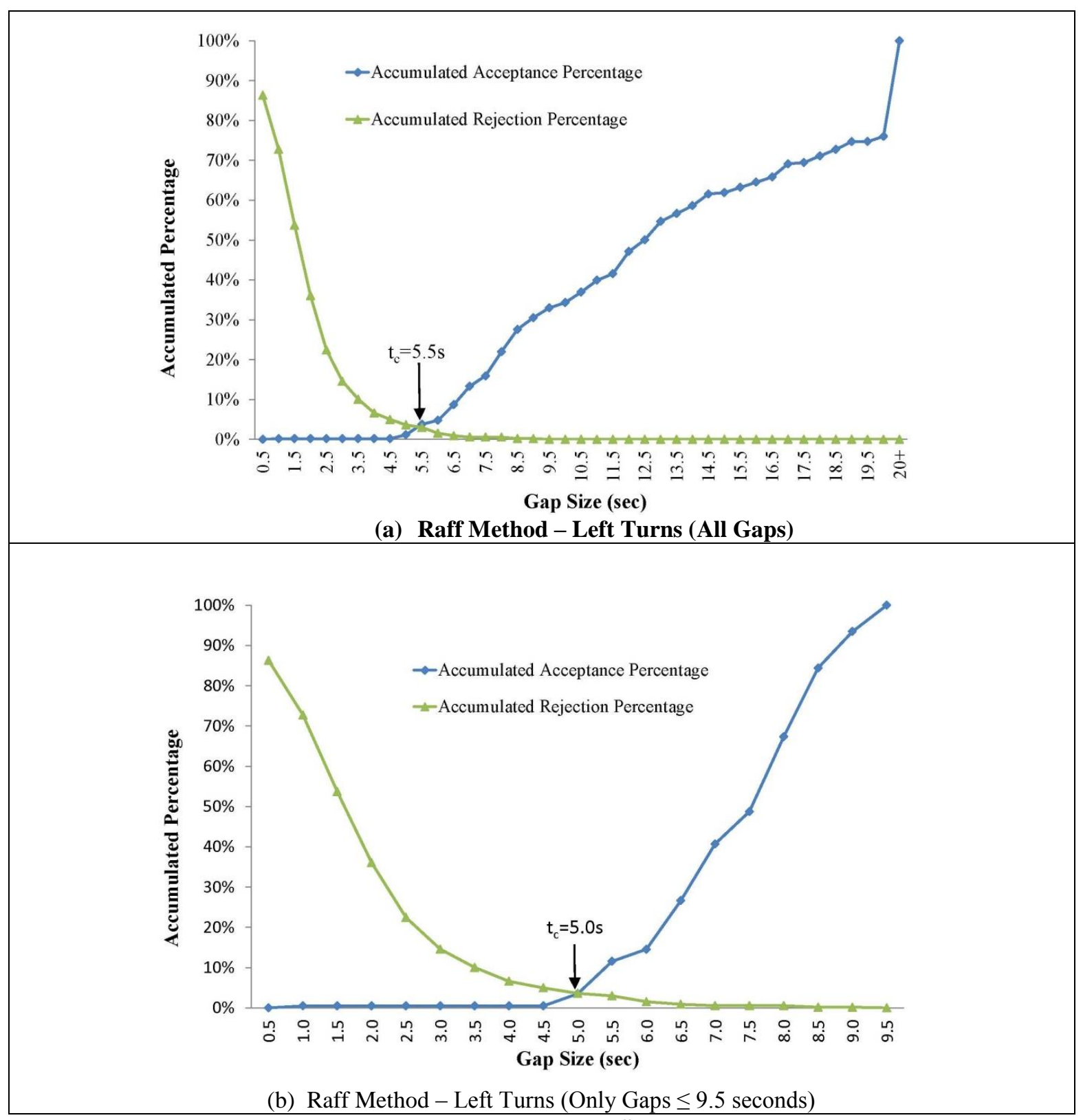

Figure 4.5: Raff Method Approach at Large Commercial Site \#1

\subsubsection{Logit Method}

The use of logit models for estimating probability has been widely accepted in traffic operations research for many years. For assessment of the critical gap the Logit Method, also known as the logistic regression method, is basically a weighted linear regression model. It can be used to estimate the probability that an event will occur (i.e., driver will accept a gap). For this analysis, the independent variable has a binary value of either zero or one (or no versus yes). The basic logistic regression model is shown below: 


$$
p=\frac{e^{g(x)}}{1+e^{g(x)}}
$$

Where,

$$
p=\text { probability of accepting a gap. }
$$

The logit of the logistic regression model is then shown as:

$$
g(x)=\ln \left(\frac{p}{1-p}\right)=\beta_{0}+\beta_{1} x
$$

Where,

$$
\begin{aligned}
& \beta_{0}, \beta_{1}=\text { regression coefficient; } \\
& x=\text { gap size or gap length. }
\end{aligned}
$$

According to the logit model, the critical gap is the $\mathrm{x}$-value when $p$ is equal to 0.5 .

Figure 4.6 presents the gap acceptance probability over gap size. By substituting a p value of 0.5 , the critical gap size determined using the logit method is 5.66 seconds for the large commercial site \#1 in Oregon.

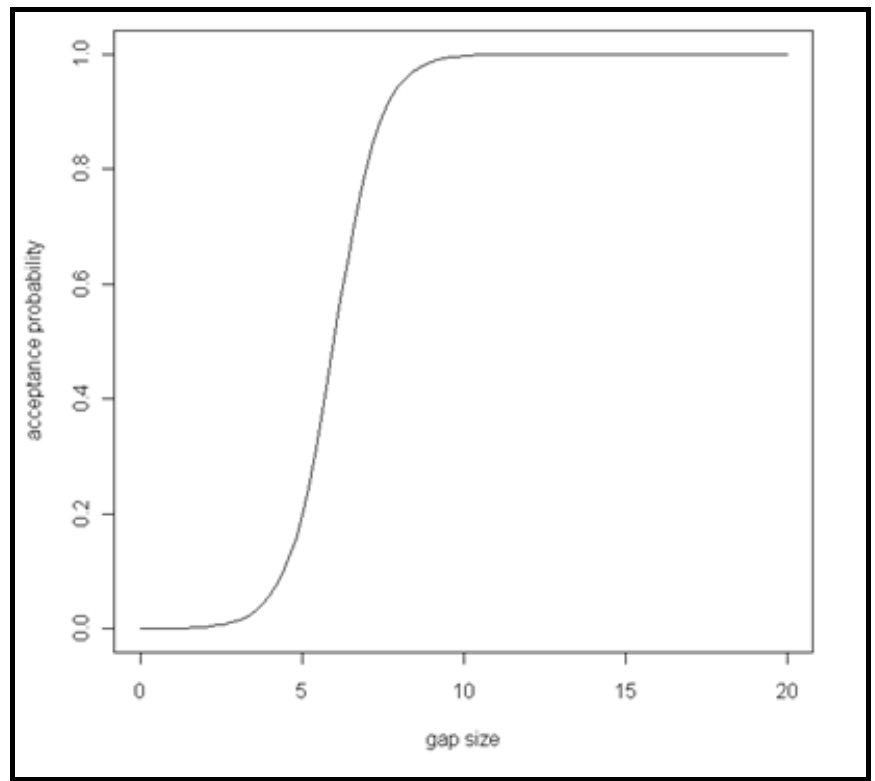

Figure 4.6: Logit Model Approach 


\subsection{RESULTS}

For comparison purposes, the research team considered four common gap-acceptance techniques; however, ultimately the more stable Raff and Logit methods were used for the final critical gap assessment of the individual sites. Since the two methods use very different approaches, the critical gaps determined using these methods are expected to differ.

Based on the Raff and Logit critical gap methods, the data analysis for the right turn out of the driveway maneuver determined that the critical gap values of the nontraversable median sites (\#5 and \#8) experienced the shortest time gaps based on the Logit method and, with only one exception at Site 6b, were the shortest time gaps for the Raff Model. This observation suggests that at roadway locations that do not have left-turn movements into driveways, the right-turning drivers appear willing to accept smaller gaps. Though it would be helpful to evaluate additional sites, this finding suggests that different cross-sectional roadway design (i.e., median versus TWLTL) may influence the right-turning gap acceptance behavior at the driveway locations.

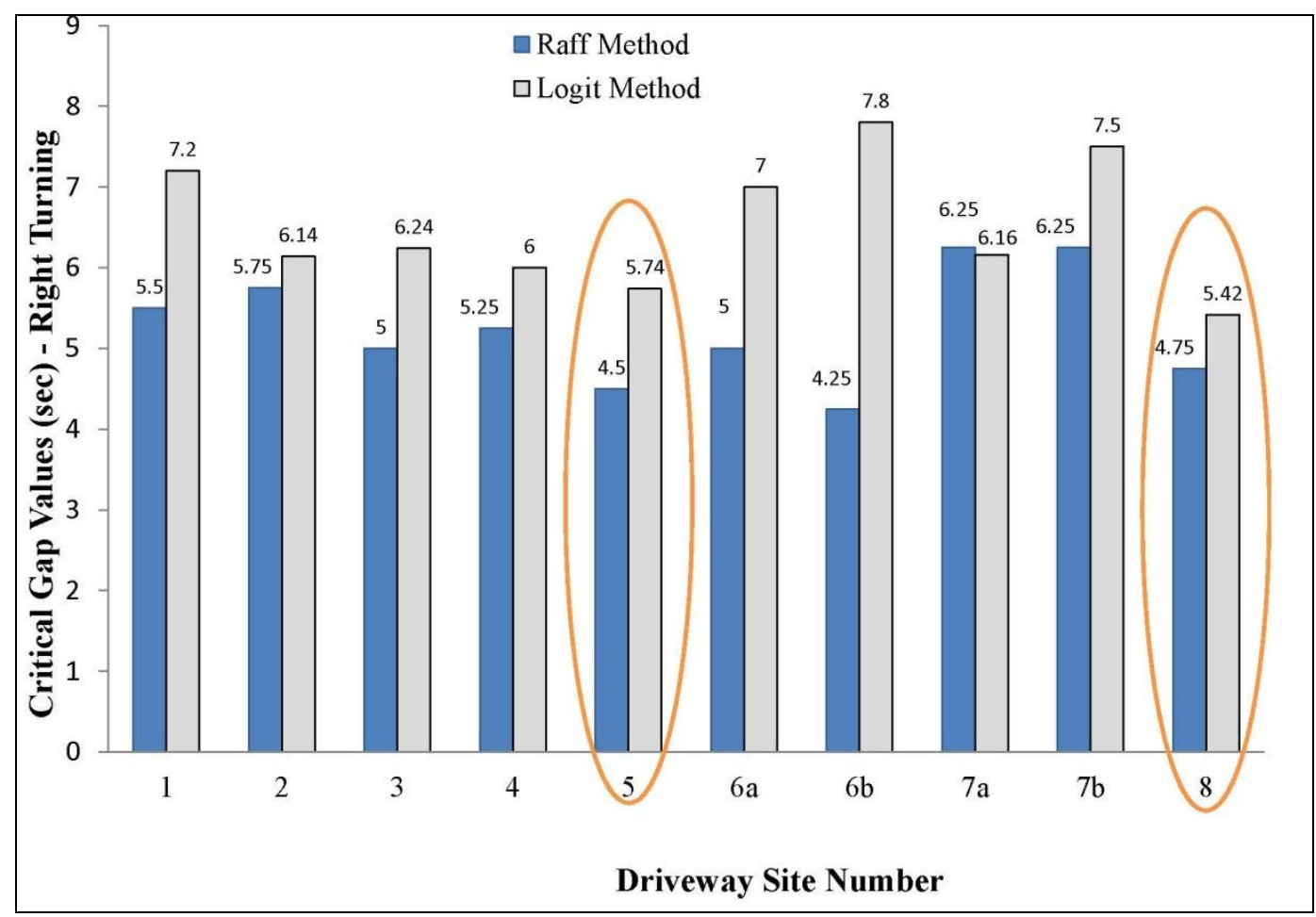

Figure 4.7: Critical Gap Comparison of Right Turns at Study Driveways

Sites \#1-5 represent the Oregon study locations where bicycle lanes are present. Sites \#6a - 7b and Site \#8 represent the Arkansas and Oklahoma sites, respectively, where bicycle lanes were not present. There is no clear evidence that the presence of a bicycle lane influenced the critical gap since the values appear similar for both configurations. 
Table 4.1: Critical Gap Values for Study Driveways

\begin{tabular}{|c|c|c|c|c|c|c|c|c|}
\hline \multirow[b]{2}{*}{ State } & \multirow[b]{2}{*}{ Site } & \multirow[b]{2}{*}{$\begin{array}{l}\text { Land Use } \\
\text { Accessed }\end{array}$} & \multicolumn{3}{|c|}{ Left-Turn Critical Gap } & \multicolumn{3}{|c|}{ Right-Turn Critical Gap } \\
\hline & & & $\begin{array}{l}\text { Raff } \\
\text { Method } \\
\text { (sec) }\end{array}$ & $\begin{array}{l}\text { Logit } \\
\text { Method } \\
\text { (sec) }\end{array}$ & $\begin{array}{l}\text { Sample } \\
\text { Size } \\
\text { (turns) }\end{array}$ & $\begin{array}{c}\text { Raff } \\
\text { Method } \\
\text { (sec) }\end{array}$ & $\begin{array}{l}\text { Logit } \\
\text { Method } \\
\text { (sec) }\end{array}$ & $\begin{array}{c}\text { Sample } \\
\text { Size } \\
\text { (turns) }\end{array}$ \\
\hline \multirow{4}{*}{$\begin{array}{c}\text { Oregon } \\
\text { (Bicycle Lanes, } \\
\text { TWLTL) }\end{array}$} & 1 & Office Supply & 4.25 & 6.00 & 341 & 5.50 & 7.20 & 259 \\
\hline & 2 & $\begin{array}{c}\text { Large Size } \\
\text { Commercial \#1 }\end{array}$ & 4.25 & 5.72 & 896 & 5.75 & 6.14 & 379 \\
\hline & 3 & $\begin{array}{c}\text { Large Size } \\
\text { Commercial \#2 }\end{array}$ & 3.75 & 4.97 & 1351 & 5.00 & 6.24 & 395 \\
\hline & 4 & $\begin{array}{c}\text { Large Size } \\
\text { Commercial \#3 }\end{array}$ & 5.00 & 5.67 & 127 & 5.25 & 6.00 & 457 \\
\hline $\begin{array}{c}\text { Oregon } \\
\text { (Bicycle Lanes, } \\
\text { Nontraversable } \\
\text { Median) }\end{array}$ & 5 & $\begin{array}{l}\text { Medium Size } \\
\text { Commercial }\end{array}$ & \multicolumn{3}{|c|}{$\begin{array}{c}\text { Not Applicable (Nontraversable } \\
\text { Median) }\end{array}$} & 4.50 & 5.74 & 563 \\
\hline \multirow{4}{*}{$\begin{array}{c}\text { Arkansas (No } \\
\text { Bicycle Lanes, } \\
\text { TWLTL) }\end{array}$} & $6 a$ & $\begin{array}{l}\text { Restaurant \#1 - } \\
\text { Day } 1\end{array}$ & 5.40 & 5.77 & 66 & 5.00 & 7.00 & 12 \\
\hline & $6 b$ & $\begin{array}{l}\text { Restaurant \#1 - } \\
\text { Day } 2\end{array}$ & 4.00 & 6.45 & 546 & 4.25 & 7.80 & 229 \\
\hline & $7 \mathrm{a}$ & $\begin{array}{c}\text { Large Size } \\
\text { Commercial \#4 - } \\
\text { Day } 1\end{array}$ & 3.00 & 6.20 & 537 & 6.25 & 6.16 & 168 \\
\hline & $7 b$ & $\begin{array}{c}\text { Large Size } \\
\text { Commercial \#4 - } \\
\text { Day } 2 \\
\end{array}$ & 3.50 & 6.00 & 361 & 6.25 & 7.50 & 131 \\
\hline $\begin{array}{c}\text { Oklahoma (No } \\
\text { Bicycle Lanes, } \\
\text { Nontraversable } \\
\text { Median) }\end{array}$ & 8 & Restaurant \#2 & \multicolumn{3}{|c|}{$\begin{array}{c}\text { Not Applicable (Nontraversable } \\
\text { Median) }\end{array}$} & 4.75 & 5.42 & 75 \\
\hline
\end{tabular}

Table 4.1 summarizes the critical gap values for all study locations. For the Arkansas sites where data collection occurred across multiple days, the critical gap is provided for each day since traffic volume and time-of-day characteristics could contribute to critical gap values. As previously noted, the observed critical gaps for right-turn maneuvers does not appear to substantially differ for facilities with and without bicycle lanes.

Table 4.1 also includes the calculated critical gap values for vehicles turning left from the TWLTL into the study driveways. Since the Oregon locations have a bicycle lane present, initial inspection indicates that the vehicle traverses an additional five to six feet during the turning maneuver. It may also be the case, however, that vehicle drivers are simply trying to clear the far side of the oncoming lane and do not directly consider the bicycle lane unless a cyclist is present. One could hypothesize that the additional distance that the left-turning vehicle must traverse would require additional time, resulting in a larger critical gap. However, by inspection of the values shown in this table and as graphically depicted in Figure 4.8, the presence of a bicycle lane does not appear to extend the critical gap value. The locations with bicycle lanes have a similar average critical gap value as those locations that do not have bicycle lanes. Sites \#5 and 
\#8 are not included in Figure 4.8 because these are the two sites with nontraversable medians, and so no vehicles are permitted to turn left into the driveway at these locations.

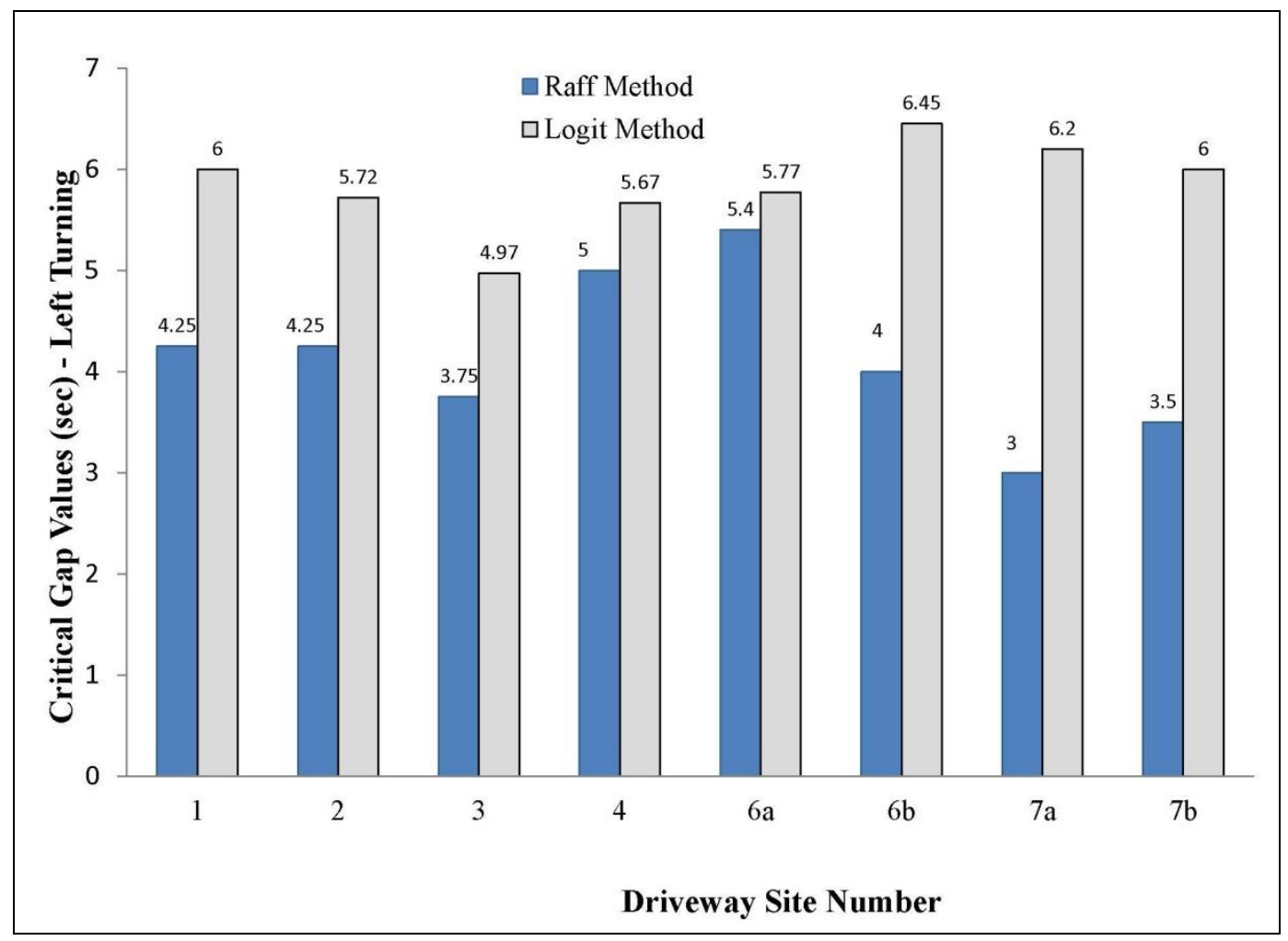

Figure 4.8: Critical Gap Comparison of Left Turns into Study Driveways 


\subsection{SIMULATION ANALYSIS}

Studies have shown that access density (total number of access points per mile in both travel directions) may directly influence safety and operational performance for through traffic along a corridor. The number of crashes generally has an increasing relationship with access density, as closely spaced access points create more complex traffic conflicts. The published literature indicated that road geometric characteristics (e.g., median type) influence safety performance. According to NCHRP Report 420 (Gluck et al., 1999), the crash rates on roadways with a nontraversable median are much lower than for a roadway with a TWLTL. Numerous studies have recommended that strategic access management applications can help improve the roadway operational performance. Analysis in the HCM further indicates that each access point would reduce the free-flow speed by $0.15 \mathrm{mph}$ (TRB, 2010). The HCM employs the access density as one of the adjustment factors for determining level of service.

The primary purpose of this study is to investigate the influence that access density (access spacing) and the roadway cross-sectional features of medians and bicycle lanes can have on traffic performance. Previous sections of this report reviewed the observed crash history and driveway critical gaps. To further assess how the driveway density may directly influence delay and travel time along the corridor, the project team used micro-simulation for this operational analysis.

\subsection{METHODOLOGY FOR ANALYSES}

\subsubsection{Simulation Models}

For the simulation analysis, the research team created hypothetical one-mile corridor models in the micro-simulation program CORSIM. Each corridor included an equal numbers of driveways on both sides of the road. For one scenario, referred to as aligned, the driveways were located directly opposite of each other so that their centerlines lined up. For the second scenario, referred to as staggered for the remainder of this report, the driveways were not located opposite to each other and were offset by known values. Figure 5.1 shows an example of aligned driveways and staggered driveways for a total number of 40 driveways combined for both sides of the road.

The project team then varied the access density for the aligned and staggered scenarios as a means of determining how driveway placement combined with density may influence traffic operations at driveways. In this study, the research team evaluated access density for 20 aligned and 40 staggered driveways. This analysis also included a scenario with 60 driveways for the aligned configuration, but the 60-driveway configuration could not be achieved for the staggered orientation. The driveway configurations were then evaluated for the two different median treatments (i.e., raised median and TWLTL) and for four levels of traffic volume for the major street (i.e., 1,000, 1,500, 2,000, and 2,500 vehicles per hour for each travel direction). Overall, the simulation task evaluated a total of 40 alternative driveway scenarios [aligned ( 3 driveway 
densities x 2 median treatments x 4 traffic volume thresholds) + staggered (2 driveway densities $\mathrm{x} 2$ medians $\mathrm{x} 4$ traffic volume thresholds)].

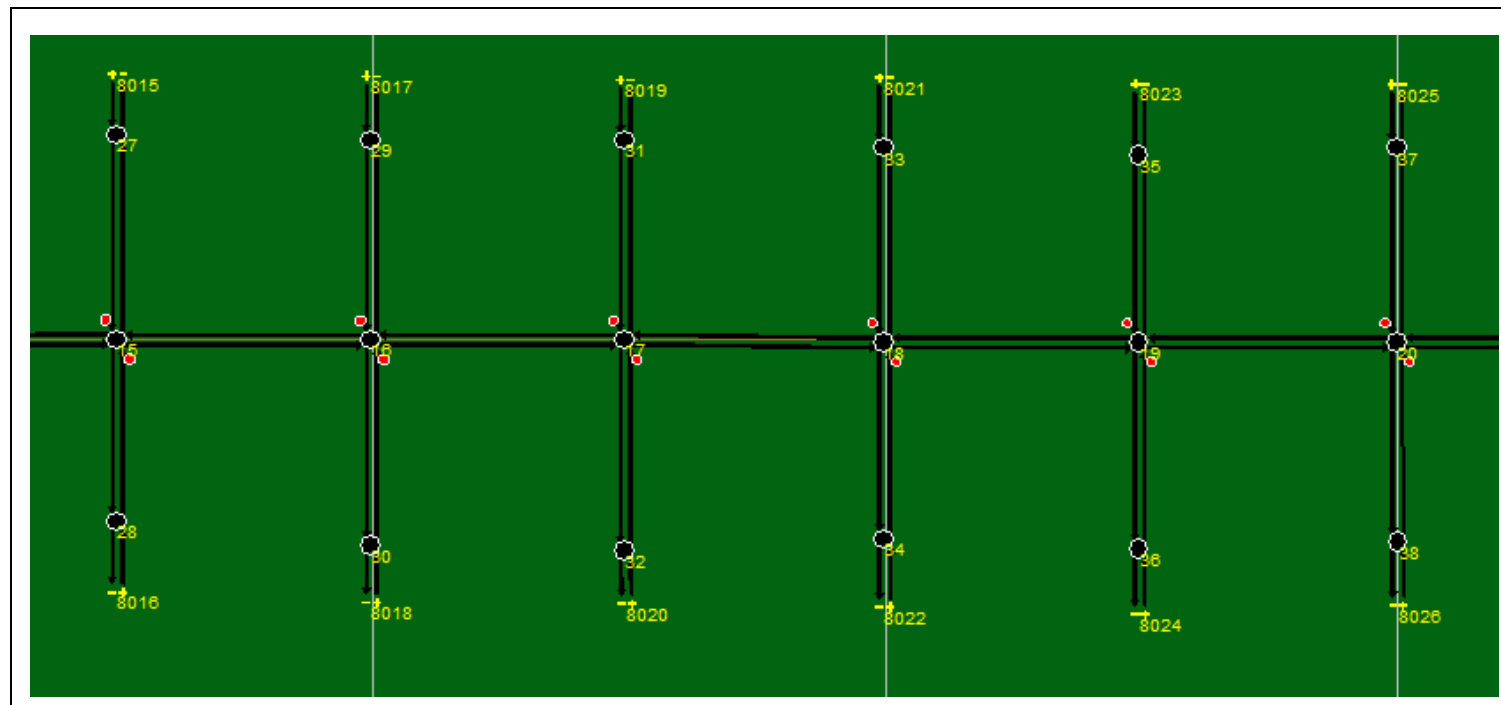

(a) Aligned driveways

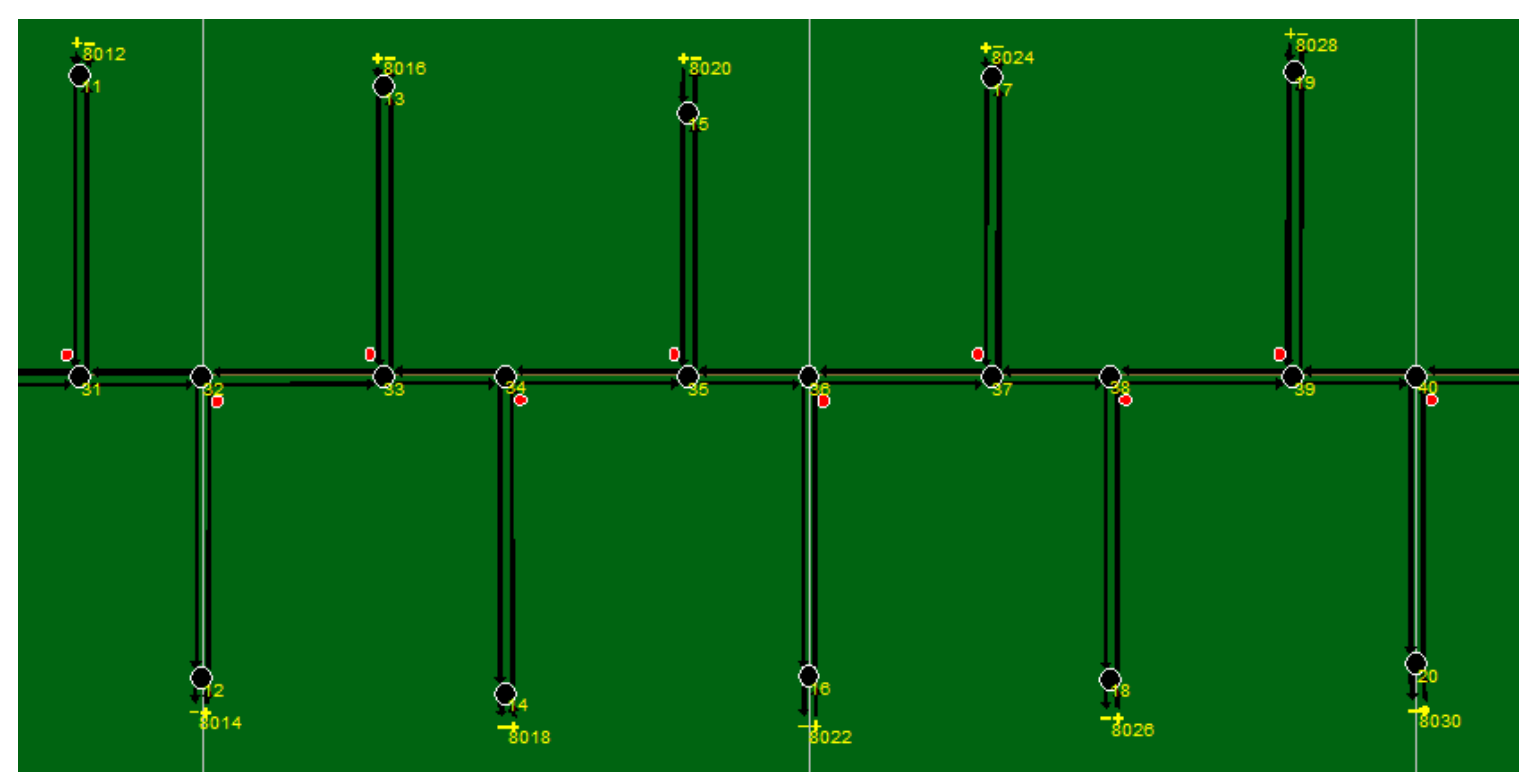

(b) Staggered driveways

Figure 5.1: Screen Shot of Driveway Layout

Due to the hypothetical nature of this simulation and the goal to maintain some consistency between the various driveway configurations, the research team assigned a traffic volume distribution at the driveways along the TWLTL median treatment corridors as 30 percent turning left and 70 percent turning right. This assumption of 70 percent right-turn vehicles was based on field observations during the gap analysis study. At study locations with raised medians, left 
turns are not permitted except at intersection and median break locations, so all of the vehicles exiting a driveway were required to turn right. To maintain a balanced network (as many vehicles leaving as entering the roadway), the traffic volume distribution on the major street was based on the overall major street volume, driveway volume, and number of driveways in each scenario. The research team used a threshold that assumed the volume of vehicles exiting the node was within a 5 percent standard deviation of vehicles entering the node. For all simulated corridors, the travel speed was assumed to be $40 \mathrm{mph}$ along the corridor and $20 \mathrm{mph}$ at the driveways.

\subsubsection{Number of Simulation Runs and Time}

A single simulation can provide a variety of results that are strongly influenced by the unique random seed number used to generate the vehicles and driver types. Therefore, multiple runs of each scenario are recommended so that average conditions can be identified for each configuration. For each alternative model, the research team simulated the traffic conditions five times, each time using different random seeds so as to eliminate the impact of the stochastic nature of CORSIM. So that comparisons could be made between the different roadway scenarios, the research team used the same set of five random seeds for all alternatives. This approach helped to minimize any possible anomalies associated with a single random seed value, and also helped to ensure the differences among all alternatives were associated with the alternatives themselves (Holm et al., 2007). For each simulation run, the team established an initialization period of 30 minutes to ensure that the overall system reached an equilibrium condition before evaluation of performance measures. The duration of each measured simulation, following completion of the initialization, lasted for 7,200 seconds (the maximum approximate time expected for a vehicle to traverse the entire corridor during constrained traffic conditions).

As a result of the simulation activities, the research team acquired traffic performance data (delay and travel time) along the corridor, and used this information as the measurement of effectiveness (MOE) for data analysis so that the various scenarios could be compared. These MOE values are reviewed and contrasted in the following section.

\subsection{FINDINGS}

The individual MOE values for varying traffic volumes are depicted in Table 5.1 (aligned driveways with a raised median); Table 5.2 (aligned driveways with a TWLTL); Table 5.3 (staggered driveways with a raised median); and Table 5.4 (staggered driveways with a TWLTL). Each of these tables has companion figures (Figure 5.2 through Figure 5.5) that graphically illustrate the relationship between the delay per vehicle and the travel time contrasted to the traffic volume. The lines in the graphic then represent the driveway density condition for each strategy. Upon initial inspection, it can be noted that there is a similar trend across all scenarios. The delay and travel time increased as traffic volumes on the major street increased. Similarly, an increasing density in driveway spacing resulted in greater observed delay and travel time along the corridor.

A close examination of the trend lines and the values across all scenarios reveals that the increasing rates and the values of MOE vary based on the specific configuration. The geometric 
design of the corridor, the level of traffic volume, and access density appear to collectively influence the MOE output values.

For Scenario 1 (aligned driveways and major street medians), Figure 5.2 demonstrates that even though the values associated with delay and travel time increased with higher traffic volume and increasing access density, the delay and travel time for each access spacing option remain reasonably similar (characterized by flatter lines in the figure). This could be explained by the simplicity of the geometric design. With driveways aligned across the road and a raised median installed along the length of the corridor, the traffic conflicts are largely simplified. Vehicles cannot execute left-turning maneuvers from a driveway to the major street or from the major street to the driveway. It can be seen that for the lowest traffic volume threshold (i.e., 1,000), the delay values for all measured levels of access density were similar. As traffic volume increased, however, more vehicles interact with each other, resulting in an increase in the delay and travel time for the more densely spaced driveway configurations.

Table 5.1: MOE Values for Scenario 1

\begin{tabular}{l|c|c|c|c}
\hline \multicolumn{5}{c}{ Scenario 1: Aligned Driveways - Raised Median on Major Street } \\
\hline \multirow{2}{*}{ MOE (second per vehicle) } & \multicolumn{4}{c}{ Major volume } \\
\cline { 2 - 5 } & $\mathbf{1 , 0 0 0}$ & $\mathbf{1 , 5 0 0}$ & $\mathbf{2 , 0 0 0}$ & $\mathbf{2 , 5 0 0}$ \\
\hline Delay per Vehicle (AD=20) & 4.73 & 4.85 & 4.80 & 5.27 \\
\hline Delay per Vehicle (AD=40) & 4.77 & 5.24 & 5.81 & 6.65 \\
\hline Delay per Vehicle (AD=60) & 4.82 & 5.50 & 6.12 & 7.44 \\
\hline Travel Time per Vehicle (AD=20) & 222.21 & 221.16 & 225.15 & 231.18 \\
\hline Travel Time per Vehicle (AD=40) & 233.19 & 230.05 & 233.13 & 239.87 \\
\hline Travel Time per Vehicle (AD=60) & 235.36 & 232.52 & 236.72 & 246.82 \\
\hline
\end{tabular}




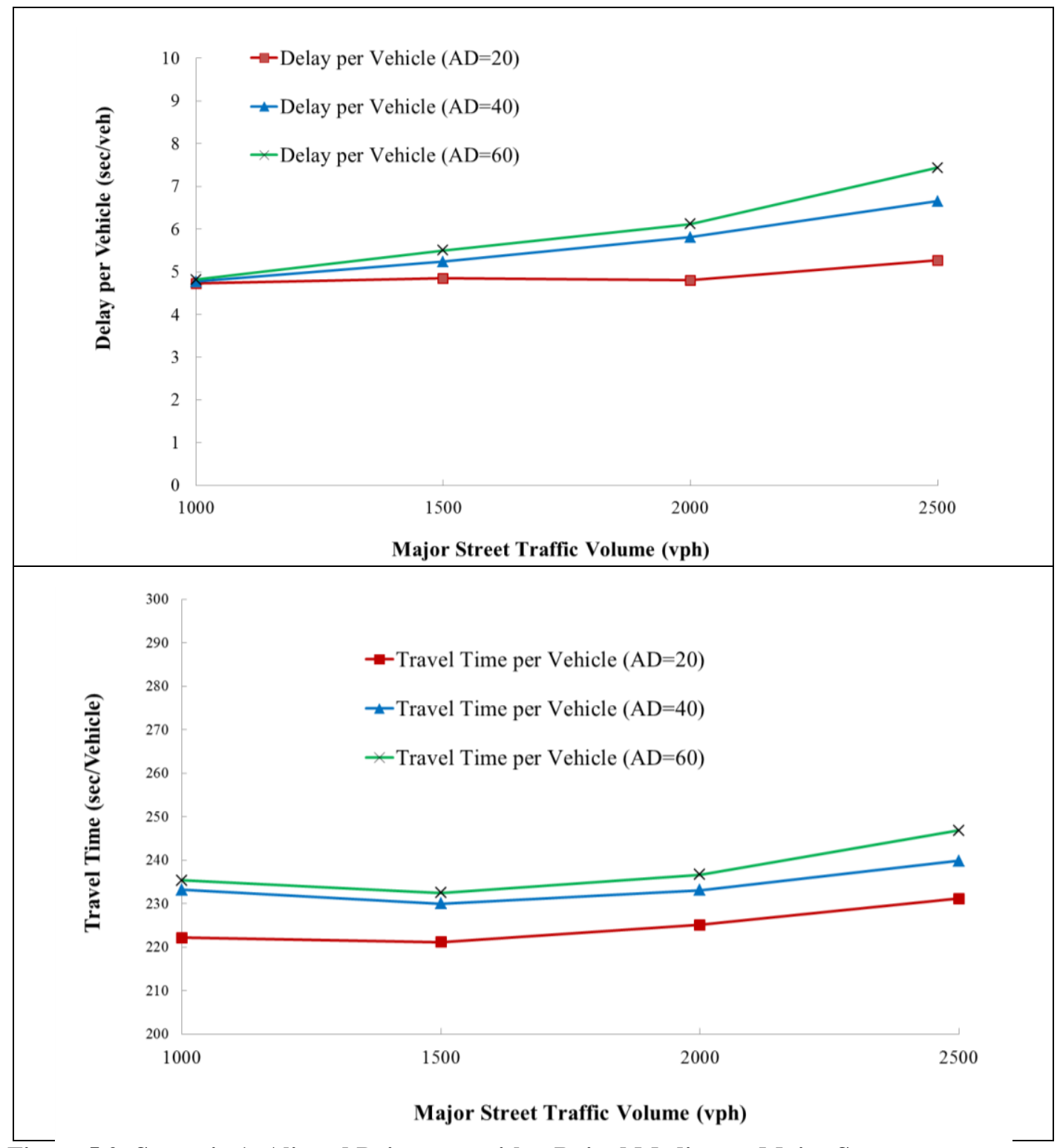

Figure 5.2: Scenario 1- Aligned Driveways with a Raised Median on Major Street

Table 5.2 and Figure 5.3 show the simulation results for Scenario 2 (aligned driveways and a TWLTL). The trend lines for travel time appear to increase at a reasonably constant rate. The observed delay substantially increased when the access density and traffic volume increased.

Comparing the two aligned driveway configurations (Scenario 1 and Scenario 2) demonstrates that delay and travel time are considerably greater at locations with a TWLTL than for the raised median configurations. This observation can be expected for higher-volume locations and more densely spaced access points since the left-turn option is not available at the median sites, resulting in smoother traffic flow and less delay along the median corridors. Similarly, corridors with a TWLTL that accommodate these left turns understandably have more vehicle conflicts at the higher volumes. These additional conflicts contribute to additional delay and travel time. 
Table 5.2: MOE Values for Scenario 2

Scenario 2: Aligned Driveways - TWLTL on Major Street

\begin{tabular}{l|c|c|c|c}
\hline \multirow{2}{*}{ MOE (second per vehicle) } & \multicolumn{4}{|c}{ Major volume } \\
\cline { 2 - 5 } & $\mathbf{1 , 0 0 0}$ & $\mathbf{1 , 5 0 0}$ & $\mathbf{2 , 0 0 0}$ & $\mathbf{2 , 5 0 0}$ \\
\hline Delay per Vehicle (AD=20) & 19.90 & 26.75 & 29.28 & 34.65 \\
\hline Delay per Vehicle (AD=40) & 21.30 & 30.85 & 41.53 & 49.67 \\
\hline Delay per Vehicle (AD=60) & 25.37 & 31.57 & 42.51 & 50.75 \\
\hline Travel Time per Vehicle (AD=20) & 234.31 & 240.49 & 245.45 & 258.28 \\
\hline Travel Time per Vehicle (AD=40) & 243.97 & 249.89 & 263.25 & 274.74 \\
\hline Travel Time per Vehicle (AD=60) & 249.97 & 257.74 & 276.20 & 287.63 \\
\hline
\end{tabular}

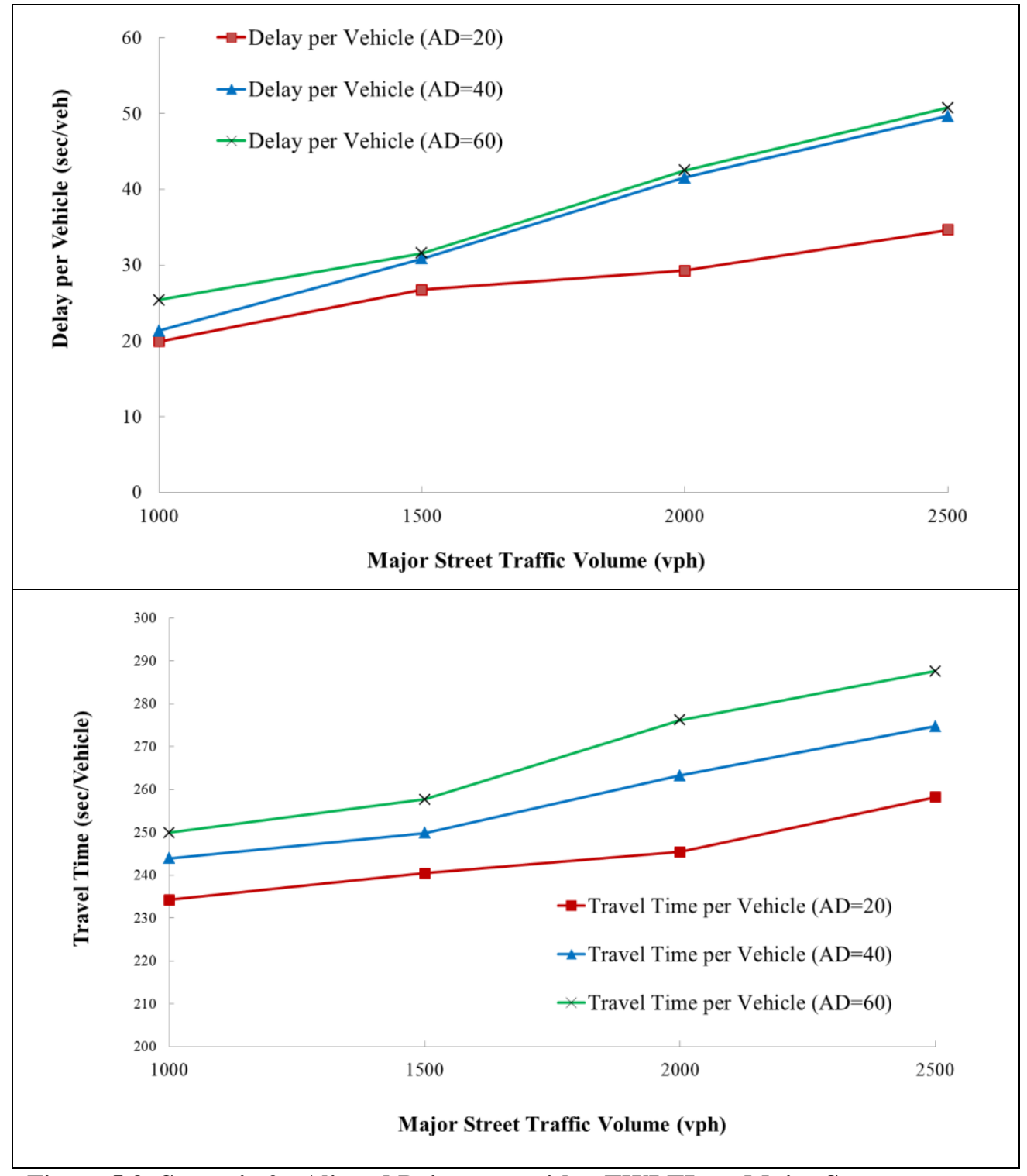

Figure 5.3: Scenario 2 - Aligned Driveways with a TWLTL on Major Street 
In Scenario 3 (staggered driveways and a raised median) and Scenario 4 (staggered driveways and a TWLTL), the research team assessed the additional impact that driveways that are not aligned with other driveways could add to the travel time and delay for a vehicle. The research team repeated the comparison previously described for Scenarios 1 and 2 for these additional staggered configurations. As previously indicated, the simulation tool limited the number of staggered driveways that could be positioned in the one-mile corridor, so only the 20 and 40 access point options are included in this staggered assessment.

As observed in Table 5.3 and Table 5.4 and shown in Figure 5.4 and Figure 5.5, the staggered configurations demonstrate a trend similar to that observed for the aligned configurations. Higher traffic volume on the major street and increasingly dense access spacing contribute to additional delays and travel times.

The simulation comparisons can also be extended to assessing how the aligned versus staggered driveway orientations contribute to observed traffic operations. For example, corridors with staggered driveway placement experienced considerably greater delay per vehicle when compared to their aligned driveway counterparts. In many cases, the observed travel times for the lower-volume 1,000 vph were similar for all configurations (ranging from 210 up to 234 seconds per vehicle for an access density of 20). However, these values vary more dramatically as traffic volume and access density increase.

Table 5.3: MOE Values for Scenario 3

Scenario 3: Staggered Driveways - Raised Median on Major Street

\begin{tabular}{l|c|c|c|c}
\hline \multirow{2}{*}{ MOE (second per vehicle) } & \multicolumn{4}{|c}{ Major volume } \\
\cline { 2 - 5 } & $\mathbf{1 , 0 0 0}$ & $\mathbf{1 , 5 0 0}$ & $\mathbf{2 , 0 0 0}$ & $\mathbf{2 , 5 0 0}$ \\
\hline Delay per Vehicle (AD=20) & 44.03 & 49.42 & 56.22 & 64.80 \\
\hline Delay per Vehicle (AD=40) & 51.75 & 56.78 & 62.37 & 71.59 \\
\hline Travel Time per Vehicle (AD=20) & 223.59 & 228.98 & 235.79 & 244.37 \\
\hline Travel Time per Vehicle (AD=40) & 231.34 & 236.38 & 241.97 & 251.19 \\
\hline
\end{tabular}




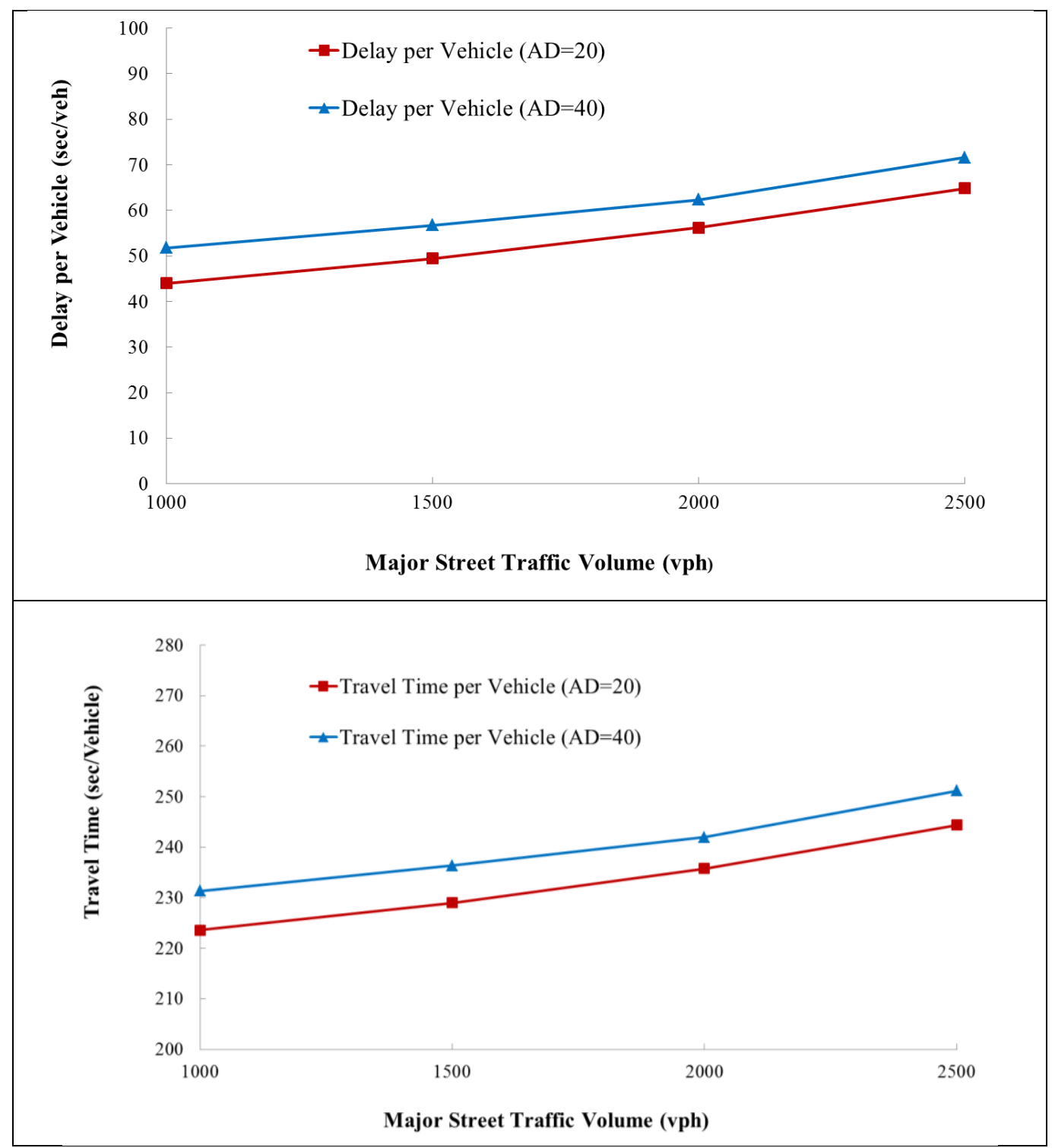

Figure 5.4: Scenario 3 - Staggered Driveways with a Raised Median on Major Street

Table 5.4: MOE Values for Scenario 4

Scenario 4: Staggered Driveways - TWLTL on Major Street

\begin{tabular}{l|c|c|c|c}
\hline \multirow{2}{*}{ MOE (second per vehicle) } & \multicolumn{4}{|c}{ Major volume } \\
\cline { 2 - 5 } & $\mathbf{1 , 0 0 0}$ & $\mathbf{1 , 5 0 0}$ & $\mathbf{2 , 0 0 0}$ & $\mathbf{2 , 5 0 0}$ \\
\hline Delay per Vehicle $(\mathrm{AD}=20)$ & 40.62 & 45.80 & 55.02 & 81.29 \\
\hline Delay per Vehicle $(\mathrm{AD}=40)$ & 56.65 & 64.38 & 75.28 & 91.79 \\
\hline Travel Time per Vehicle $(\mathrm{AD}=20)$ & 210.20 & 215.38 & 224.59 & 250.88 \\
\hline Travel Time per Vehicle $(\mathrm{AD}=40)$ & 236.25 & 243.98 & 254.88 & 271.38 \\
\hline
\end{tabular}




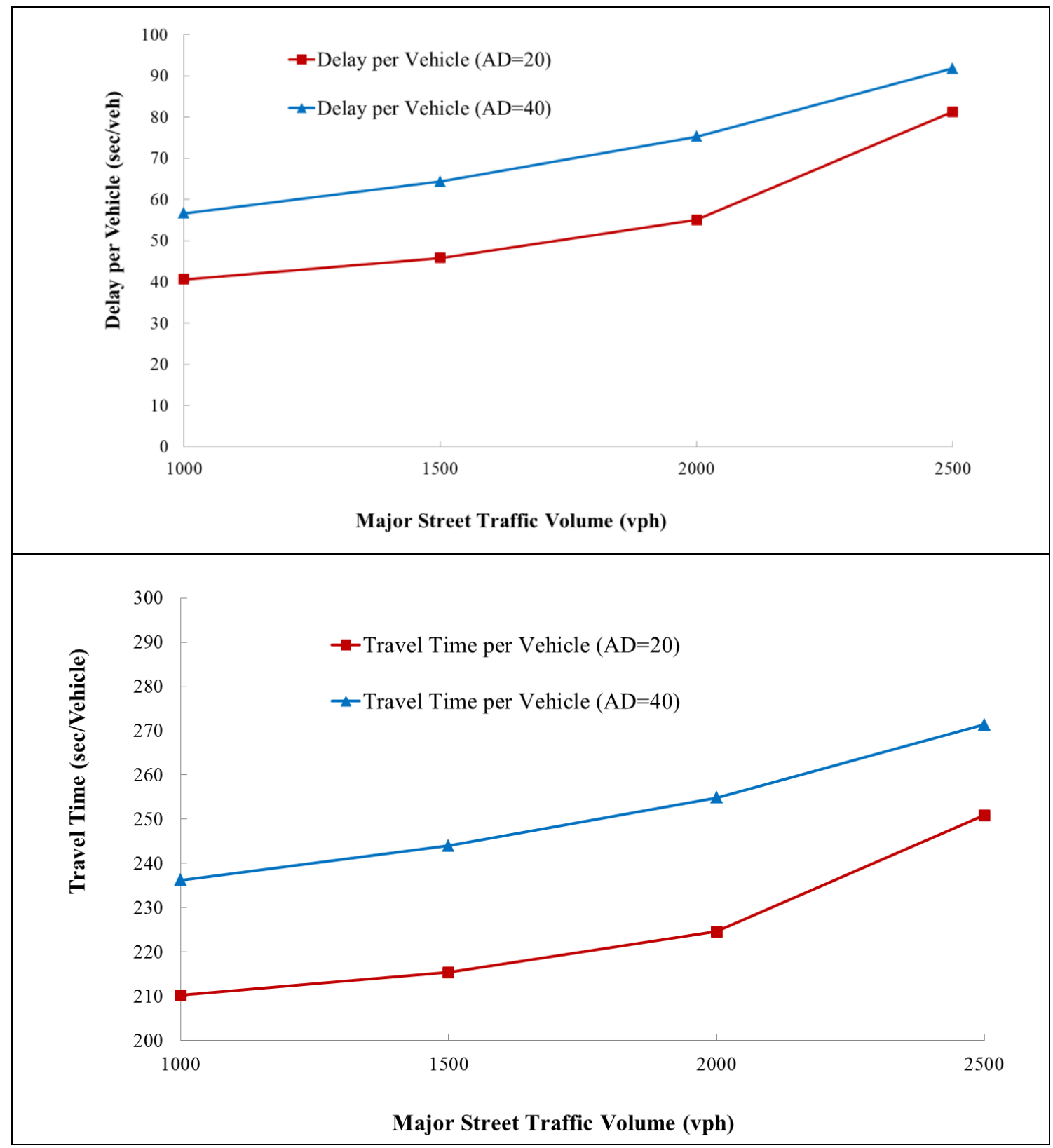

Figure 5.5: Scenario 4 - Staggered Driveways with a TWLTL on Major Street

Generally, the simulation study demonstrated that locations with raised medians are characterized by less delay and improved travel times when compared to locations with a TWLTL. The delays and travel times tend to increase with increased traffic volume and driveway density. The orientation of driveways on opposing sides of the streets also have some influence on increased delays for vehicles along the corridor; however, this influence is not as substantial as the increasing traffic volume and driveway density characteristics. 


\subsection{CONCLUSIONS AND RECOMMENDATIONS}

This study evaluated crashes, critical gaps, and traffic operations (based on micro-simulation) for a variety of driveway configurations. Field study sites were located in Oregon, Arkansas and Oklahoma and included arterial corridor sites with and without bicycle lanes as well as corridors with a raised median or a TWLTL. The research team evaluated the influence the bicycle facilities and median treatments had on driveway and corridor operations.

For the crash analysis, the research team acquired road characteristic and historic crash information for driveway study sites, and noted that the Oregon location with a raised median experienced only rear-end and angle crashes at the midblock driveway locations. Though the research team expected the percentage of angle crashes to be reduced and the percentage of rearend crashes to increase, it appears that the presence of the median also minimized other crash types including sideswipe crashes at the study sites. Though this study only includes a limited sample of driveways and crash data was not available for all locations, these findings suggest that the presence of a median will help to reduce a variety of crashes associated with midblock driveway locations.

The research team then evaluated critical gap values at the study locations. Initial analysis included four gap-acceptance methods. Ultimately, the research team used the Raff and the Logit methods to compare the estimated critical gap values and found that they varied widely, in some cases even for the same location on different days or based on different critical gap-assessment techniques. As expected, the right-turning critical gaps were generally greater than left-turning critical gaps at the same locations (often by differences ranging from 0.5 to 1.5 seconds). In a comparison of critical gap values between Oregon (where bicycle lanes were present) and Arkansas or Oklahoma (where bicycle lanes were not present), there were no indications that the presence of a bicycle lane adversely affects the critical gap value for left-turning vehicles.

The comparison of right-turn critical gap values at locations with raised medians when compared to locations with TWLTLs indicated that the right-turn critical gap values are generally lower at driveway locations with medians than at those without. One likely explanation of this finding is that the workload for the driver may be decreased at these locations. In other words, even though a left-turning vehicle into the driveway should not adversely influence the execution of a right turn out of the driveway, locations where the road has a raised median enable the driver to focus more directly on approaching vehicles from the left. This results in what appears to be shorter critical gap values for right-turn maneuvers out of the driveways.

Initially, the research team expected that the results of this study could potentially suggest that the presence of a bicycle lane does not adversely affect corridor operations and safety at driveway locations. Due to the cross sections of the arterials in this study, the presence of a median more dramatically influenced the corridor operations and subsequent safety. The bicycle lane provides additional sight-distance visibility, but also requires vehicles turning left into the 
driveway to traverse an additional distance. Based on the findings from this analysis, these factors associated with the bicycle lane seem to offset each other. As a result, the presence of a bicycle lane does not adversely influence gap-acceptance behavior at driveway locations. Based on the available crash data, however, the presence of bicycles in a bicycle lane are in direct conflict with driveway maneuvers and a small number of bicycle-related crashes can be expected to occur. It is important to note that the project team did not observe any bicycles at the Arkansas or Oklahoma sites yet saw several bicycles at the Oregon locations. Consequently, the presence of the bicycle lanes at the Oregon locations encouraged the selection of the corridors by bicyclists and their presence, with the possible exception of turning maneuvers. This did not adversely influence corridor operations at these locations. The research team recommends future in-depth studies that individually focus on the influence of bicycle lanes at driveway locations.

The research team also performed simulation analysis in order to examine the influence that median type, traffic volume, and access density have on traffic operational performance. By comparing the results from strategically designed simulation model alternatives, the analysis demonstrated that a higher level of traffic volume on the street and more densely spaced driveways (i.e., driveways located more closely to each other) would result in increased delay and travel time along the corridor. The study also confirmed that replacing a raised median with a TWLTL would create more traffic conflicts, and cause longer delay and travel times at higher traffic-volume thresholds. The simulation output also contrasted aligned and staggered driveway configurations. Aligned driveways provided a somewhat option in terms of delay and travel time.

The observations from this study clearly indicate that traffic volume, driveway density, and driveway orientation (to other driveways) collectively play a role in the safety and operations along a corridor. In addition, the bicycle analysis suggested that additional crashes may be expected between turning vehicles and bicycles, but the extent of this presumed safety influence was limited. Operationally, the presence of the bicycle lane did not increase gap-acceptance behavior by drivers turning left into a driveway (from a TWLTL). Though the vehicles traversed a longer path, the drivers had the benefit of additional site distance due to the presence of the bicycle lane. A future study that focuses more on the influence of vehicles turning right out of a driveway at locations with and without bicycle lanes is recommended. 


\subsection{REFERENCES}

\section{Cited References:}

American Association of State Highway and Transportation Officials. A Policy on Geometric Design of Highways and Streets. Washington, D.C., 1990, 1994, 2001, 2004, and 2011.

Dixon, K.K., I. Van Schalkwyk, and R.D. Layton. Balancing Urban Driveway Design Demands Based on Stopping Sight Distance. Transportation Research Record: Journal of the

Transportation Research Board, No. 2120, TRB, National Research Council, Washington, D.C., 2009, pp. 18-27.

Fitzpatrick, K., J. Mason, Jr., and D. Harwood. Comparison of Sight Distance Procedures for Turning Vehicles from a Stop-Controlled Approach, Transportation Research Record, No. 1385, TRB, National Research Council, Washington, D.C., 1991, pp. 1-11.

Flora, J.W., and K.M. Keitt. Access Management for Streets and Highways. United States Department of Transportation, Federal Highway Administration, 1982.

Gluck, J., H.S. Levinson, and V.G. Stover. Impacts of Access Management Techniques. NCHRP Report 420. Transportation Research Board, National Research Council, Washington, D.C., 1999.

Harwood, D.W., J.M. Mason, Jr., and R.E. Brydia. Sight Distance for Stop-Controlled Intersections Based on Gap Acceptance. Transportation Research Record, No. 1701, TRB, National Research Council, Washington, D.C., 2000, pp. 32-41.

Harwood, D.W., J.M. Mason, Jr., R.E. Brydia, M.T. Pietrucha, and G.L. Gittings. Intersection Sight Distance, NCHRP Report 383, Transportation Research Board, National Research Council, Washington, D.C., 1996, 113 p.

Holm, P., D. Tomich, J. Sloboden, and C. Lowrance. Traffic Analysis Toolbox Volume IV: Guidelines for Applying CORSIM Microsimulation Modeling Software. Report No. FHWAHOP-07-079, Washington, D.C., 2007.

Kyte, M., Z. Tian, Z. Mir, Z. Hameedmansoor, W. Kittelson, M. Vandehey, B. Robinson, W. Brilon, L. Bondzio, N. Wu, R. Troutbeck. Capacity and Level of Service at Unsignalized Intersections, Final Report. Volume 1 - Two-Way Stop-Controlled Intersections. NCHRP Web Document, Issue 5. TRB, National Research Council, Washington, D.C., 1996, 149 p. 
Lerner, N.D., R.W. Huey, H.W. McGee, and A. Sullivan. Older Driver Perception-Reaction Time for Intersection Sight Distance and Object Detection. Volume I: Final Report. Report No. FHWA-RD-93-168. Washington, D.C., 1995.

Mason, J. M., K. Fitzpatrick, and D.W. Hardwood. Field Observations of Truck Operational Characteristics Related to Intersection Sight Distance. Transportation Research Record, No. 1280, TRB, National Research Council, Washington, D. C., 1990, pp. 163-72.

Micsky, R.J., and J.M. Mason. Sight Distances for Vehicles Turning Left Off Major Roadways, Second National Conference on Access Management, Vail, CO, 1996.

Raff, M.S., and J.W. Hart. A Volume Warrant for Stop Signs. Eno Foundation for Highway Traffic Control, Saugatuck, CT, 1950.

Stover, V.G., and F.J. Koepke. Transportation and Land Development, 2nd Edition. Institute of Transportation Engineers, Washington, D.C., 2002.

Transportation Research Board. Access Management Manual. Transportation Research Board of the National Academies, Washington, D.C., 2003.

Transportation Research Board. Highway Capacity Manual: Special Report 209, $3^{\text {rd }}$ Edition. National Research Council, Washington, D.C., 1994.

Transportation Research Board. Highway Capacity Manual. Transportation Research Board of the National Academies, Washington, D.C., 2010.

Troutbeck, R.J. Estimating the Critical Acceptance Gap from Traffic Movements: Research Report No 92-5, Queensland University of Technology, Brisbane, Queensland, Australia, 1992.

\section{Background References Not Directly Cited:}

Fitzpatrick, K. Gaps Accepted at Stop-Controlled Intersections. Transportation Research Record, No. 1303, TRB, National Research Council, Washington, D. C., 1991, pp. 103-12.

Gattis, J.L. Gaps Accepted at Atypical Stop-Controlled Intersections. Journal of Transportation Engineering. Volume 125(3), 1999, pp.201-207.

Layton, R.D. Intersection Sight Distance. The Kiewit Center for Infrastructure and Transportation. Corvallis, OR, 2005. 
Transportation Research Board Committee on Access Management. Driveway and Street Intersection Spacing. Transportation Research Circular, Issue 456. Transportation Research Board of the National Academies, Washington, D.C., 1996.

Gattis, J.L. Gap Acceptance at Non-Standard Stop-Controlled Intersections". Transportation Research Board. Report MBTC FR 1059, University of Arkansas, Mack-Blackwell Transportation Center, AR, 1998.

Gattis, J. and Low, S. 1999. Gap Acceptance at Atypical Stop-Controlled Intersections. Journal of Transportation Engineering, Vol. 125(3),American Association of Civil Engineers, Washington, D.C., 1999, pp.201-207.

Harwood, D.W., J.M. Mason, Jr., and R.E. Brydia. Design Policies for Sight Distance at StopControlled Intersections Based on Gap Acceptance. Transportation Research Part A, Issue 33, 1999, pp. 199-216.

Hewitt, R. H. Measuring Critical Gap. Transportation Science, Volume 17, No.1, 1983, pp. 87109.

Hewitt, R.H. A Comparison between Some Methods of Measuring Critical Gap. Traffic Engineering and Control, Vol. 26(1), 1985, pp.13-22.

Koekpe, F. J., and H. S. Levinson. Access Management Guidelines for Activity Centers, NCHRP Report 348, Transportation Research Board, National Research Council, Washington, D.C., 1992. 
APPENDIX A. ABBREVIATION SUMMARY 
A-2 
Table A.1: Abbreviation Summaries

\begin{tabular}{l|l}
\multicolumn{1}{c|}{ Acronym } & \multicolumn{1}{c}{ Definition } \\
\hline AASHTO & American Association of State Highway and Transportation Officials \\
\hline ADT & Average Daily Traffic \\
\hline CALTRANS & California Department of Transportation \\
\hline HCM & Highway Capacity Manual \\
\hline MOE & Measurement of Effectiveness \\
\hline NCHRP & National Cooperative Highway Research Program \\
\hline OTREC & Oregon Transportation Research and Education Consortium \\
\hline TWLTL & Two-Way Left-Turn Lane \\
\hline
\end{tabular}


A-4 


\section{APPENDIX B. DETAILED DRIVEWAY INFORMATION}




\section{B-2}


The following section will provide detailed information for each data collection driveway location, including location information, traffic information, geometric design information, aerial photos, and gap-acceptance analysis results.

\section{Driveway Site 1: Office Supply}

\section{OfficeMax, $9^{\text {th }}$ St, Corvallis, OR}

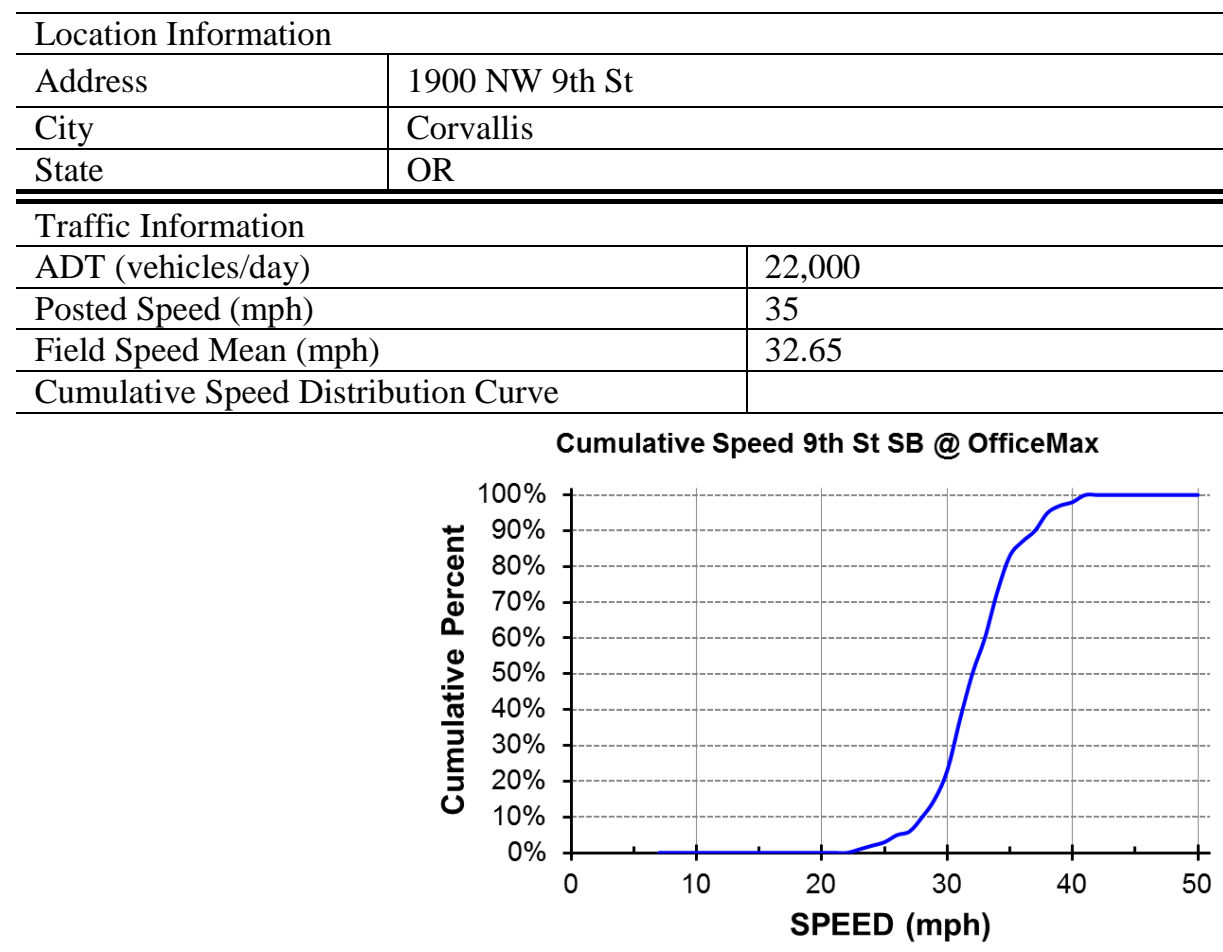

\begin{tabular}{l|l}
\hline \hline \multicolumn{2}{l}{ Geometric Design Information - Roadway in Vicinity of Driveway } \\
\hline Width of Roadway (ft) & 62 \\
\hline Number of Lanes & 4 lanes + TWLTL \\
\hline Lane Width (ft) & 12 \\
\hline Present of Bicycle Lane & Yes \\
\hline Present of Sidewalk & Yes \\
\hline \hline Geometric Design Information - Driveway & 24 \\
\hline Width of Driveway (ft) & 2 \\
\hline Number of Lanes & 12 \\
\hline Lane Width (ft) & No \\
\hline Median in Driveway & 958 \\
\hline Distance to Nearest Upstream Signal & \\
\hline \hline Data Collection Information & Sept $15^{\text {th }}, 2011$ \\
\hline Date & 3 hours \\
\hline Duration of Traffic Videos & Sunny \\
\hline Weather & Dry \\
\hline Pavement Surface Condition & D \\
\hline
\end{tabular}

Figure B.1: Driveway Site 1 - Road and Traffic Data 


\section{Aerial Photos:}

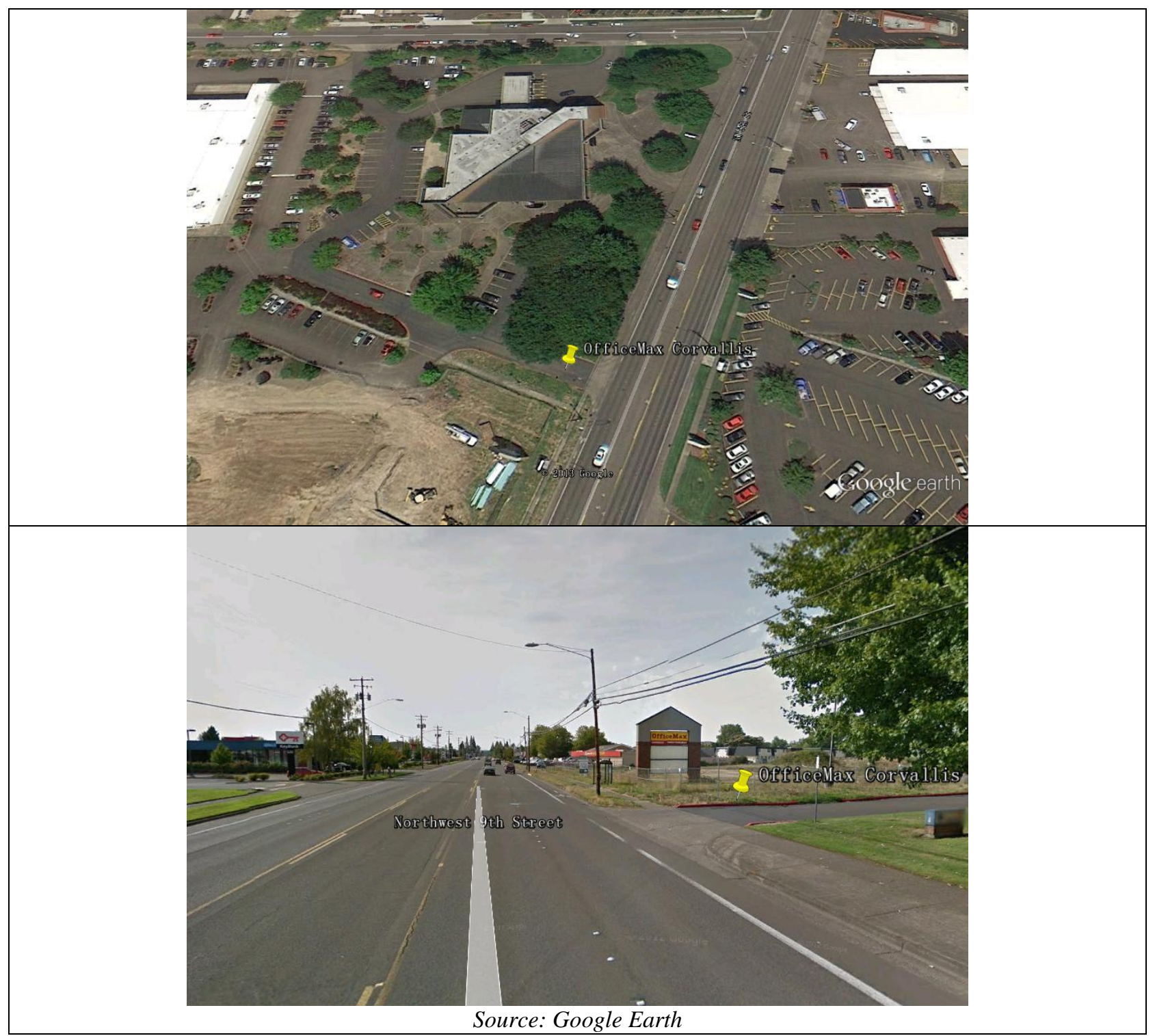

Figure B.2: Driveway Site 1 - Aerial Photos

\section{Gap-acceptance Results:}

Table B.1: Driveway Site 1 - Gap-acceptance Study Results

\begin{tabular}{l|c|c}
\hline \multirow{2}{*}{ Analysis Methods } & \multicolumn{2}{|c}{ Critical Gap (sec) } \\
\cline { 2 - 3 } & Left Turn & Right Turn \\
\hline Greenshield Method & 5.75 & 5.75 \\
\hline Raff Method & 4.75 & 6.00 \\
\hline Cumulative Acceptance Method & 4.75 & 5.75 \\
\hline Logit Method & 6.00 & 7.20 \\
\hline
\end{tabular}




\section{Gap-acceptance Analysis for Left Turns:}

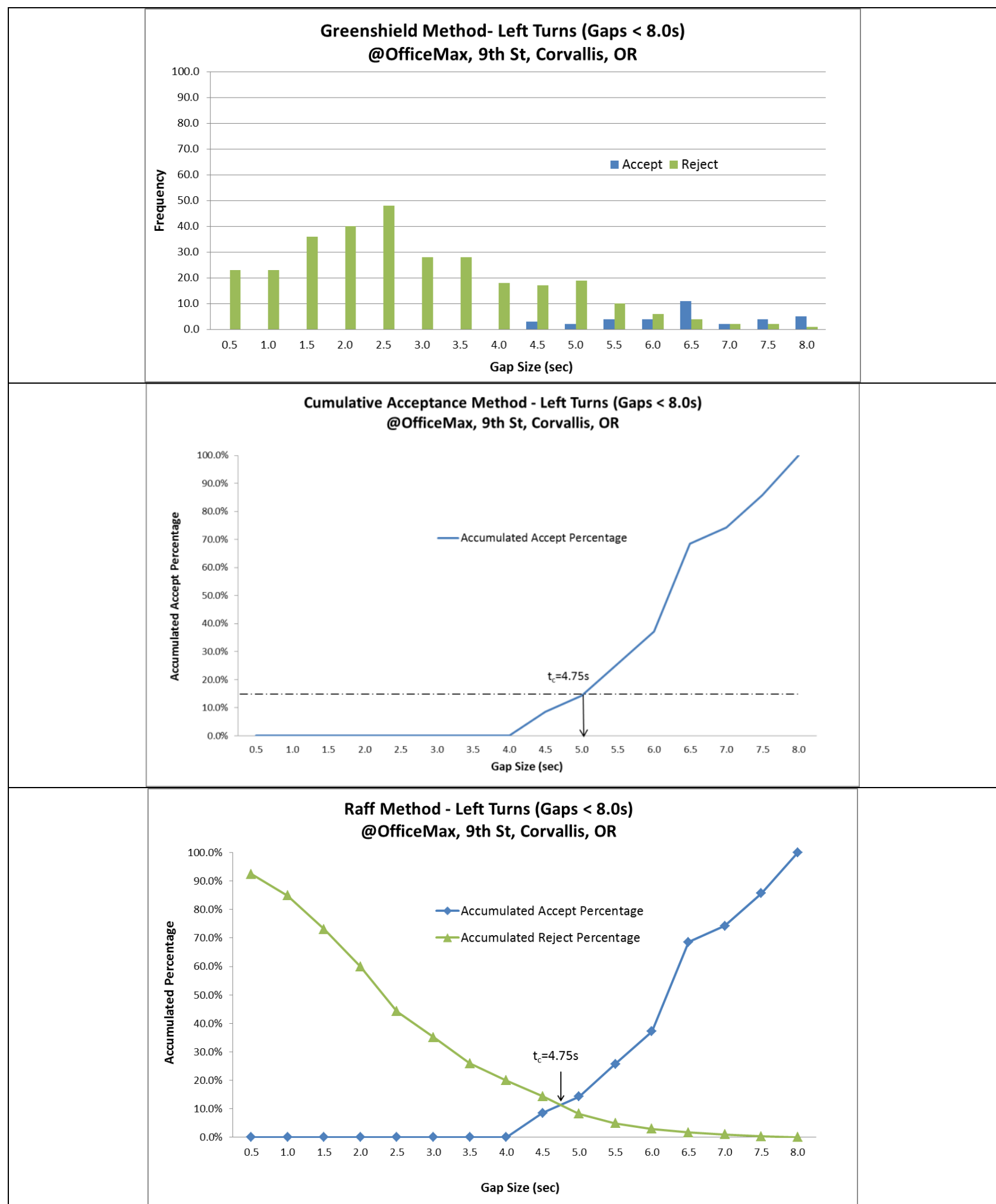

Figure B.3: Driveway Site 1 - Gap-acceptance Analysis for Left Turns 


\section{Gap-acceptance Analysis for Right Turns:}

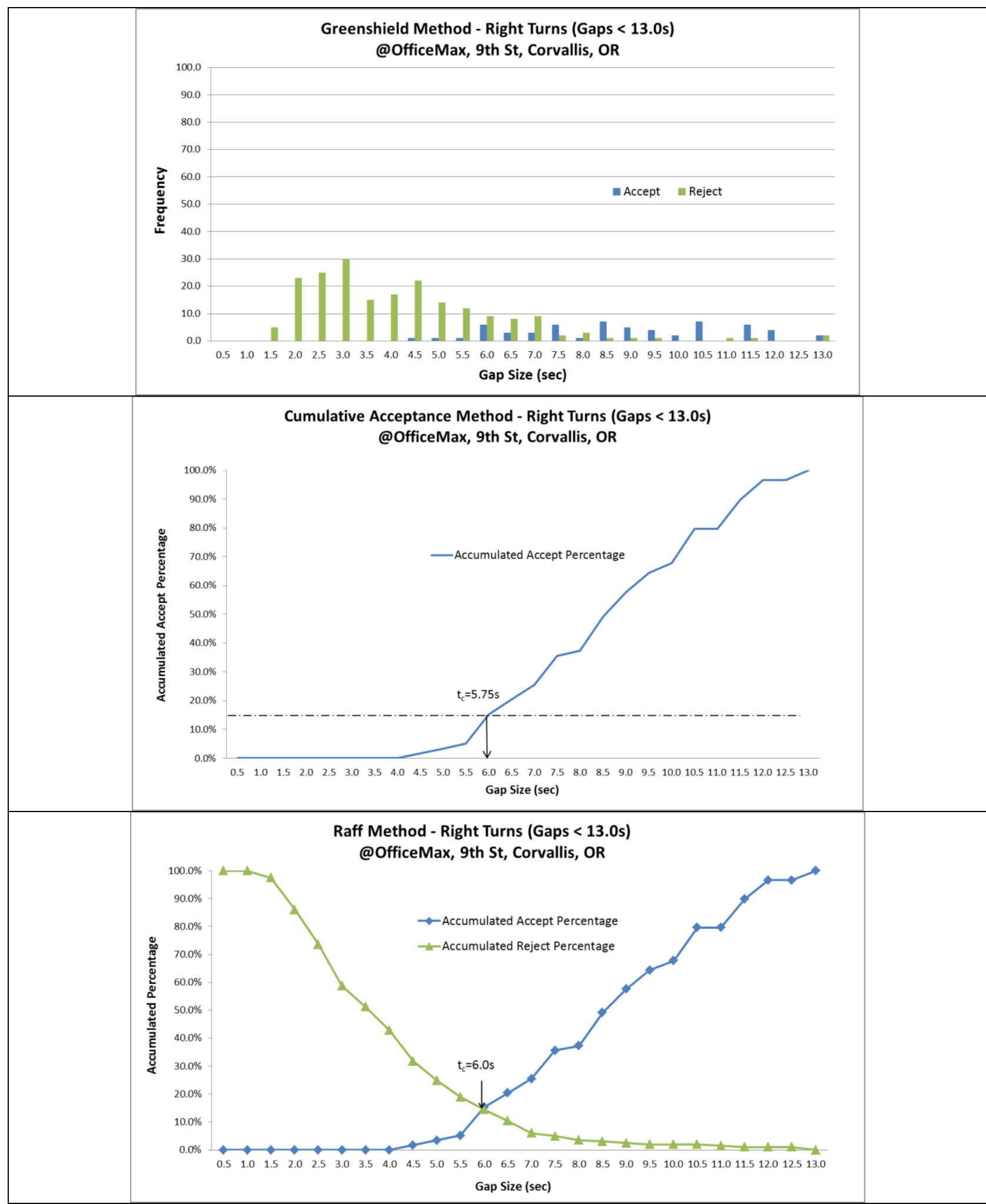

Figure B.4: Driveway Site 1 - Gap-acceptance Analysis for Right Turns 


\section{Driveway Site 2: Large-size Commercial \#1}

\section{Wal-Mart, Lancaster Dr, Salem, OR}

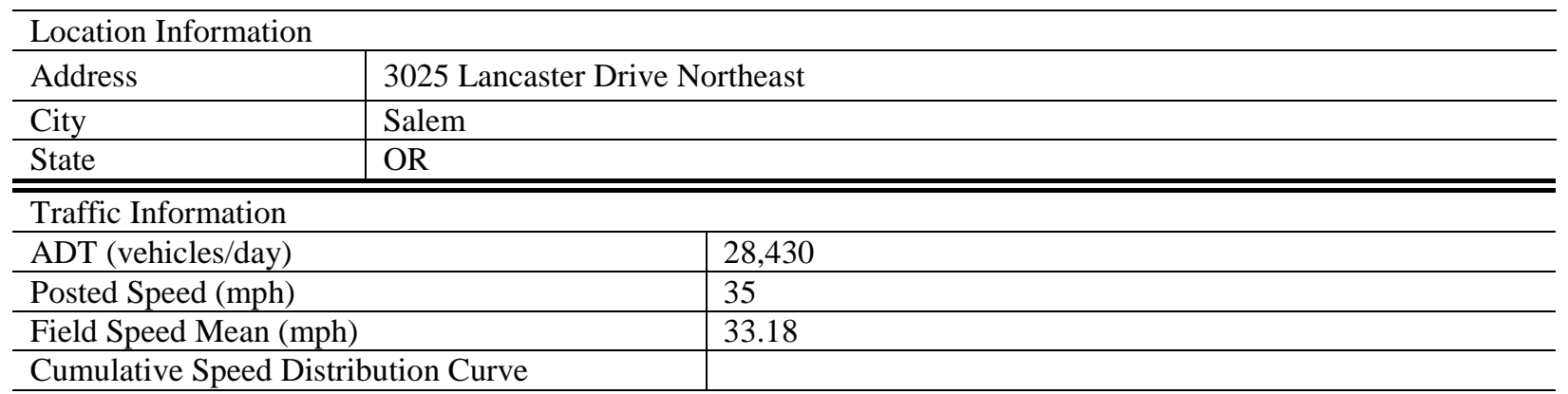

Cumulative Speed Lancaster SB @ Walmart

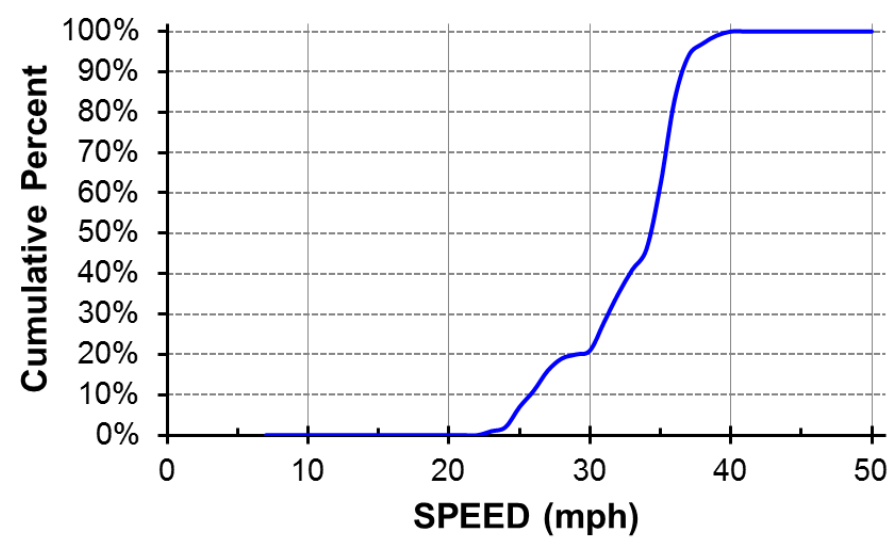

\begin{tabular}{l|l}
\hline \hline \multicolumn{2}{l}{ Geometric Design Information - Roadway in Vicinity of Driveway } \\
\hline Width of Roadway (ft) & 67 \\
\hline Number of Lanes & 4 lanes + TWLTL \\
\hline Lane Width (ft) & 11 \\
\hline Present of Bicycle Lane & Yes \\
\hline Present of Sidewalk & Yes \\
\hline \hline Geometric Design Information - Driveway & 40 \\
\hline Width of Driveway (ft) & 3 \\
\hline Number of Lanes & $12,12,16$ \\
\hline Lane Width (ft) & None \\
\hline Median in Driveway & 593.69 \\
\hline Distance to Nearest Upstream Signal & \\
\hline \hline Data Collection Information & Sep 21 st, 2011 \\
\hline Date & 3 hours \\
\hline Duration of Traffic Videos & Sunny \\
\hline Weather & Dry \\
\hline Pavement Surface Condition &
\end{tabular}

Figure B.5: Driveway Site 2 - Road and Traffic Data 


\section{Aerial Photos:}

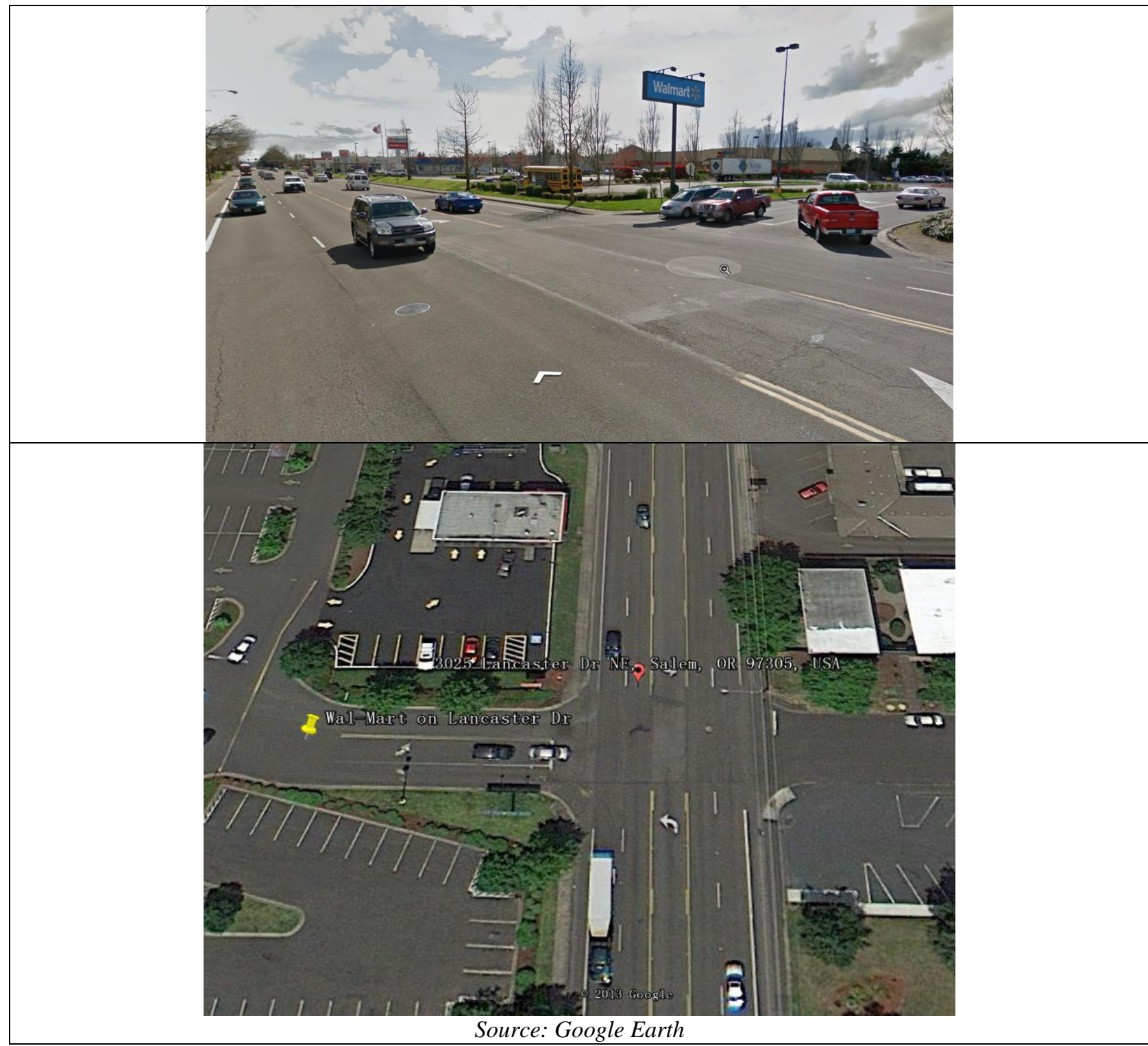

Figure B.6: Driveway Site 2 - Aerial Photos

\section{Gap-acceptance Results:}

Table B.2: Driveway Site 2 - Gap-acceptance Study Results

\begin{tabular}{l|c|c}
\hline \multirow{2}{*}{ Analysis Methods } & \multicolumn{2}{|c}{ Critical Gap (sec) } \\
\cline { 2 - 3 } & Left Turn & Right Turn \\
\hline Greenshield Method & 5.75 & 5.75 \\
\hline Raff Method & 4.25 & 5.75 \\
\hline Cumulative Acceptance Method & 4.70 & 6.25 \\
\hline Logit Method & 5.72 & 6.14 \\
\hline
\end{tabular}




\section{Gap-acceptance Analysis for Left Turns:}

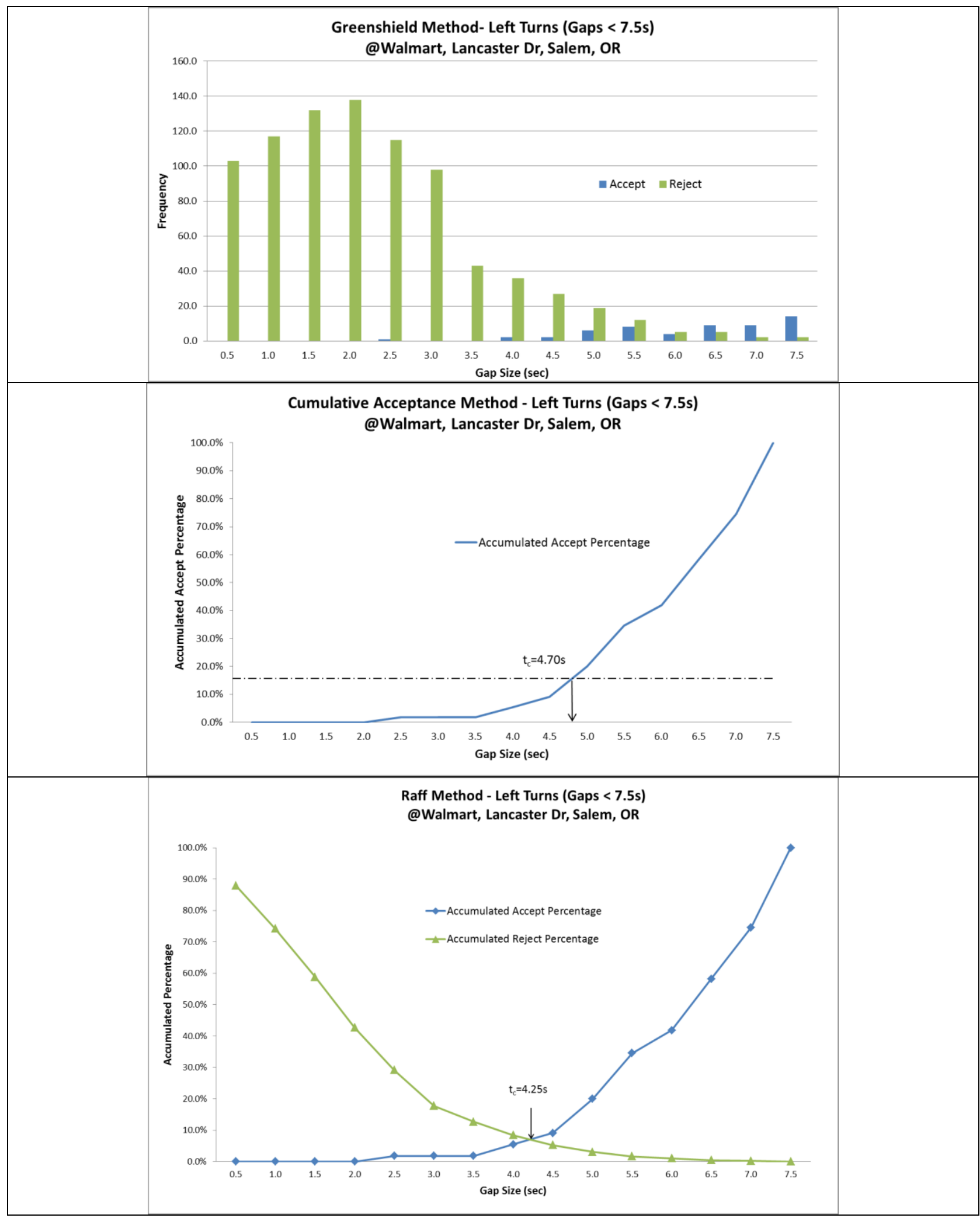

Figure B.7: Driveway Site 2 - Gap-acceptance Analysis for Left Turns 


\section{Gap-acceptance Analysis for Right Turns:}

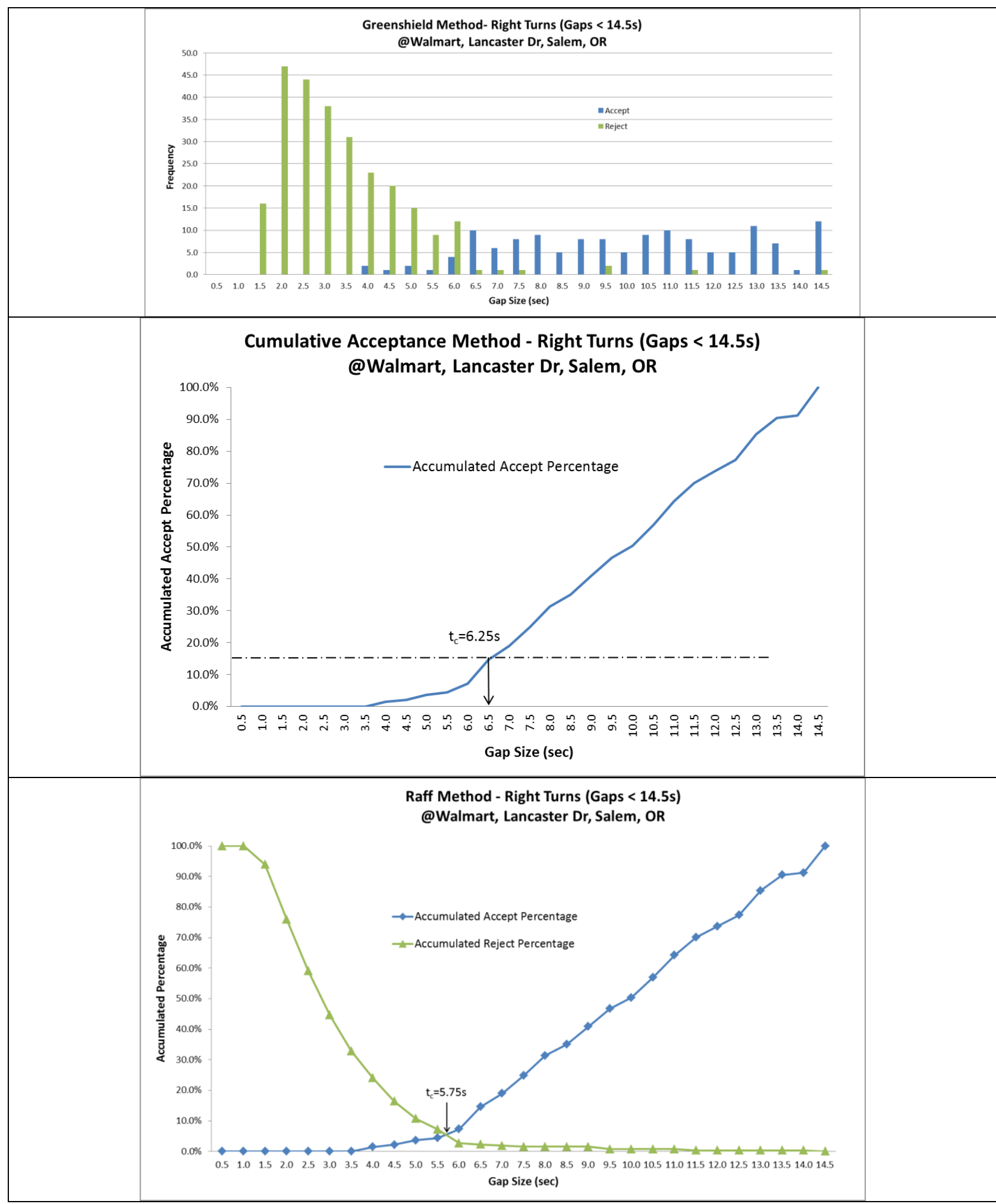

Figure B.8: Driveway Site 2 - Gap-acceptance Analysis for Right Turns 
Driveway Site 3: Large-size Commercial \#2:

\section{Fred Meyer, Commercial St SE, Salem, OR}

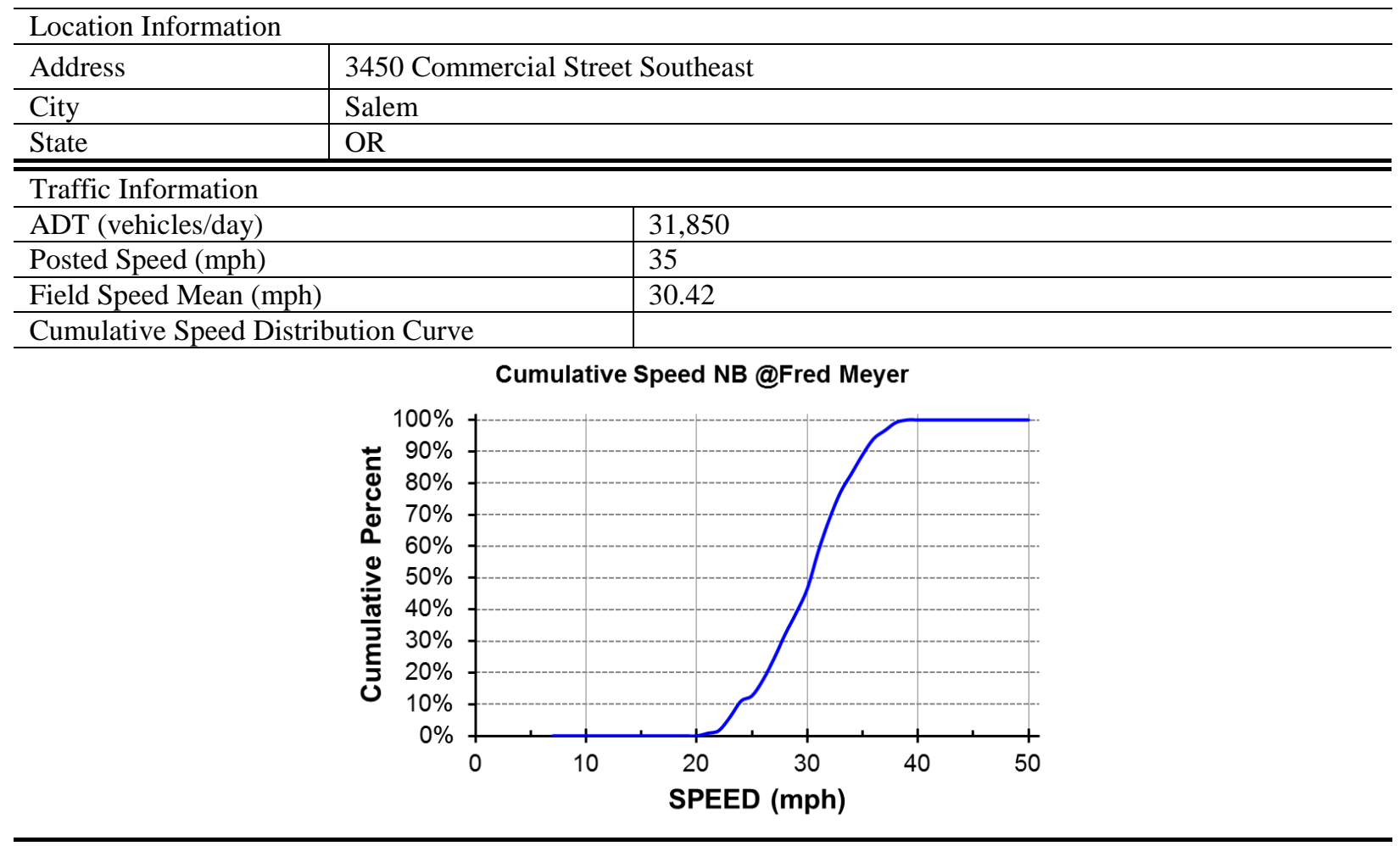

\begin{tabular}{l|l}
\hline \hline \multicolumn{2}{l}{ Geometric Design Information - Roadway in Vicinity of Driveway } \\
\hline Width of Roadway (ft) & 80 \\
\hline Number of Lanes & 4 lanes + TWLTL \\
\hline Lane Width (ft) & 12 \\
\hline Present of Bicycle Lane & Yes \\
\hline Present of Sidewalk & Yes \\
\hline \hline Geometric Design Information - Driveway & 40 \\
\hline Width of Driveway (ft) & 3 \\
\hline Number of Lanes & $12,12,16$ \\
\hline Lane Width (ft) & None \\
\hline Median in Driveway & 518 \\
\hline Distance to Nearest Upstream Signal & \\
\hline \hline Data Collection Information & Nov $1^{\text {st }, 2011}$ \\
\hline Date & 3 hours \\
\hline Duration of Traffic Videos & Sunny \\
\hline Weather & Dry \\
\hline Pavement Surface Condition &
\end{tabular}

Figure B.9: Driveway Site 3 - Road and Traffic Data 


\section{Aerial Photo:}

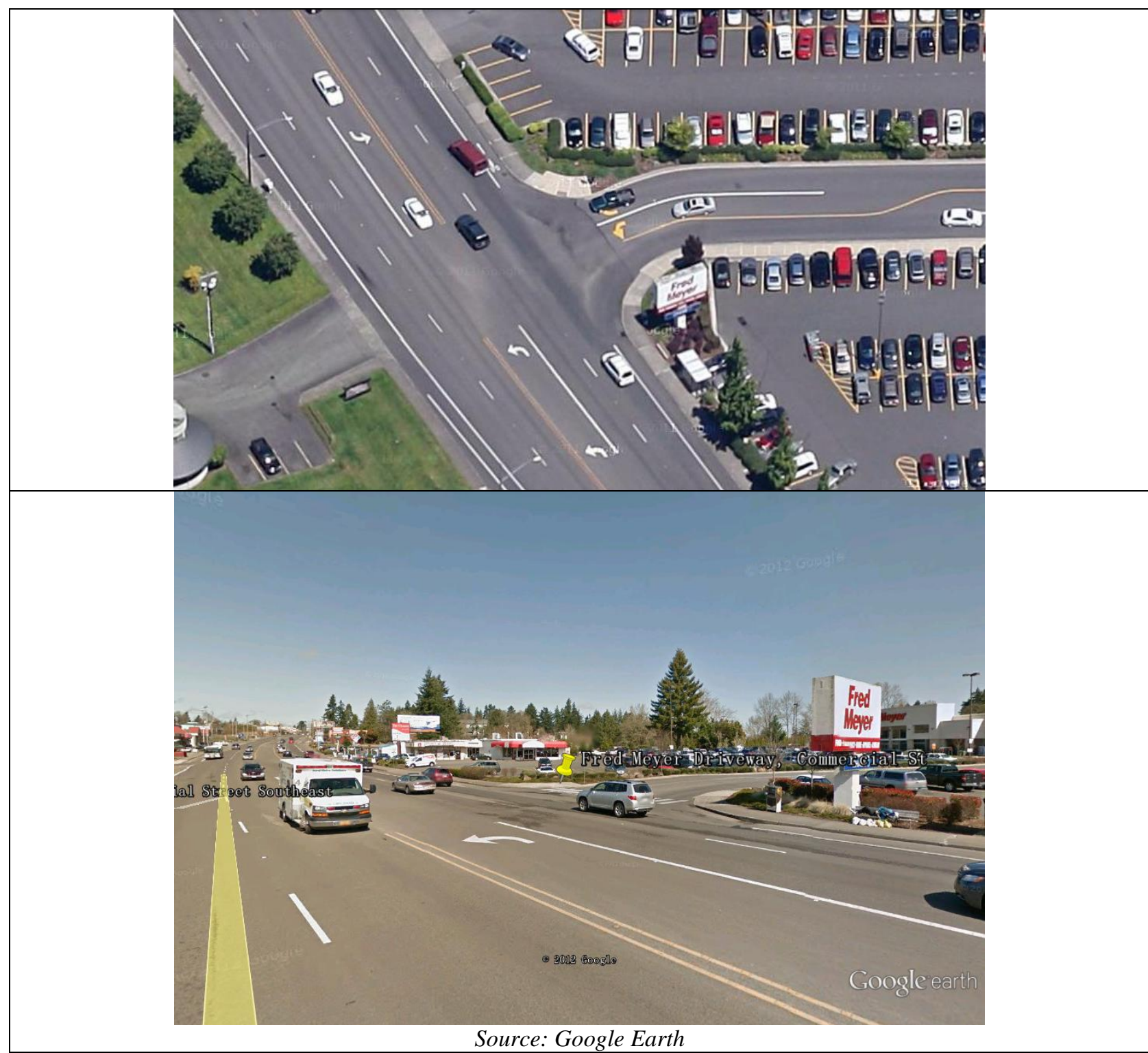

Figure B.10: Driveway Site 3 - Aerial Photos

\section{Gap-acceptance Results:}

Table B.3: Driveway Site 3 - Gap-acceptance Study Results

\begin{tabular}{l|c|c}
\hline \multirow{2}{*}{ Analysis Methods } & \multicolumn{2}{|c}{ Critical Gap (sec) } \\
\cline { 2 - 3 } & Left Turn & Right Turn \\
\hline Greenshield Method & 4.75 & 6.75 \\
\hline Raff Method & 3.75 & 5.00 \\
\hline Cumulative Acceptance Method & 4.83 & 5.37 \\
\hline Logit Method & 4.97 & 6.24 \\
\hline
\end{tabular}




\section{Gap-acceptance Analysis for Left Turns:}

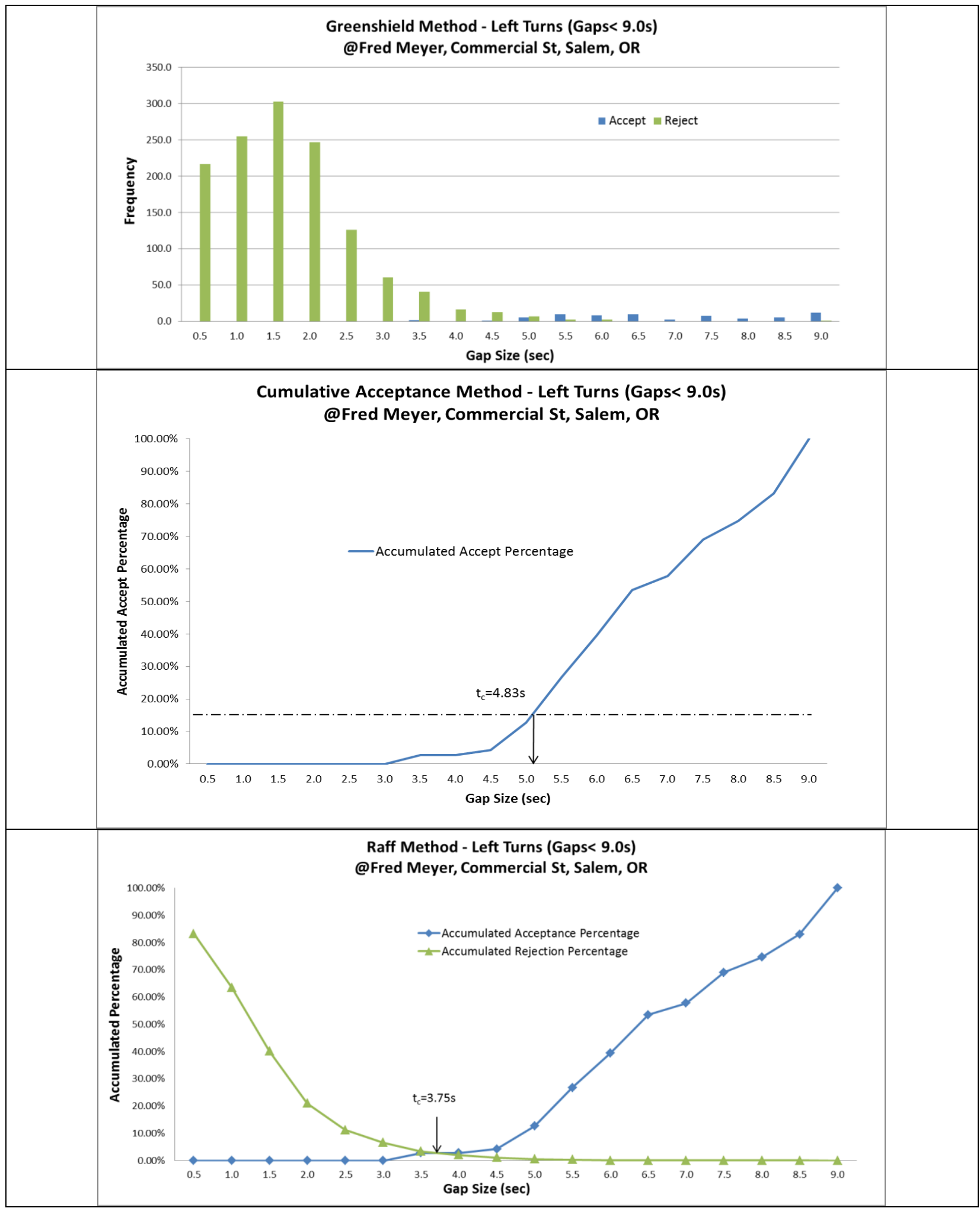

Figure B.11: Driveway Site 3 - Gap-acceptance Analysis for Left Turns 


\section{Gap-acceptance Analysis for Right Turns:}

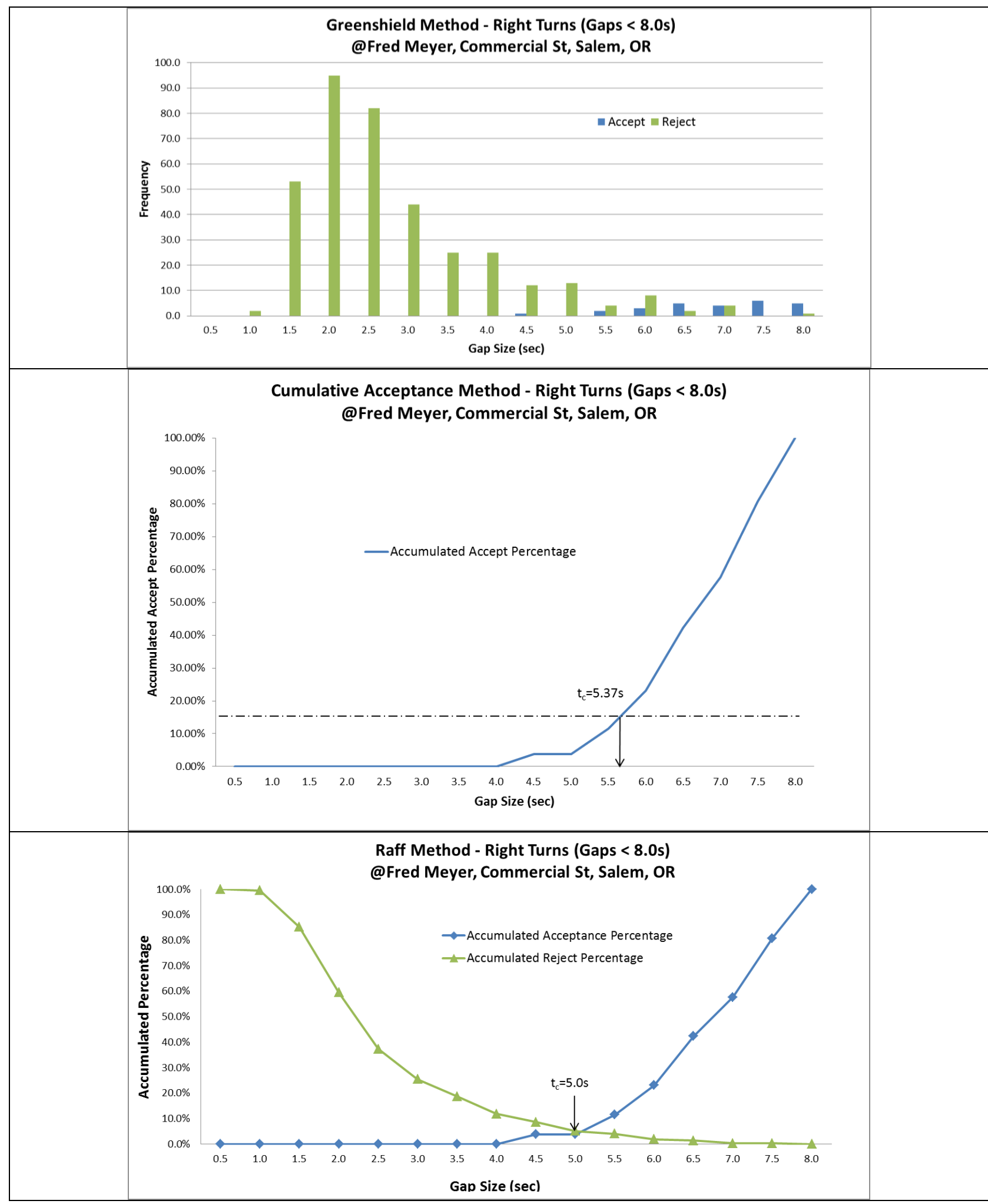

Figure B.12: Driveway Site 3 - Gap-acceptance Analysis for Right Turns 


\section{Driveway Site 4: Large-size Commercial \#3}

\section{Walmart, Commercial St SE, Salem, OR}

\begin{tabular}{l|l}
\hline Location Information & \multicolumn{2}{l}{} \\
\hline Address & 5250 Commercial St SE, Salem, OR \\
\hline City & Salem \\
\hline State & OR \\
\hline \hline Traffic Information & 30470 \\
\hline ADT (vehicles/day) & 35 \\
\hline Posted Speed (mph) & 36.1 \\
\hline Field Speed Mean (mph) & \\
\hline Cumulative Speed Distribution Curve &
\end{tabular}

Cumulative Speed Distribution Curve

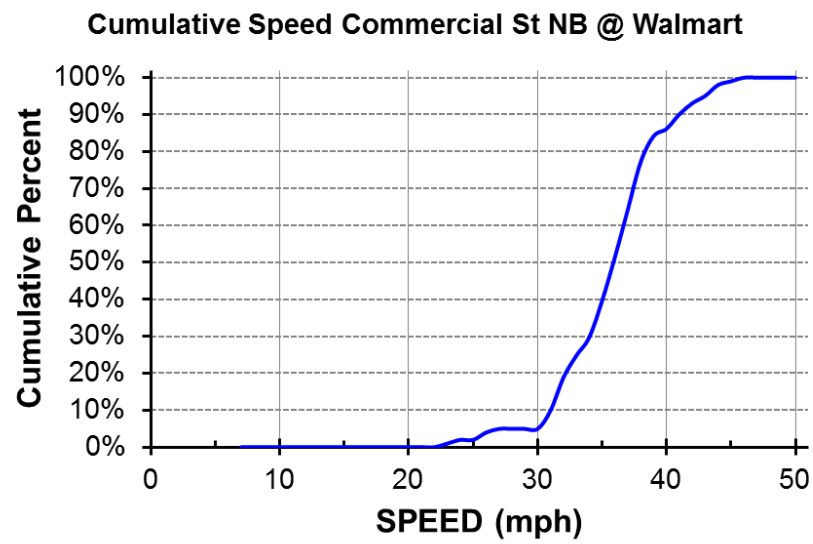

\begin{tabular}{l|l}
\hline \hline \multicolumn{2}{l}{ Geometric Design Information - Roadway in Vicinity of Driveway } \\
\hline Width of Roadway (ft) & 80 \\
\hline Number of Lanes & 4 lanes + TWLTL \\
\hline Lane Width (ft) & 12 \\
\hline Present of Bicycle Lane & Yes \\
\hline Present of Sidewalk & Yes \\
\hline \hline Geometric Design Information - Driveway & 40 \\
\hline Width of Driveway (ft) & 3 \\
\hline Number of Lanes & $12,12,16$ \\
\hline Lane Width (ft) & None \\
\hline Median in Driveway & $718 \mathrm{ft}$ \\
\hline Distance to Nearest Upstream Signal & \\
\hline \hline Data Collection Information & Nov $8^{\text {st } \text { and } 10^{\text {th }}, 2011}$ \\
\hline Date & 3 hours \\
\hline Duration of Traffic Videos & Cloudy \\
\hline Weather & Dry \\
\hline Pavement Surface Condition & Dad
\end{tabular}

Figure B.13: Driveway Site 4 - Road and Traffic Data 


\section{Aerial Photo:}

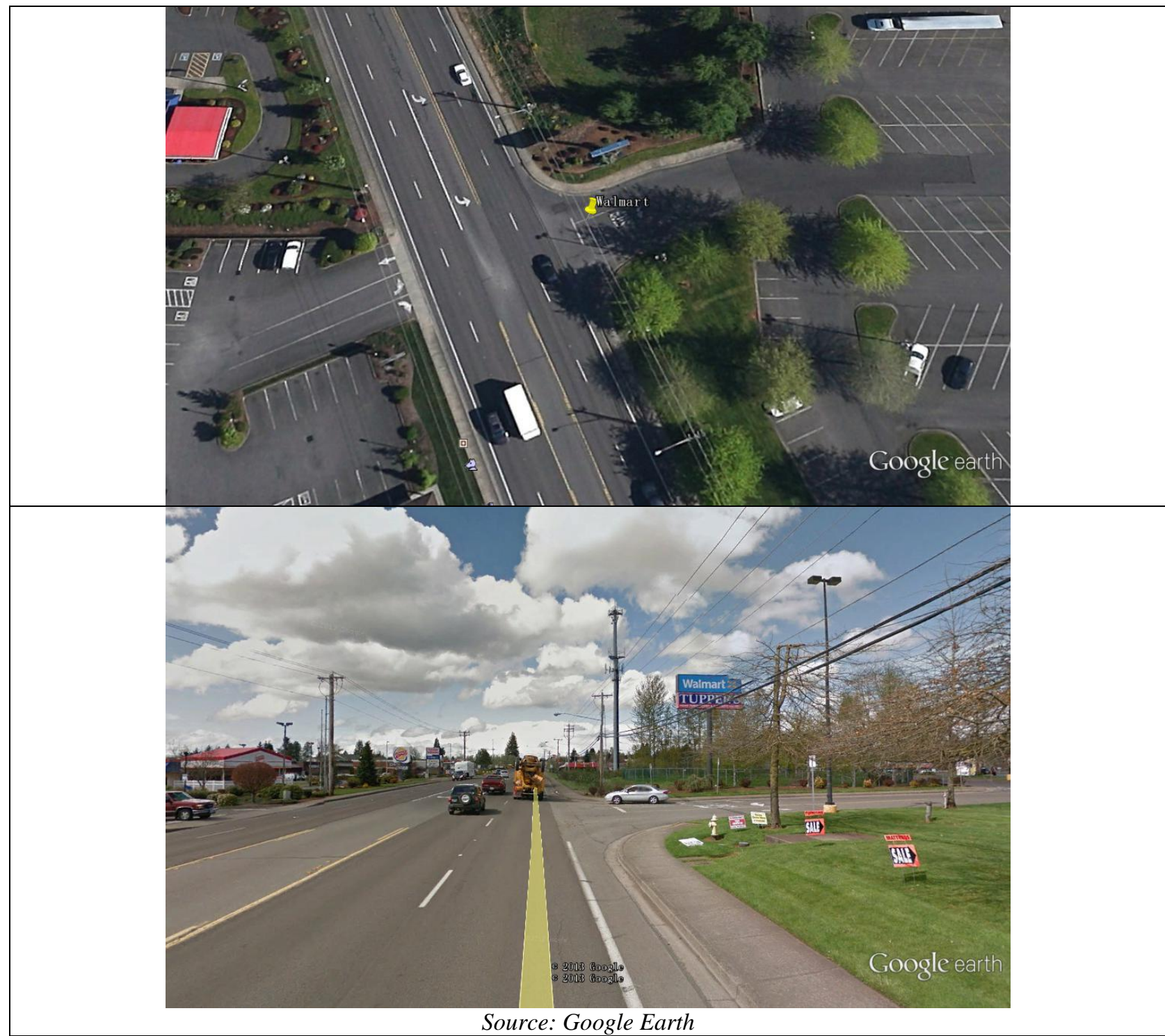

Figure B.14: Driveway Site 4 - Aerial Photos

\section{Gap-acceptance Results:}

Table B.4: Driveway Site 4 - Gap-acceptance Study Results

\begin{tabular}{l|c|c}
\hline \multirow{2}{*}{ Analysis Methods } & \multicolumn{2}{|c}{ Critical Gap (sec) } \\
\cline { 2 - 3 } & Left Turn & Right Turn \\
\hline Greenshield Method & 5.50 & 6.75 \\
\hline Raff Method & 5.00 & 5.25 \\
\hline Cumulative Acceptance Method & 5.75 & 5.00 \\
\hline Logit Method & 5.67 & 6.00 \\
\hline
\end{tabular}




\section{Gap-acceptance Analysis for Left Turns:}

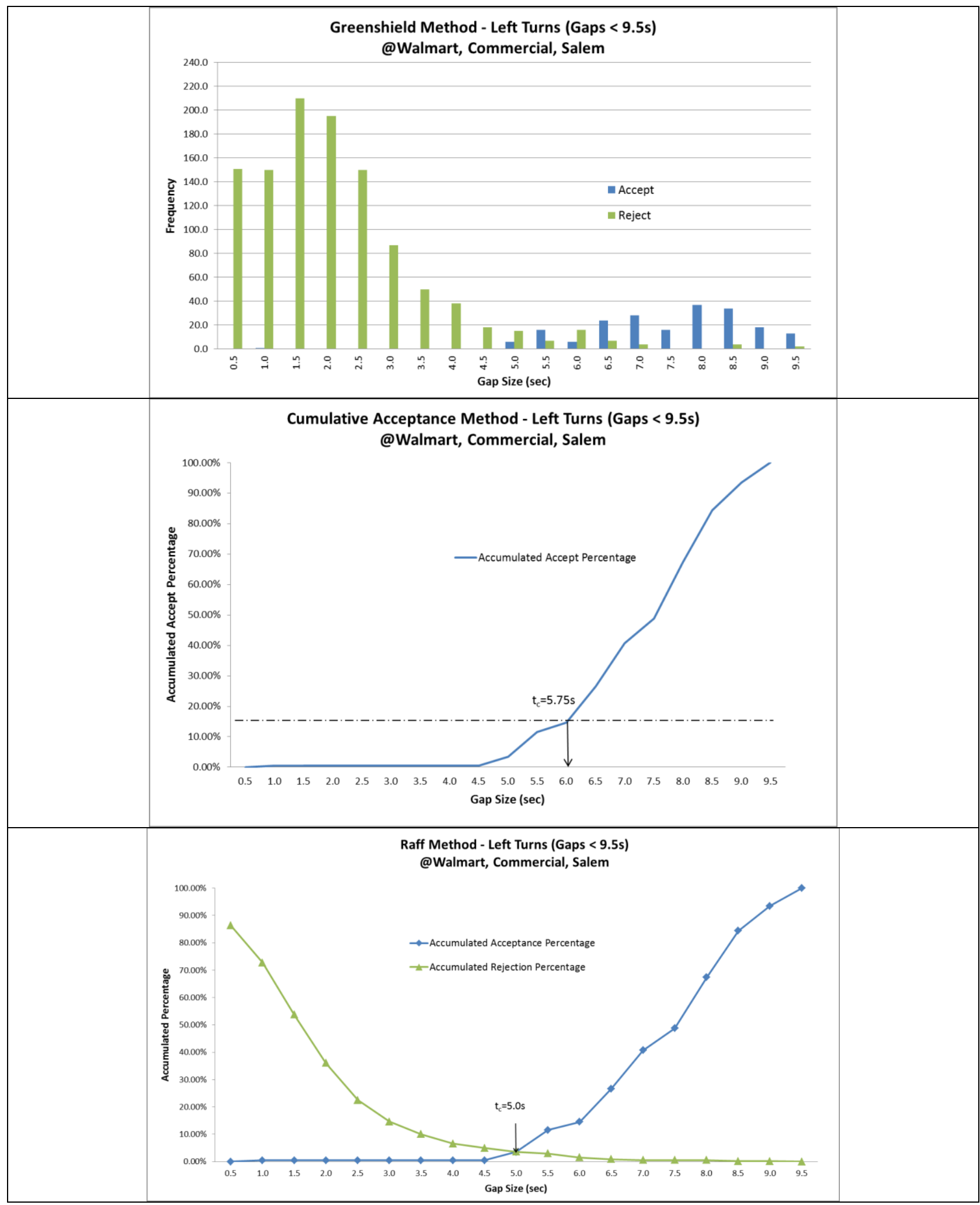

Figure B.15: Driveway Site 4 - Gap-acceptance Analysis for Left Turns 


\section{Gap-acceptance Analysis for Right Turns:}

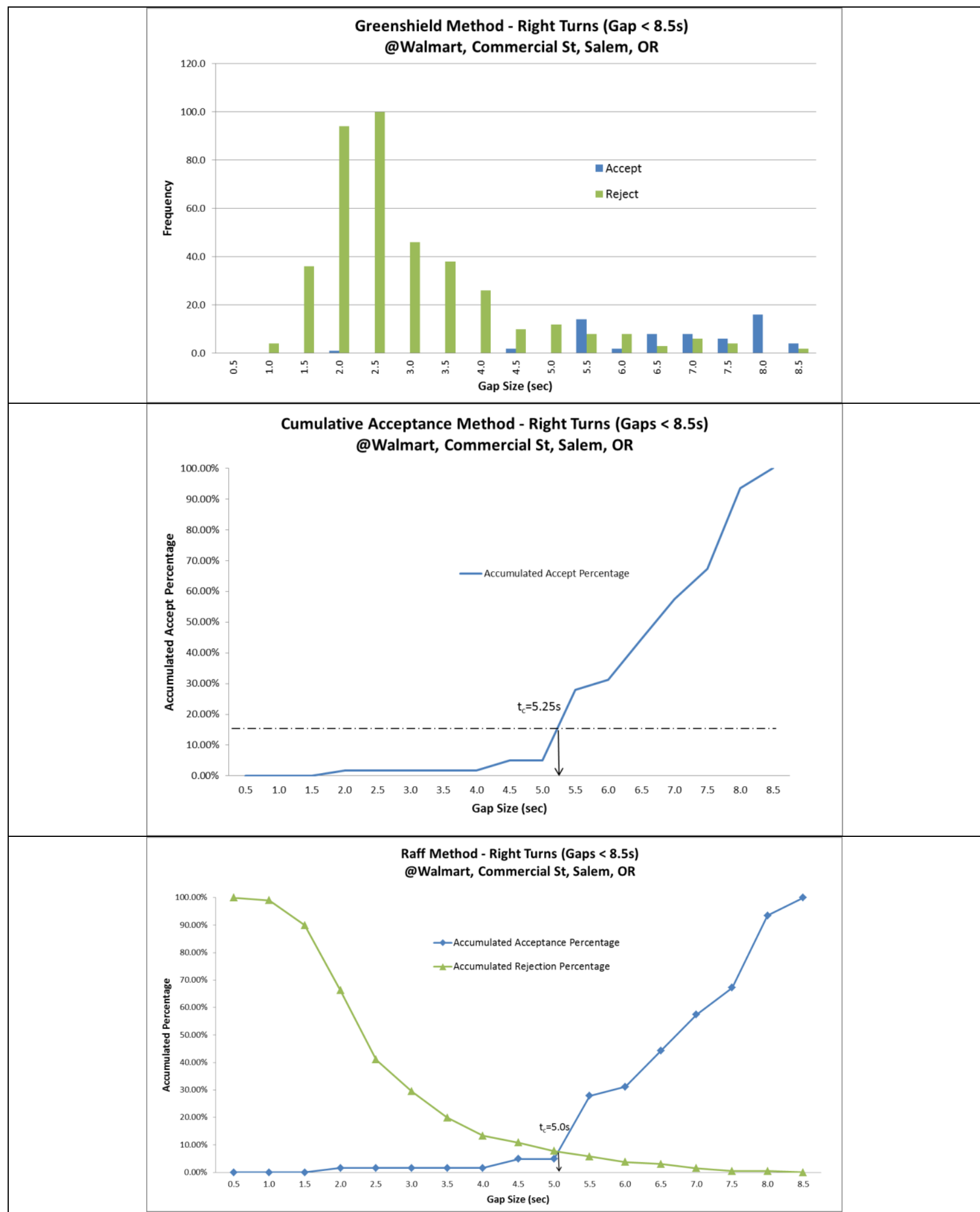

Figure B.16: Driveway Site 4 - Gap-acceptance Analysis for Right Turns 


\section{Driveway Site 5: Medium-size Commercial}

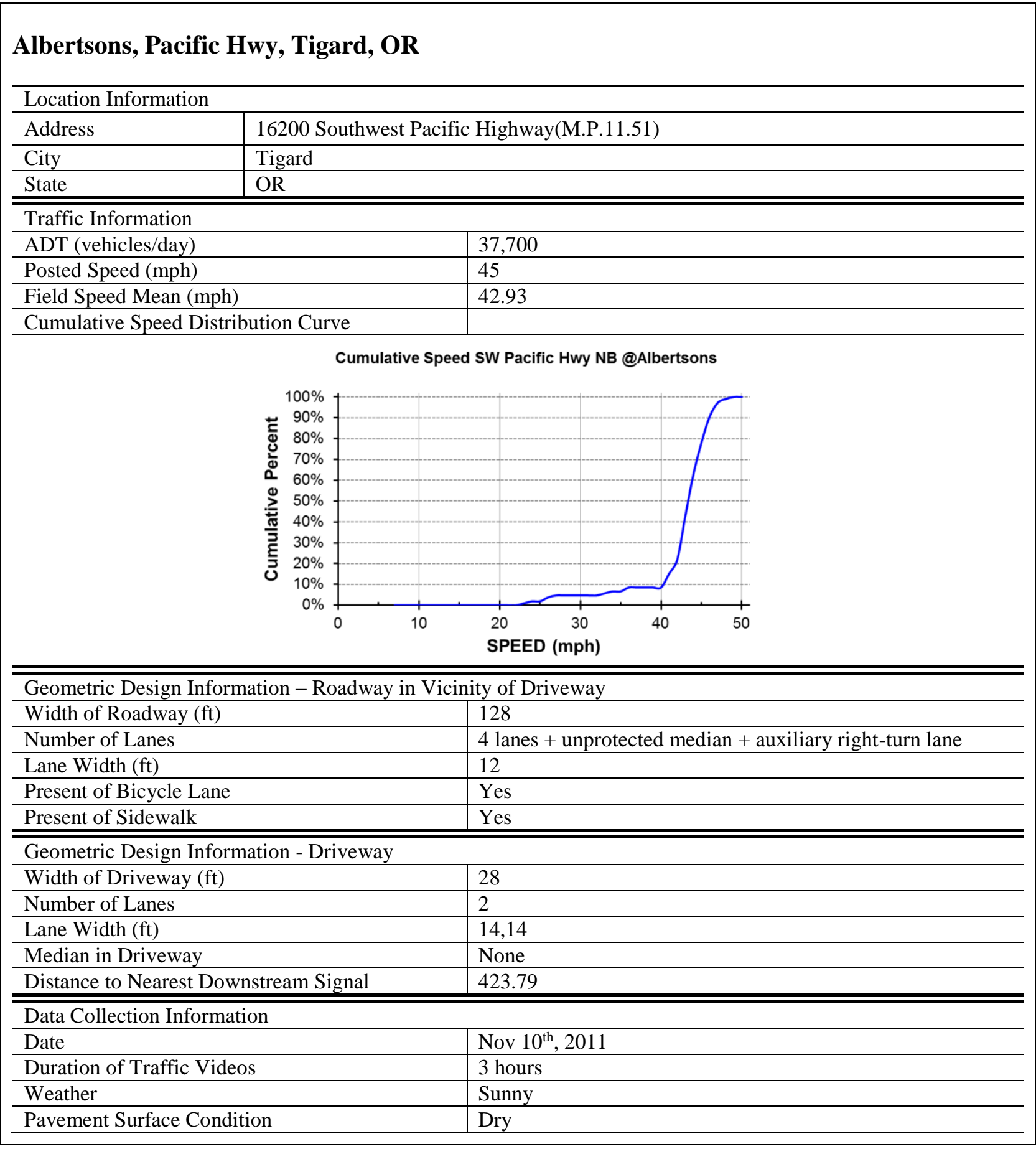

Figure B.17: Driveway Site 5 - Road and Traffic Data 


\section{Aerial Photos:}

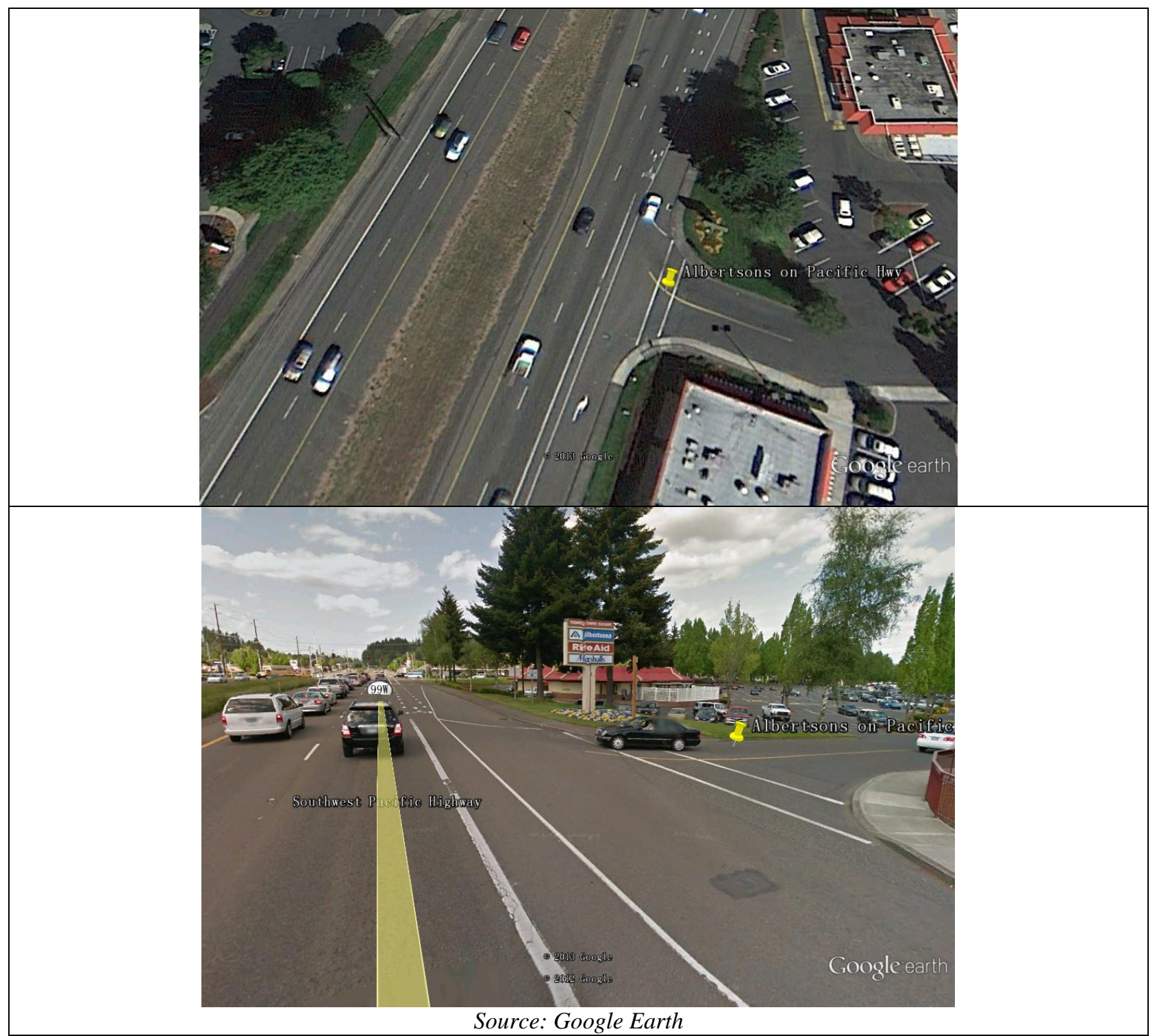

Figure B.18: Driveway Site 5 - Aerial Photos

\section{Gap-acceptance Results:}

Table B.5: Driveway Site 5 - Gap-acceptance Study Results

\begin{tabular}{l|c|c}
\hline \multirow{2}{*}{ Analysis Methods } & \multicolumn{2}{|c}{ Critical Gap (sec) } \\
\cline { 2 - 3 } & Left Turn & Right Turn \\
\hline Greenshield Method & NA & 6.75 \\
\hline Raff Method & NA & 4.50 \\
\hline Cumulative Acceptance Method & NA & 4.70 \\
\hline Logit Method & NA & 5.74 \\
\hline
\end{tabular}




\section{Gap-acceptance Analysis for Right Turns:}

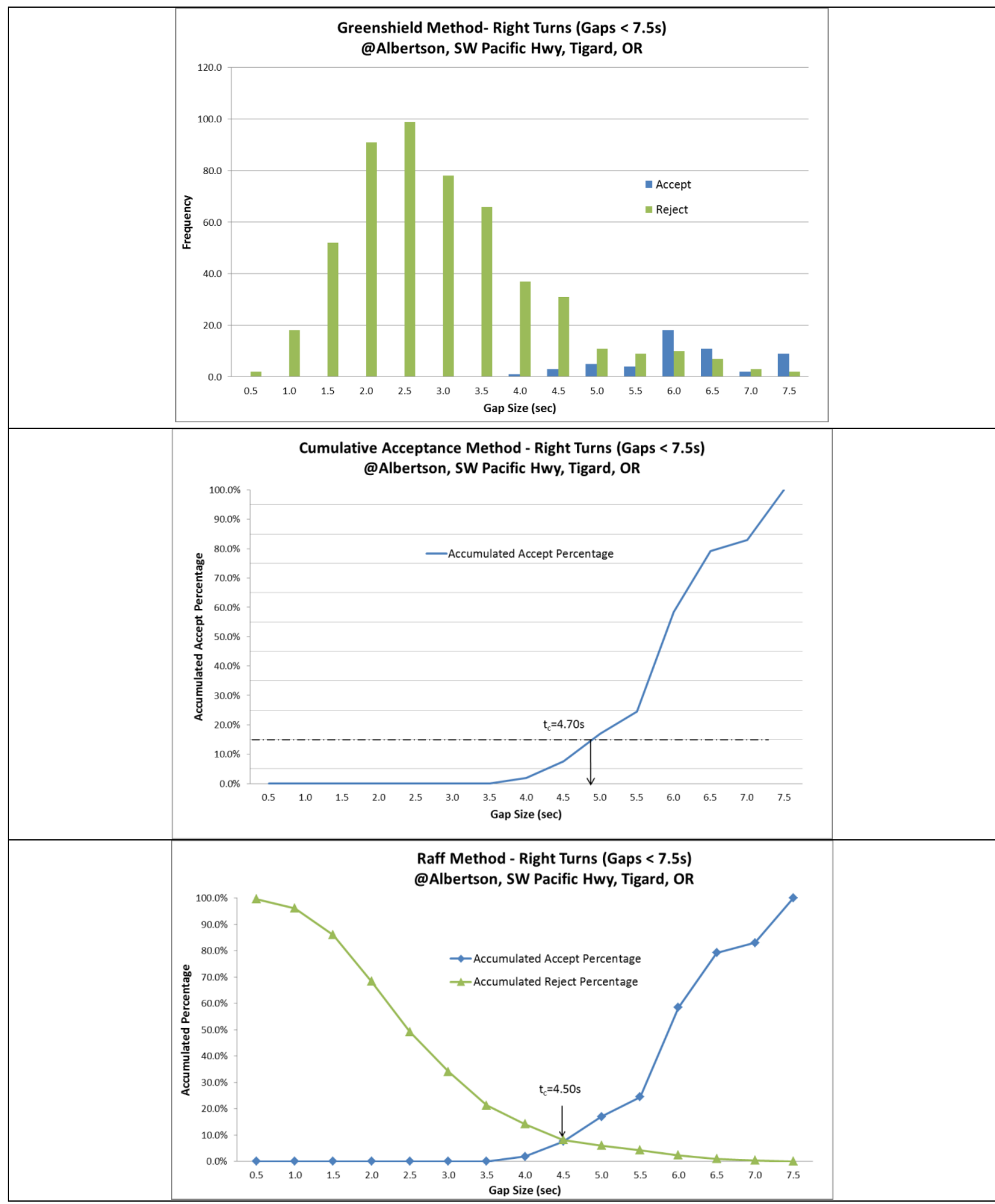

Figure B.19: Driveway Site 5 - Gap-acceptance Analysis for Right Turns 


\section{Driveway Site 6a: Restaurant \#1 - Day 1}

\section{McAllister's, Walton Blvd, Bentonville, AR}

\begin{tabular}{l|l}
\hline Location Information & \multicolumn{2}{l}{} \\
\hline Address & 900 SE Walton Blvd \\
\hline City & Bentonville \\
\hline State & AR \\
\hline \hline Traffic Information & \\
\hline ADT (vehicles/day) & 34000 \\
\hline Posted Speed (mph) & 50 \\
\hline Field Speed Mean (mph) & 36.45 \\
\hline Cumulative Speed Distribution Curve & \\
\hline
\end{tabular}

Cumulative Speed Distribution Curve

Cumulative Speed Walton EB @ McAlister's

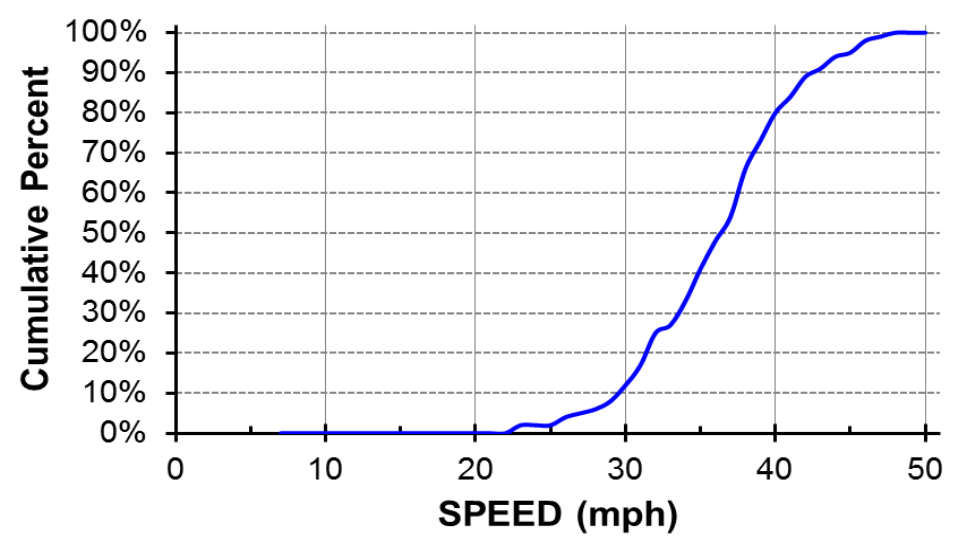

\begin{tabular}{l|l}
\hline \hline \multicolumn{2}{l}{ Geometric Design Information - Roadway in Vicinity of Driveway } \\
\hline Width of Roadway (ft) & 58 \\
\hline Number of Lanes & 4 lanes + TWLTL \\
\hline Lane Width (ft) & 12 \\
\hline Present of Bicycle Lane & No \\
\hline Present of Sidewalk & Yes \\
\hline \hline Geometric Design Information - Driveway & 22 \\
\hline Width of Driveway (ft) & 2 \\
\hline Number of Lanes & 11 \\
\hline Lane Width (ft) & No \\
\hline Median in Driveway & 699 \\
\hline Distance to Nearest Upstream Signal (ft) & \\
\hline \hline Data Collection Information & June $28^{\text {th }}, 2011$ \\
\hline Date & 0.5 hour \\
\hline Duration of Traffic Videos & Sunny \\
\hline Weather & Dry \\
\hline Pavement Surface Condition & Data \\
\hline
\end{tabular}

Figure B.20: Driveway Site 6a - Road and Traffic Data 


\section{Aerial Photos:}

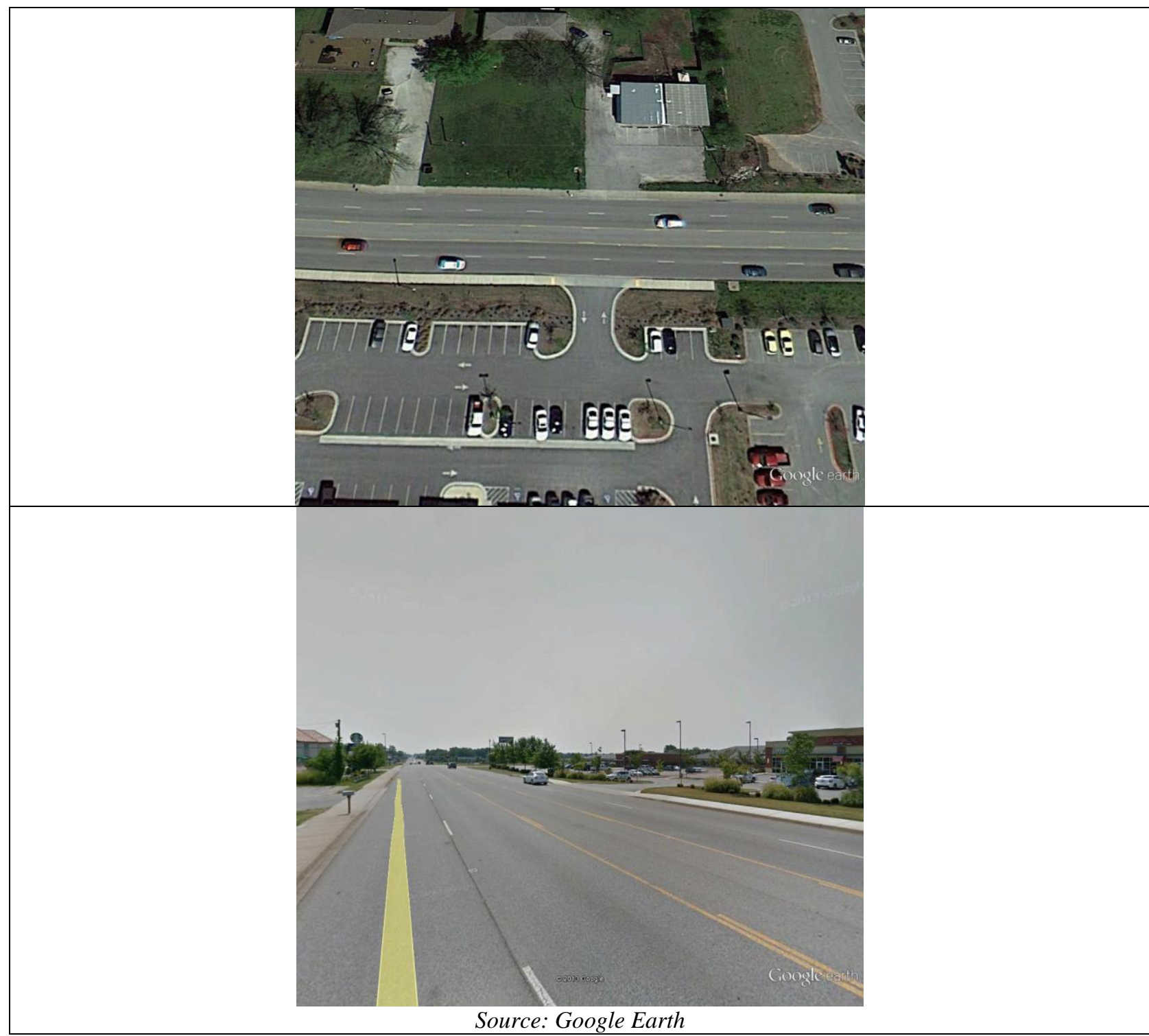

Figure B.21: Driveway Site 6a - Aerial Photos

\section{Gap-acceptance Results:}

Table B.6: Driveway Site 6a - Gap-acceptance Study Results

\begin{tabular}{l|c|c}
\hline \multirow{2}{*}{ Analysis Methods } & \multicolumn{2}{|c}{ Critical Gap (sec) } \\
\cline { 2 - 3 } & Left Turn & Right Turn \\
\hline Greenshield Method & 6.75 & 5.25 \\
\hline Raff Method & 5.40 & 5.00 \\
\hline Cumulative Acceptance Method & 5.60 & NA \\
\hline Logit Method & 5.77 & 7.00 \\
\hline
\end{tabular}




\section{Gap-acceptance Analysis for Left Turns:}

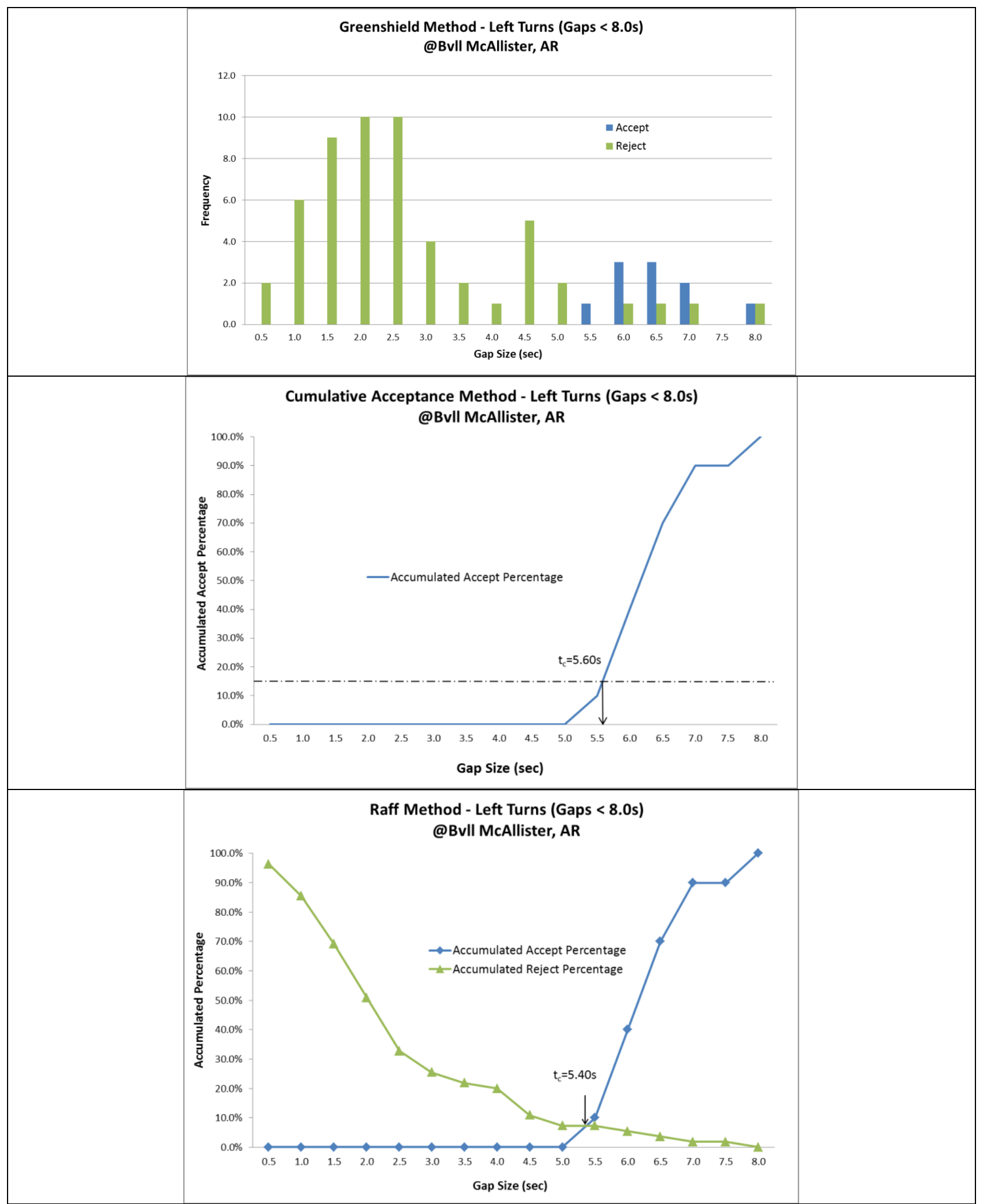

Figure B.22: Driveway Site 6a - Gap-acceptance Analysis for Left Turns 
Gap-acceptance Analysis for Right Turns:

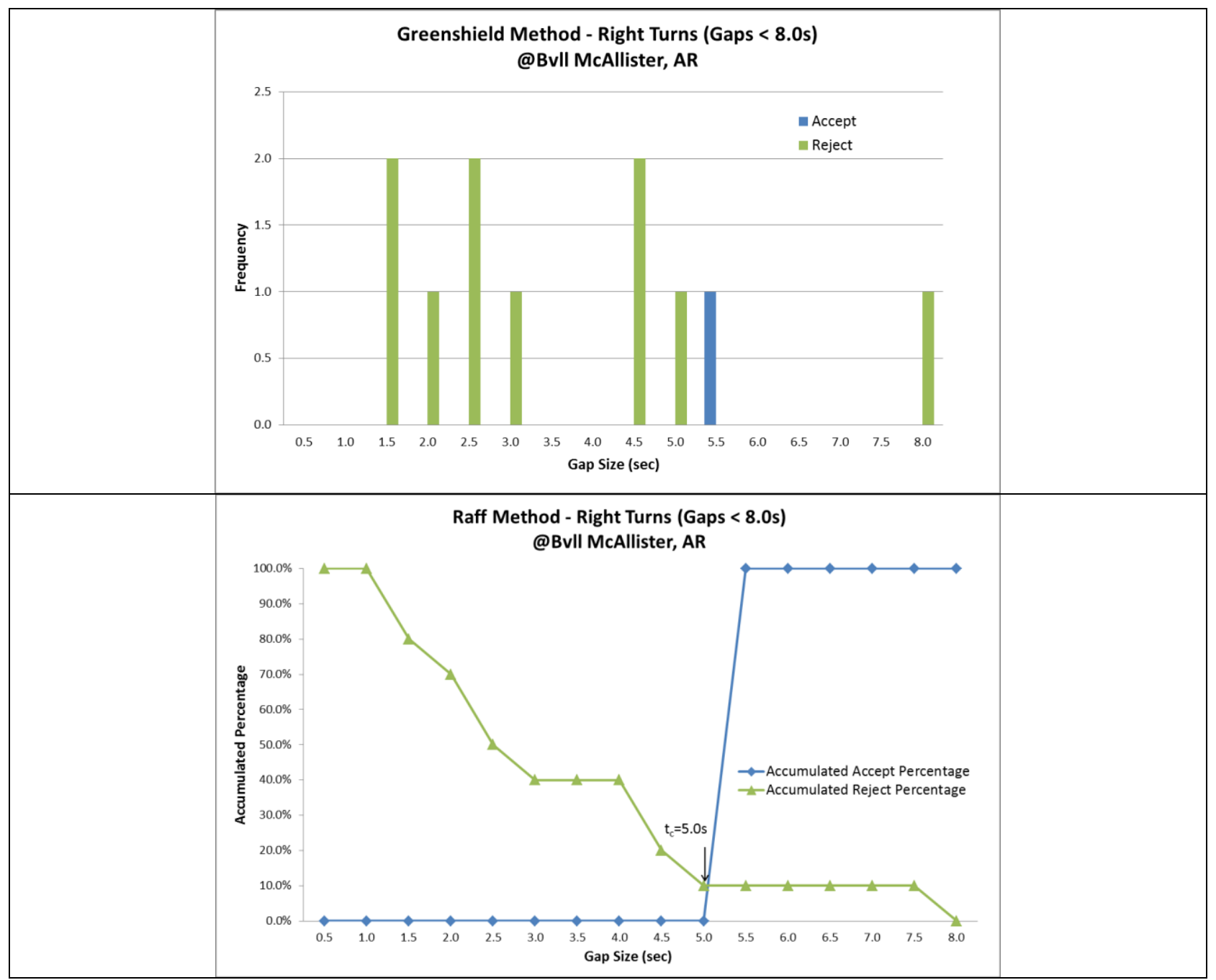

Figure B.23: Driveway Site 6a - Gap-acceptance Analysis for Right Turns 
Driveway Site 6b: Restaurant \#1 - Day 2

McAllister's, Walton Blvd, Bentonville, AR
\begin{tabular}{l|l}
\hline Location Information \\
\hline Address & 900 SE Walton Blvd \\
\hline City & Bentonville \\
\hline State & AR \\
\hline \hline Traffic Information & 34000 \\
\hline ADT (vehicles/day) & 50 \\
\hline Posted Speed (mph) & 36.45 \\
\hline Field Speed Mean (mph) & \\
\hline Cumulative Speed Distribution Curve &
\end{tabular}

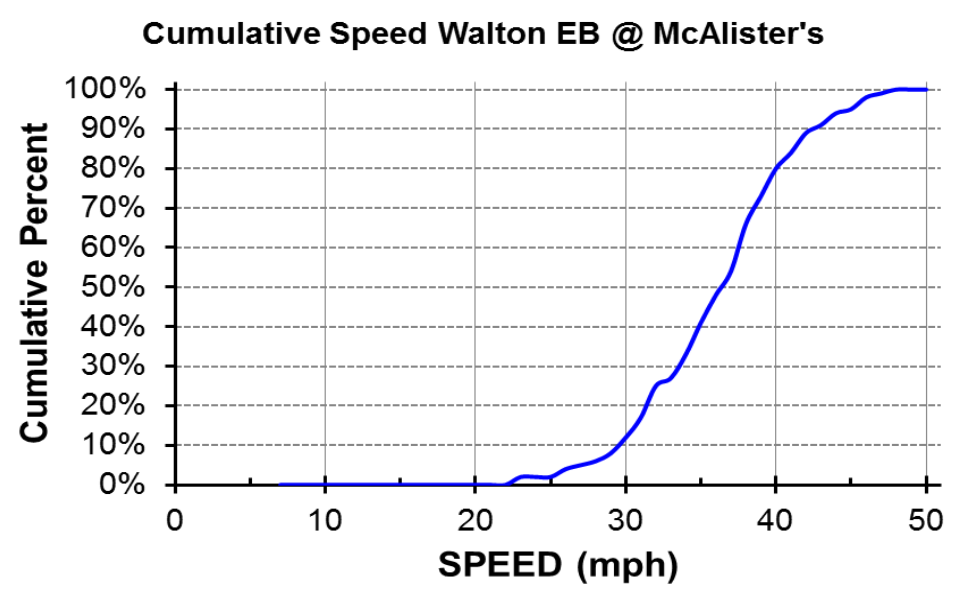

\begin{tabular}{l|l}
\hline \hline \multicolumn{2}{l}{ Geometric Design Information - Roadway in Vicinity of Driveway } \\
\hline Width of Roadway (ft) & 58 \\
\hline Number of Lanes & 4 lanes + TWLTL \\
\hline Lane Width (ft) & 12 \\
\hline Present of Bicycle Lane & No \\
\hline Present of Sidewalk & Yes \\
\hline \hline Geometric Design Information - Driveway & \multicolumn{2}{l}{} \\
\hline Width of Driveway (ft) & 22 \\
\hline Number of Lanes & 2 \\
\hline Lane Width (ft) & 11 \\
\hline Median in Driveway & No \\
\hline Distance to Nearest Upstream Signal (ft) & 699 \\
\hline \hline Data Collection Information & \\
\hline Date & June $29^{\text {th }}, 2011$ \\
\hline Duration of Traffic Videos & 1.5 hours \\
\hline Weather & Sunny \\
\hline Pavement Surface Condition & Dry \\
\hline
\end{tabular}

Figure B.24: Driveway Site 6b - Road and Traffic Data 


\section{Aerial Photos:}

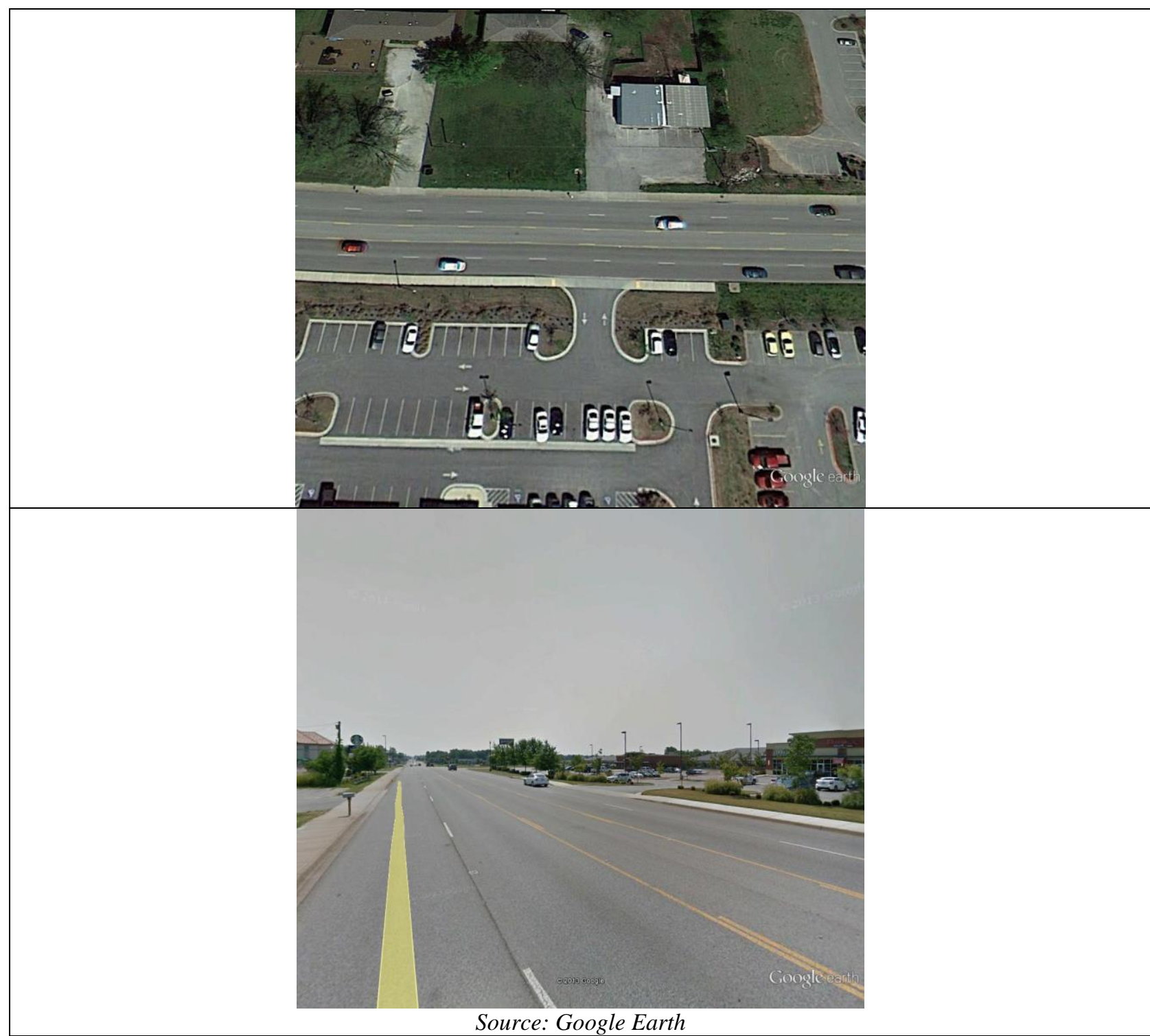

Figure B.25: Driveway Site 6b - Aerial Photos

\section{Gap-acceptance Results:}

Table B.7: Driveway Site 6b - Gap-acceptance Study Results

\begin{tabular}{l|c|c}
\hline \multirow{2}{*}{ Analysis Methods } & \multicolumn{2}{|c}{ Critical Gap (sec) } \\
\cline { 2 - 3 } & Left Turn & Right Turn \\
\hline Greenshield Method & 5.75 & 7.75 \\
\hline Raff Method & 4.00 & 4.25 \\
\hline Cumulative Acceptance Method & 3.75 & 2.00 \\
\hline Logit Method & 6.45 & 7.80 \\
\hline
\end{tabular}




\section{Gap-acceptance Analysis for Left Turns:}

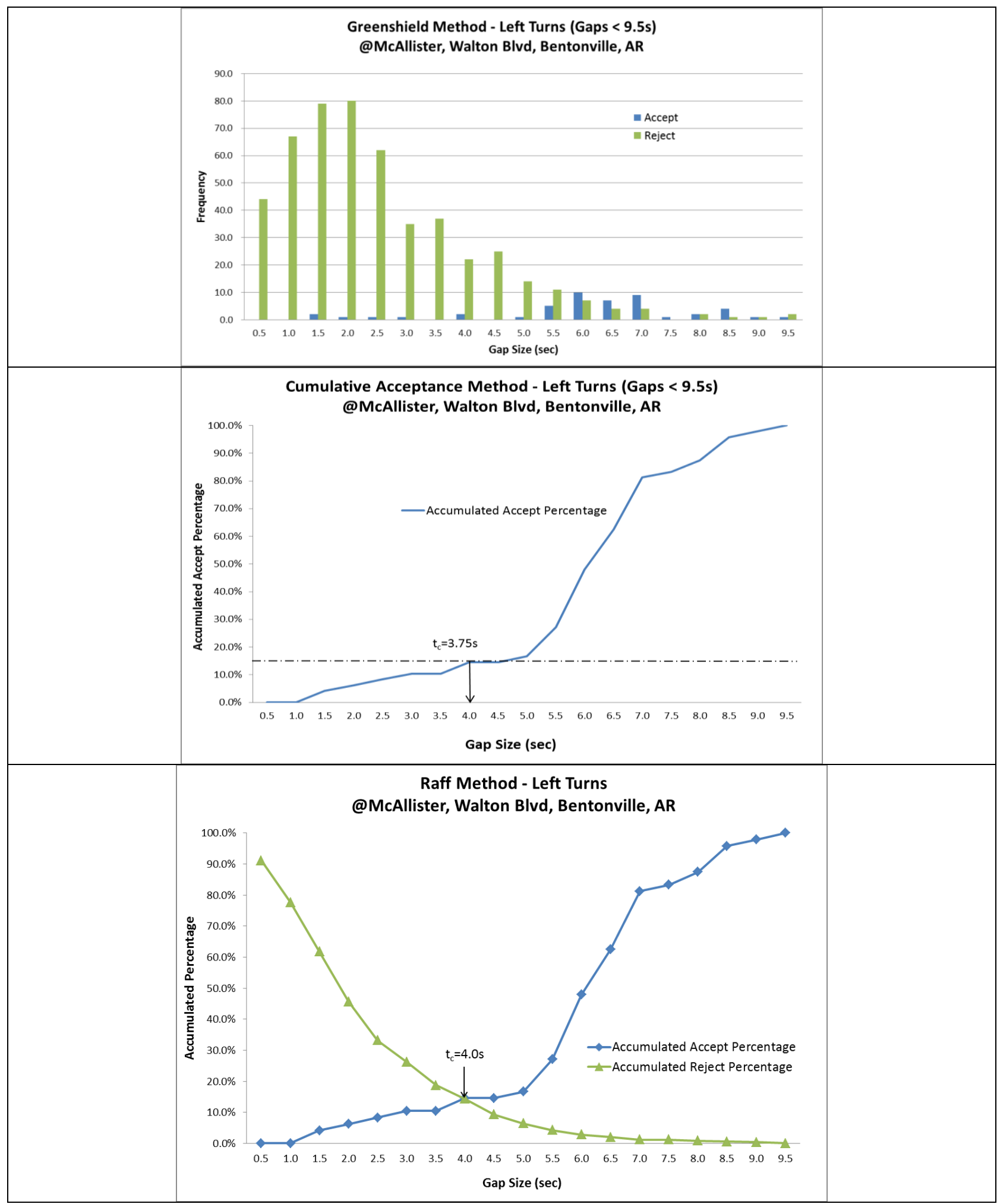

Figure B.26: Driveway Site 6b - Gap-acceptance Analysis for Left Turns 


\section{Gap-acceptance Analysis for Right Turns:}

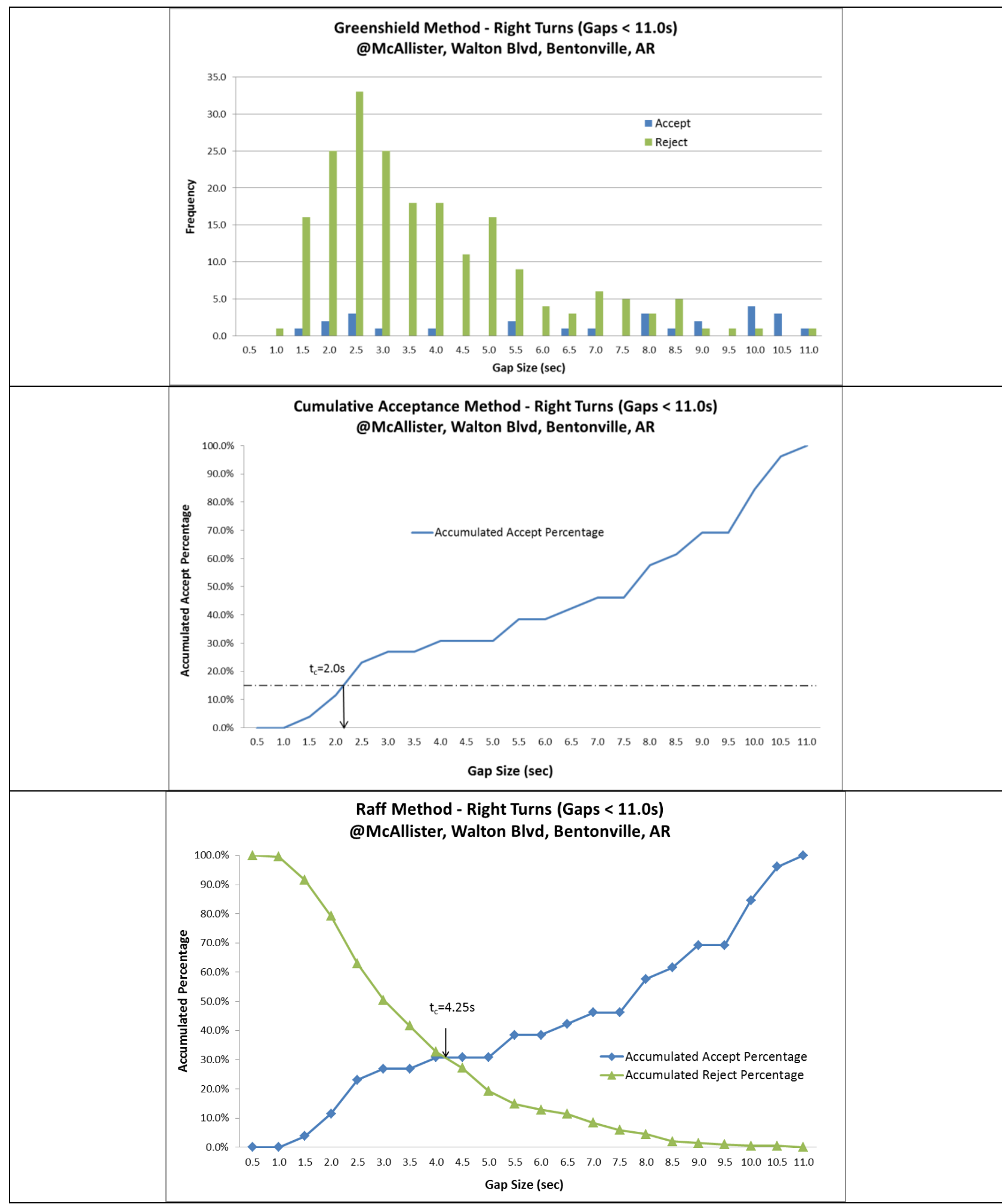

Figure B.27: Driveway Site 6b - Gap-acceptance Analysis for Right Turns 
Driveway Site 7a - Large-size Commercial \#4 - Day 1

Wal-Mart in Fayetteville, AR
\begin{tabular}{l|l}
\hline Location Information \\
\hline Address & 2875 Martin Luther King Jr Blvd \\
\hline City & Fayetteville \\
\hline State & AR \\
\hline
\end{tabular}

Traffic Information

\begin{tabular}{l|l}
\hline ADT (vehicles/day) & 38,000
\end{tabular}

\begin{tabular}{l|l}
\hline Posted Speed (mph) & 35,000 \\
\hline
\end{tabular}

\begin{tabular}{l|l}
\hline Field Speed Mean (mph) & 35.61
\end{tabular}

Cumulative Speed Distribution Curve

Cumulative Speed MLK EB @ Walmart

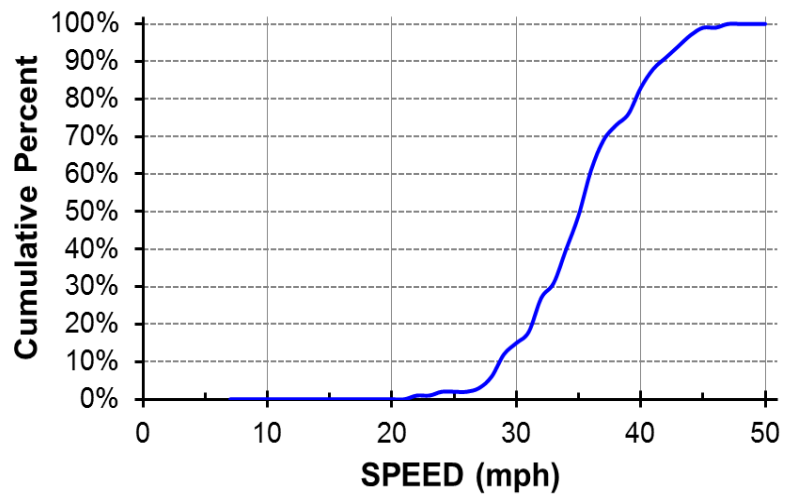

\begin{tabular}{l|l}
\hline \hline \multicolumn{2}{l}{ Geometric Design Information - Roadway in Vicinity of Driveway } \\
\hline Width of Roadway (ft) & 58 \\
\hline Number of Lanes & 4 lanes + TWLTL \\
\hline Lane Width (ft) & 12 \\
\hline Present of Bicycle Lane & No \\
\hline Present of Sidewalk & Yes \\
\hline \hline Geometric Design Information - Driveway & 36 \\
\hline Width of Driveway (ft) & 3 \\
\hline Number of Lanes & 12 \\
\hline Lane Width (ft) & No \\
\hline Median in Driveway & 845 \\
\hline Distance to Nearest Upstream Signal (ft) & \\
\hline \hline Data Collection Information & June $2^{\text {nd }, 2011}$ \\
\hline Date & 1 hour \\
\hline Duration of Traffic Videos & Cloudy - Sunny \\
\hline Weather & Dry \\
\hline Pavement Surface Condition & Data \\
\hline
\end{tabular}

Figure B.28: Driveway Site 7a - Road and Traffic Data 


\section{Aerial Photos:}

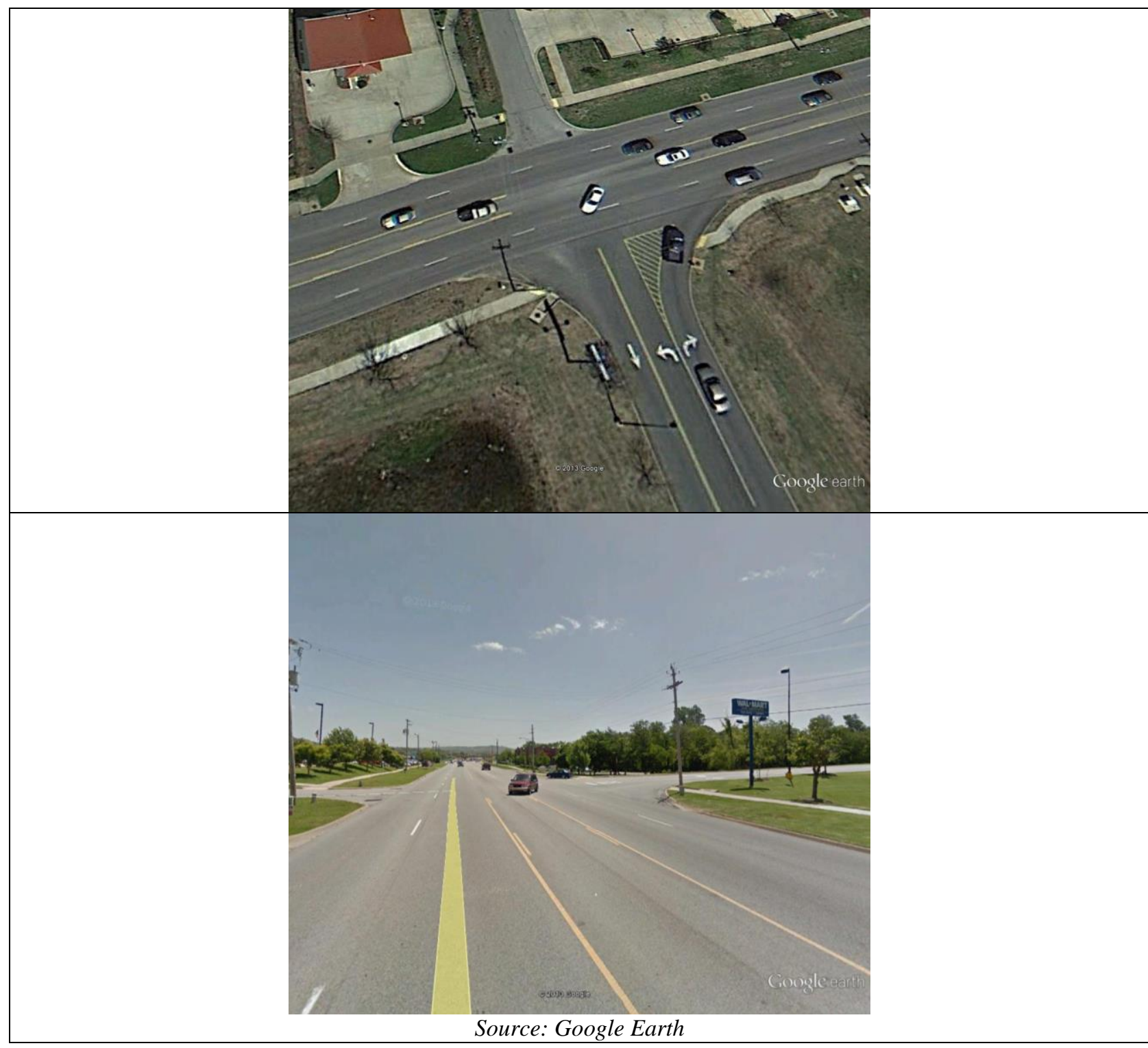

Figure B.29: Driveway Site 7a - Aerial Photos

\section{Gap-acceptance Results:}

Table B.8: Driveway Site 7a - Gap-acceptance Study Results

\begin{tabular}{l|c|c}
\hline \multirow{2}{*}{ Analysis Methods } & \multicolumn{2}{|c}{ Critical Gap (sec) } \\
\cline { 2 - 3 } & Left Turn & Right Turn \\
\hline Greenshield Method & 6.50 & 6.75 \\
\hline Raff Method & 3.00 & 6.25 \\
\hline Cumulative Acceptance Method & 2.75 & 6.30 \\
\hline Logit Method & 6.20 & 6.16 \\
\hline
\end{tabular}




\section{Gap-acceptance Analysis for Left Turns:}

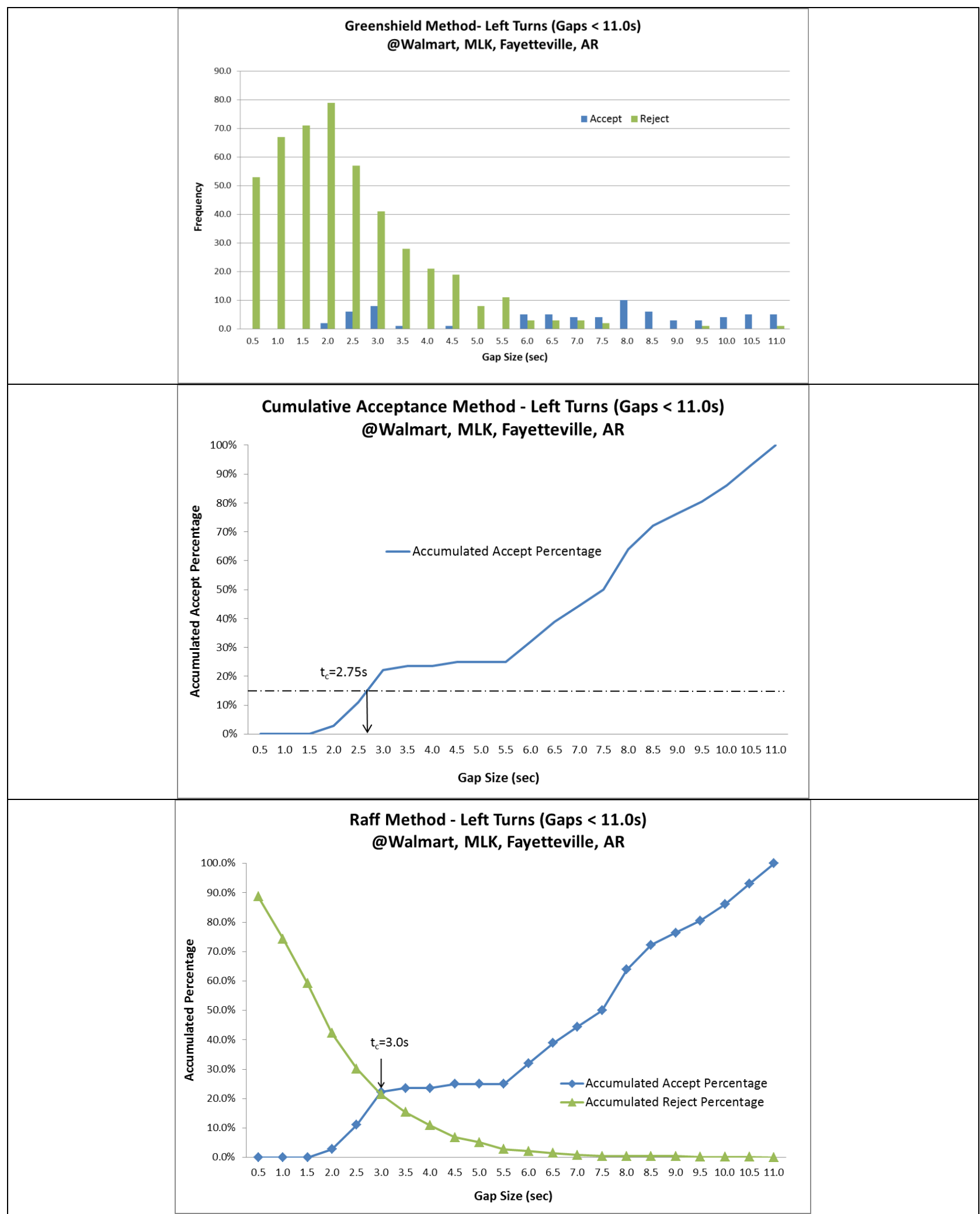

Figure B.30: Driveway Site 7a - Gap-acceptance Analysis for Left Turns 


\section{Gap-acceptance Analysis for Right Turns:}

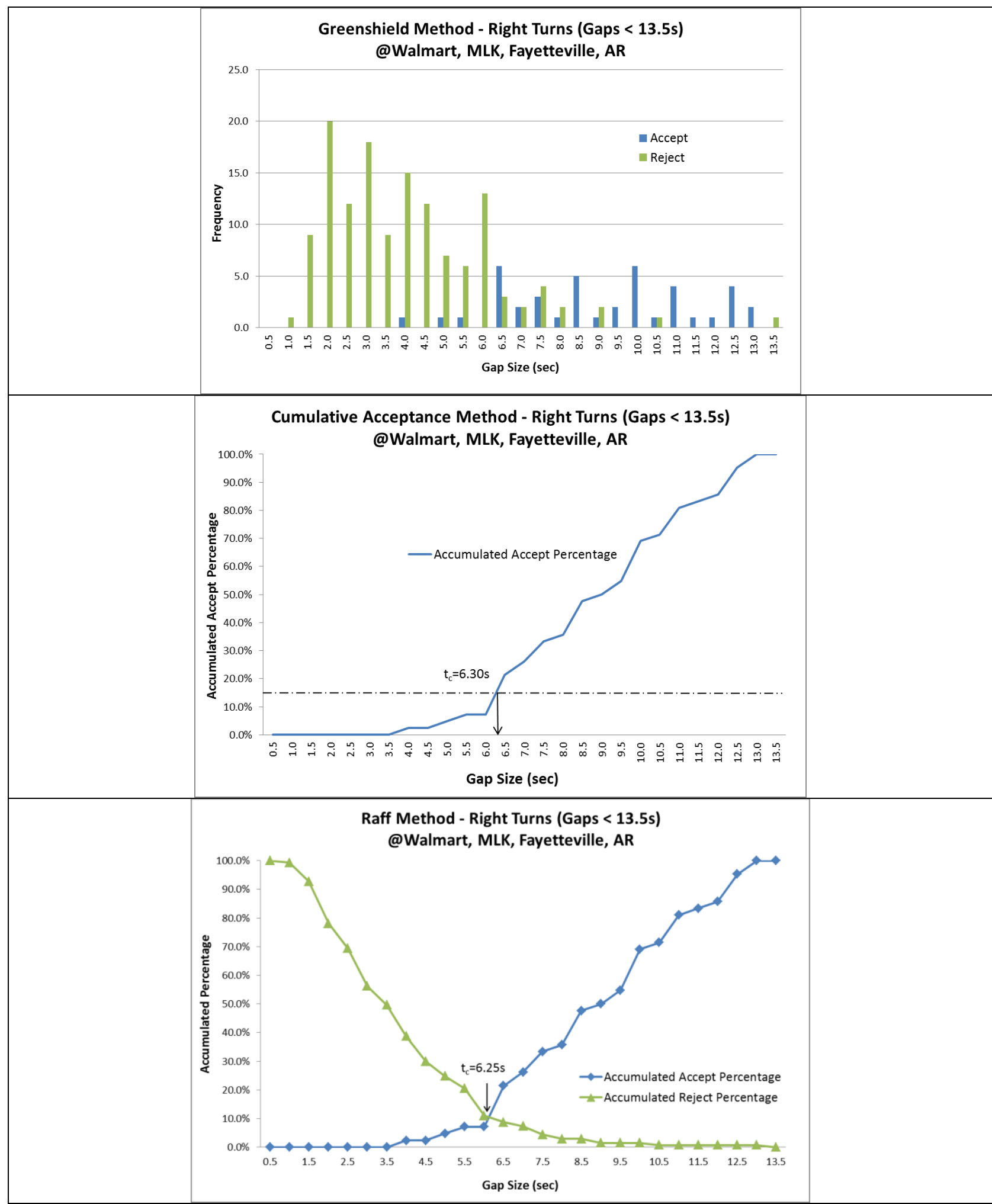

Figure B.31: Driveway Site 7a - Gap-acceptance Analysis for Right Turns 
Driveway Site 7b: Large Commercial \#4 - Day 2

\section{Wal-Mart in Fayetteville, AR}

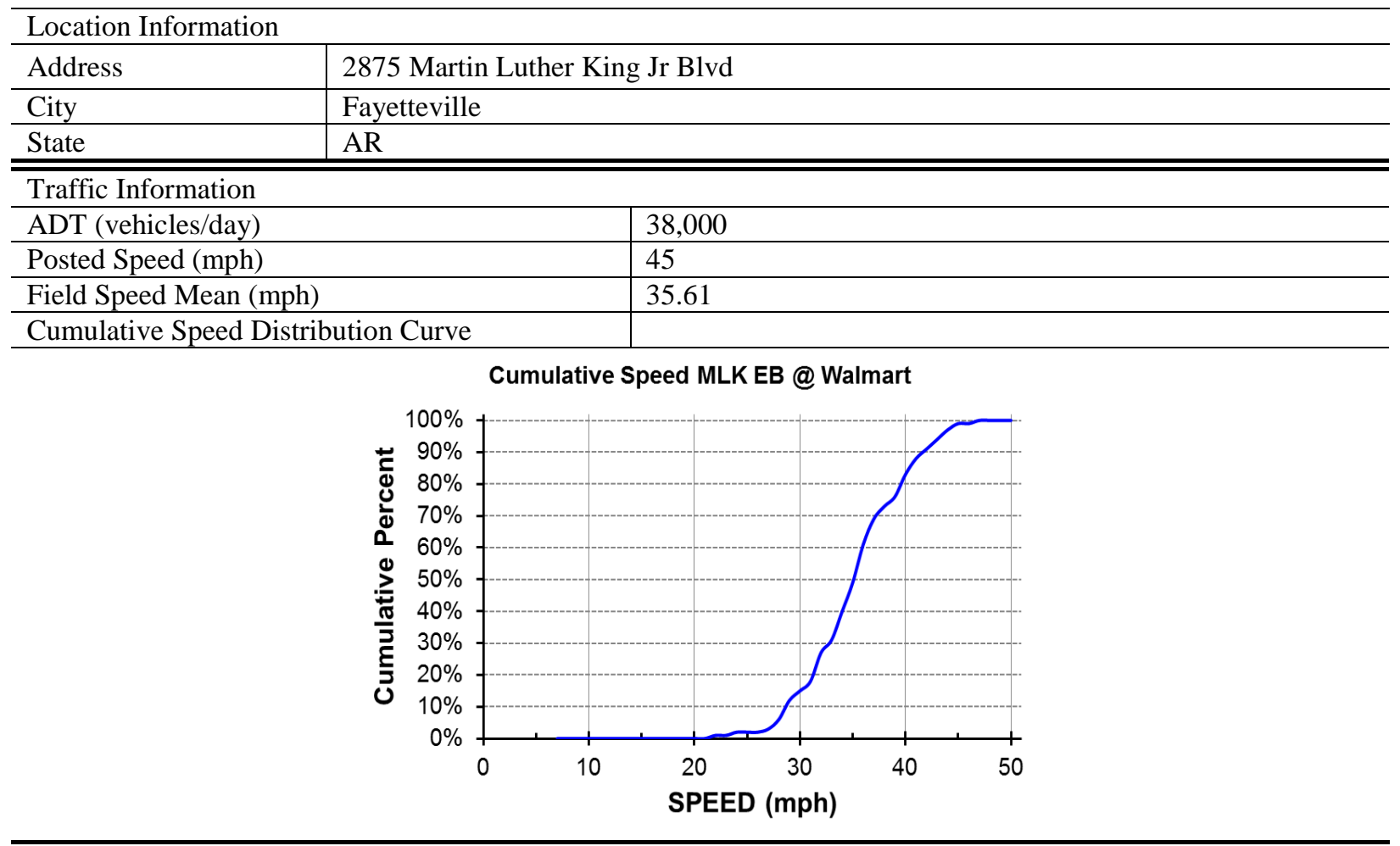

\begin{tabular}{l|l}
\hline \hline \multicolumn{2}{l}{ Geometric Design Information - Roadway in Vicinity of Driveway } \\
\hline Width of Roadway (ft) & 58 \\
\hline Number of Lanes & 4 lanes + TWLTL \\
\hline Lane Width (ft) & 12 \\
\hline Present of Bicycle Lane & No \\
\hline Present of Sidewalk & Yes \\
\hline \hline Geometric Design Information - Driveway & \\
\hline Width of Driveway (ft) & 36 \\
\hline Number of Lanes & 3 \\
\hline Lane Width (ft) & 12 \\
\hline Median in Driveway & No \\
\hline Distance to Nearest Upstream Signal (ft) & 845 \\
\hline \hline Data Collection Information & \\
\hline Date & July $25^{\text {th }, 2011}$ \\
\hline Duration of Traffic Videos & 1 hour \\
\hline Weather & Sunny \\
\hline Pavement Surface Condition & Dry \\
\hline
\end{tabular}

Figure B.32: Driveway Site 7b - Road and Traffic Data 


\section{Aerial Photos:}

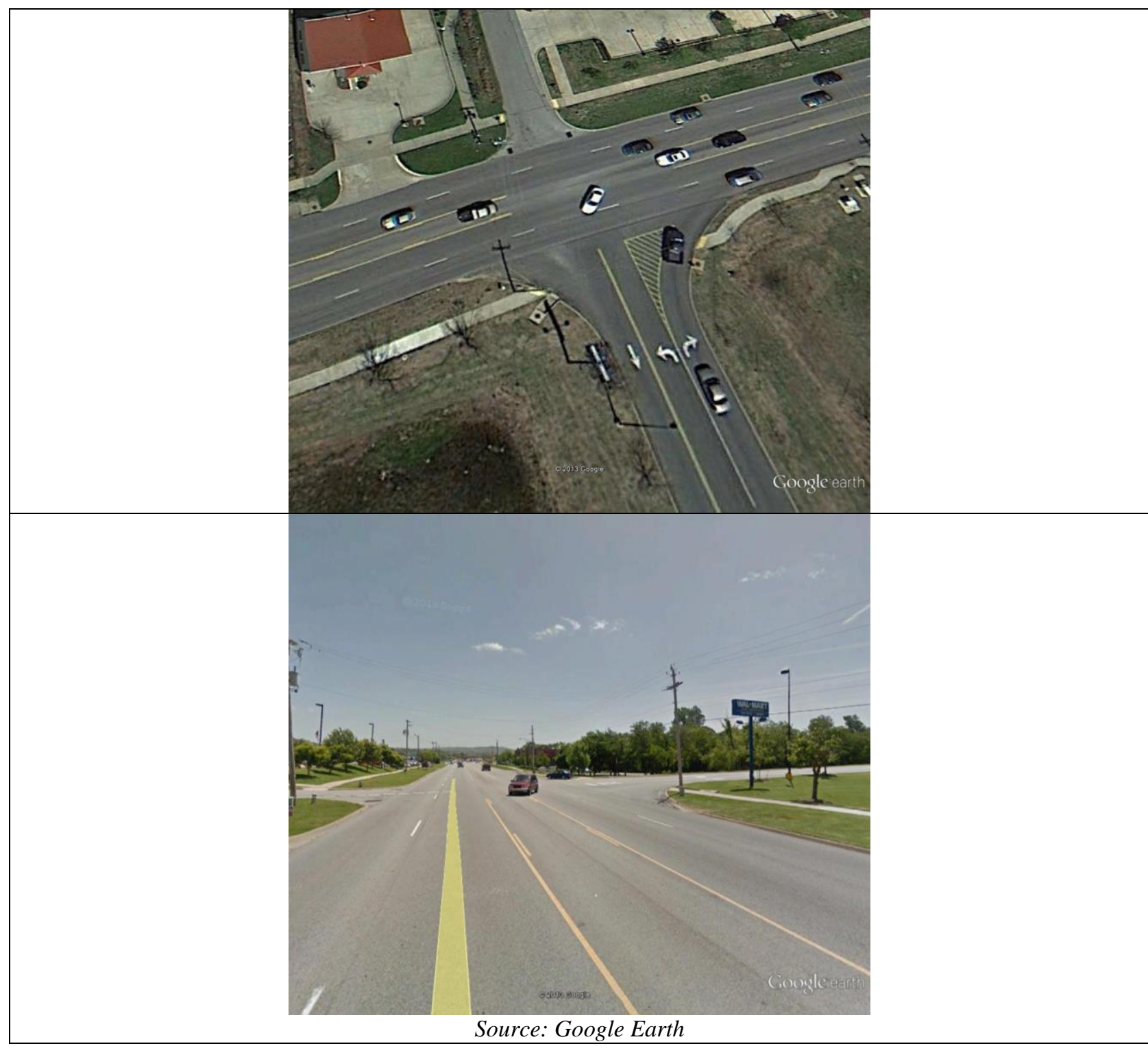

Figure B.33: Driveway Site 7b - Aerial Photos

\section{Gap-acceptance Results:}

Table B.9: Driveway Site 7b - Gap-acceptance Study Results

\begin{tabular}{l|c|c}
\hline \multirow{2}{*}{ Analysis Methods } & \multicolumn{2}{|c}{ Critical Gap (sec) } \\
\cline { 2 - 3 } & Left Turn & Right Turn \\
\hline Greenshield Method & 7.25 & 6.75 \\
\hline Raff Method & 3.50 & 6.25 \\
\hline Cumulative Acceptance Method & 4.10 & 6.70 \\
\hline Logit Method & 6.00 & 7.50 \\
\hline
\end{tabular}




\section{Gap-acceptance Analysis for Left Turns:}

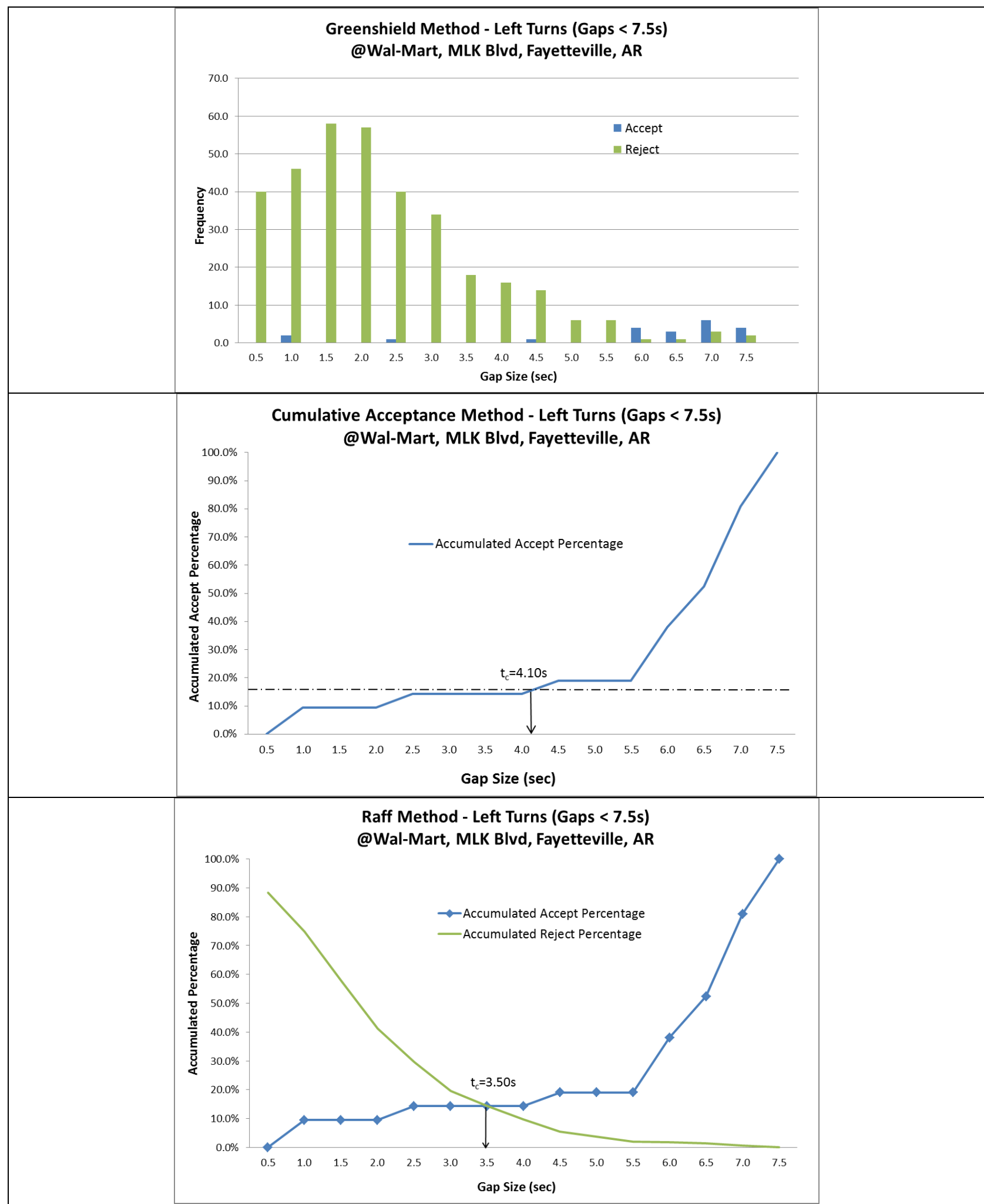

Figure B.34: Driveway Site 7b - Gap-acceptance Analysis for Left Turns 


\section{Gap-acceptance Analysis for Right Turns:}

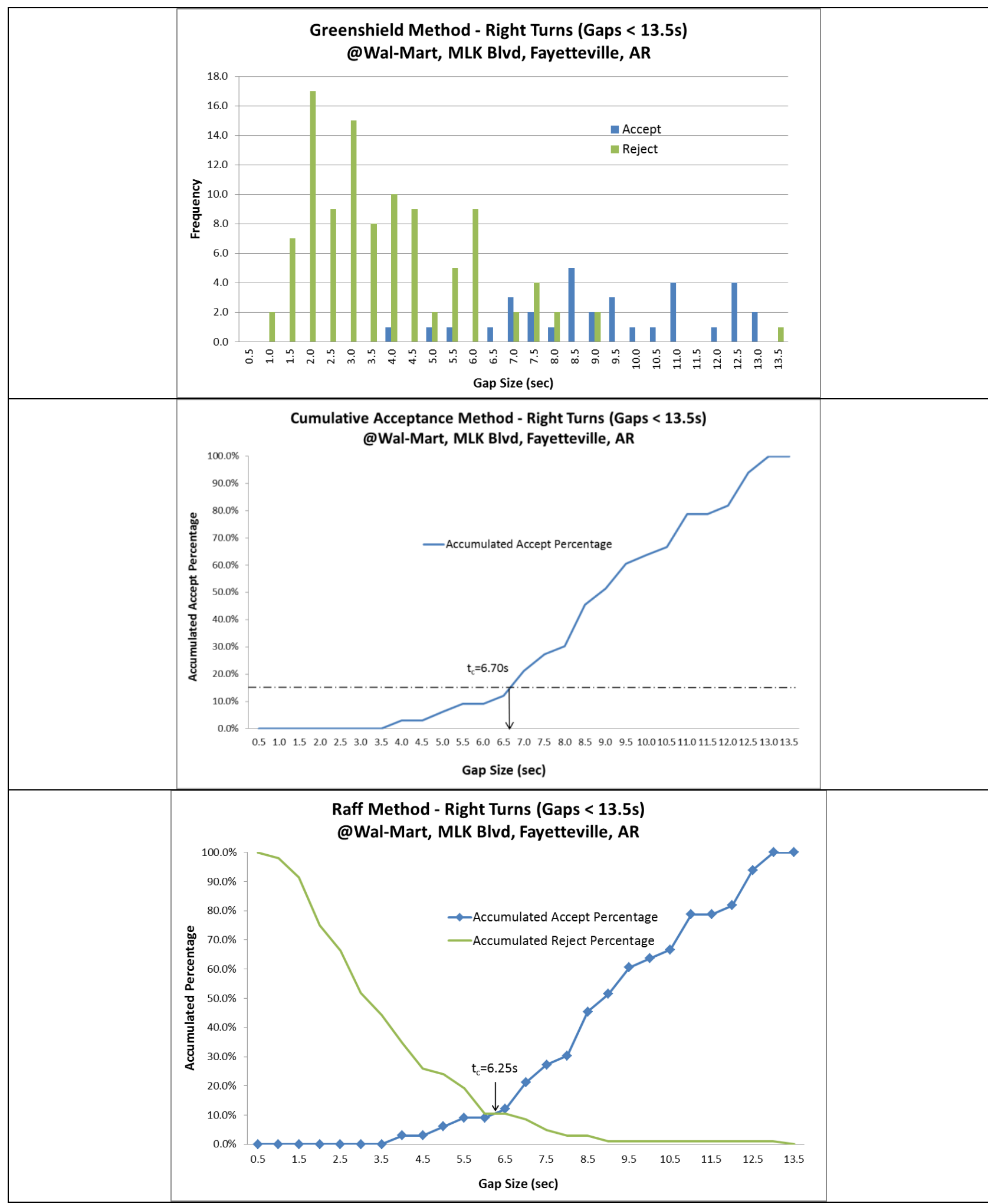

Figure B.35: Driveway Site 7b - Gap-acceptance Analysis for Right Turns 


\section{Driveway Site 8: Restaurant \#2}

\section{Panera Bread, Memorial Dr, Tulsa, AR}

Location Information

\begin{tabular}{l|l}
\hline Address & 8922 S Memorial Dr \\
\hline City & Tulsa \\
\hline State & OK \\
\hline \hline Traffic Information \\
\hline ADT (vehicles/day)
\end{tabular}

ADT (vehicles/day)

Posted Speed (mph)

28,000

Field Speed Mean (mph)

45

Cumulative Speed Distribution Curve

Cumulative Speed Memorial SB @ Panera's

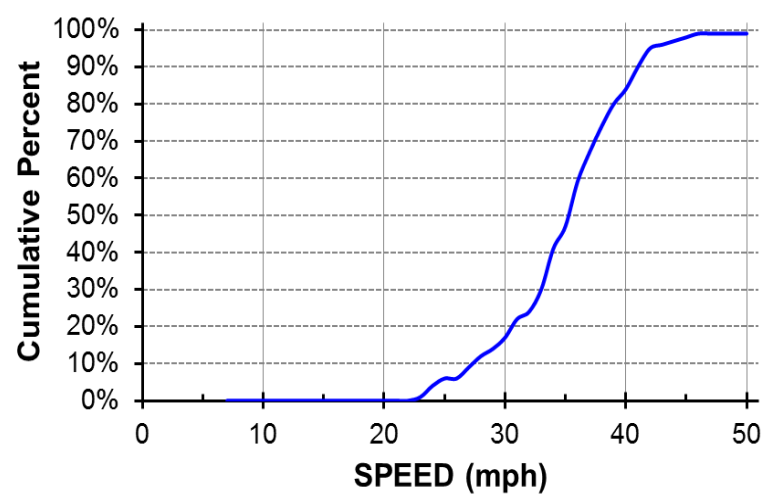

Geometric Design Information - Roadway in Vicinity of Driveway

\begin{tabular}{l|l}
\hline Width of Roadway (ft) & 92 \\
\hline
\end{tabular}

\begin{tabular}{ll}
\hline Number of Lanes & 4 lanes + raised median
\end{tabular}

\begin{tabular}{l|l}
\hline Lane Width $(\mathrm{ft})$ & 12
\end{tabular}

\begin{tabular}{|l|l}
\hline Present of Bicycle Lane & No \\
\hline
\end{tabular}

\begin{tabular}{l|l}
\hline Present of Sidewalk & No \\
\hline
\end{tabular}

Geometric Design Information - Driveway

\begin{tabular}{|l|l}
\hline Width of Driveway (ft) & 26
\end{tabular}

\begin{tabular}{|l|l|}
\hline Number of Lanes & 2 \\
\hline
\end{tabular}

\begin{tabular}{l|l}
\hline Lane Width (ft) & 12 \\
\hline
\end{tabular}

\begin{tabular}{l|l}
\hline Median in Driveway & No \\
\hline
\end{tabular}

\begin{tabular}{|l|l}
\hline Distance to Nearest Upstream Signal & $560 \mathrm{ft}$ \\
\hline
\end{tabular}

Data Collection Information

\begin{tabular}{l|l}
\hline Date & Aug $4^{\text {th }}, 2011$
\end{tabular}

\begin{tabular}{ll}
\hline Duration of Traffic Videos & 1.8 hours
\end{tabular}

\begin{tabular}{l|l}
\hline Weather & Cloudy - Sunny
\end{tabular}

Pavement Surface Condition $\quad$ Dry

Figure B.36: Driveway Site 8 - Road and Traffic Data 


\section{Aerial Photos:}

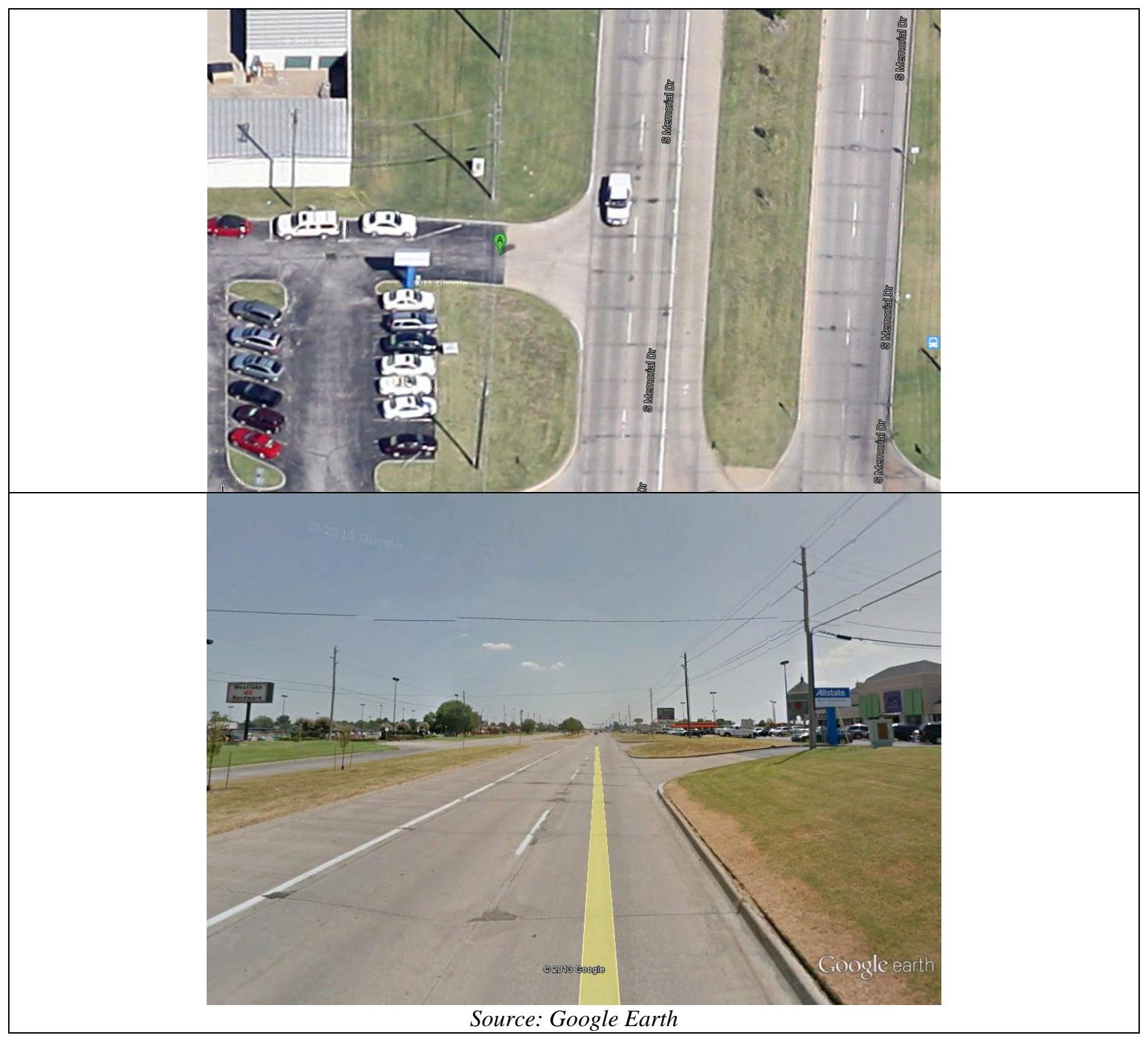

Figure B.37: Driveway Site 8 - Aerial Photos

\section{Gap-acceptance Results:}

Table B.10: Driveway Site 8 - Gap-acceptance Study Results

\begin{tabular}{l|c|c}
\hline \multirow{2}{*}{ Analysis Methods } & \multicolumn{2}{|c}{ Critical Gap (sec) } \\
\cline { 2 - 3 } & Left Turn & Right Turn \\
\hline Greenshield Method & NA & 4.75 \\
\hline Raff Method & NA & 4.75 \\
\hline Cumulative Acceptance Method & NA & 4.50 \\
\hline Logit Method & NA & 5.42 \\
\hline
\end{tabular}




\section{Gap-acceptance Analysis for Right Turns:}

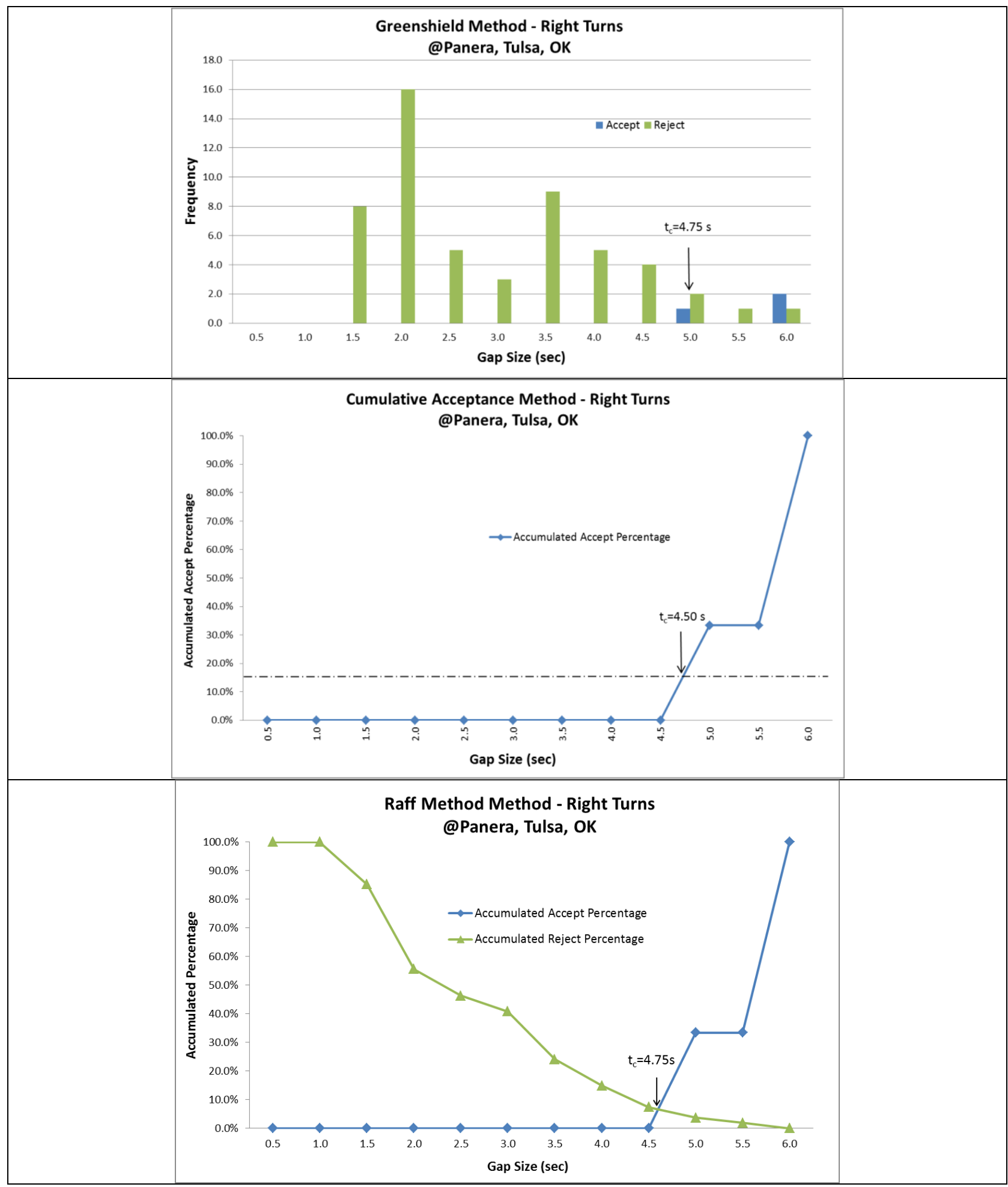

Figure B.38: Driveway Site 8 - Gap-acceptance Analysis for Left Turns 